Zweiter Beratungsgegenstand:

\title{
Der Plan als verwaltungsrechtliches Institut
}

1. Bericht von Professor Dr. Max I m b od e n, Basel

I. Norm und Verfügung als idealtypische Grundformen

Rechtssatz und Verfügung, allgemeine Norm und Verwaltungsakt sind die gestaltenden Elemente der öffentlich-rechtlichen Verhaltensordnung. Auf diese Zweiheit sind die Begriffe und Institutionen des Verwaltungsrechtes ausgerichtet. Ihr folgt vor allem die in Deutschland, Osterreich und der Schweiz bestehende Staats- und Verwaltungsgerichtsbarkeit: durch Normenkontrolle und durch Verfügungsanfechtung soll die Geltung von Verfassung und Gesetz sichergestellt werden.

Der idealtypische Dualismus der rechtsgestaltenden Grundformen vermag freilich nicht die volle Wirklichkeit aufzunehmen ${ }^{1}$ ). Vier rechtliche Phänomene vor allem entziehen sich einer eindeutigen Rückführung auf die beiden Grundkategorien "allgemeine Norm" und „rechtssatzgebundene Verfügung". Als irreguläre Formen sind sie innerhalb der bestehenden justizmäßigen Rechtskontrolle nur beschränkt erfaßbar:

a) Am stärksten kontrastieren von den klassischen Gestaltungstypen des modernen Rechtsstaates die vom Staat und seinen Verwaltungseinheiten getätigten $R$ e c h t s g e s c h äf t e. Sowohl der im Rahmen des fiskalischen Wirkungsbereiches des Staates stehende privatrechtliche Vertrag wie der öffentlichrechtliche Kontrakt weisen auf eine andere Strukturschicht hin als Norm und Verfügung ${ }^{2}$ ).

b) Eine weitere Irregularität bildet der Ermessens$a \mathrm{t}^{3}$ ). Losgelöst von der ihn tragenden Grundlage bietet or

1) G. J e 11 in e k, Gesetz und Verordnung, Neudruck 1919, S. 367 Anm. 3; R. H. H e r r n r it t , Grundlehren des Verwaltungsrechtes, 1921, S. 271 Anm. 13; H. P e t e r 8, Lehrbuch der Verwaltung, 1949, S. 152; E. F o r s t h of $f$, Lehrbuch des Verwaltungsrechts, 7. Aufl., S. 185/86; O. B a c h of in Festschrift für W. Laforet, 1952, S. 315; W. B r o h m, Rechtsschutz im Bauplanungsrecht, 1959, S. 44.

2) M. I m b ode $n$, Der verwaltungsrechtliche Vertrag, 1958, S. $49 \mathrm{ff}$., S. $64 \mathrm{ff}$., S. $75 / 76$.

3) W. J e 11 i n e k, Gesetz, Gesetzesanwendung und Zweckmäßigkeitserwägung, 1913, S. 190; M. I m b o d e n, Das Gesetz als Garantie rechtsstaatlicher Verwaltung, 1954, S. 14. 
sich zwar als individuell-konkreter Erlaß dar. Eingeordnet in das Gefüge der Rechtserzeugung ist er indessen nicht oder nur beschränkt gesetzesgebunden. Als besondere Anordnung bestimmt der Ermessensakt selbständig und ohne inhaltliche Vorbestimmung durch einen Rechtssatz, was im öffentlichen Interesse liegt. Funktionell steht er damit zugleich an Stelle des Gesetzes ${ }^{4}$ ).

c) Nicht rückführbar auf die Kategorien Norm und Verfügung sind sodann die als "Verwaltungsverord$\mathrm{n} u \mathrm{n} g$ e $\mathrm{n}^{\text {" }}$ bezeichneten allgemeinen Dienstanweisungen ${ }^{5}$ ). Gerichtet an eine bestimmte $\mathrm{Zahl}$ weisungsunterworfener Organe wirken sie als "verbindliche Ermessensrichtlinien" zugleich auch auf die Allgemeinheit zurück.

d) Als weiteres rechtsstaatliches Irregulare, als ,aliud" gegenüber Rechtssatz und Verwaltungsakt, hat schließlich die neuere Verwaltungsrechtslehre den P l a n qualifizier $t^{\mathrm{B}}$ ).

II. Normative und linear-geometrische Ba uvorschriften

\section{A. Die Bedeutung des Gegensatzes}

Das Instrument des Planes wurde entwickelt mit der modernen Gestaltung der Siedelungsräume. Die Raumplanung ist, wenn auch keineswegs die einzige, so doch zweifellos die rechtlich am meisten durchgestaltete Planungsform. Sie baut auf Vorbilder auf, die im Bereiche der Enteignung oder der landwirtschaftlichen Bodenumlegung längst zu klassischen Rechtsinstituten geworden sind ${ }^{7}$ ). Die Raumplanung sei hier, pars pro toto, zum Modell genommen.

Um die rechtliche Besonderheit der plangebundenen Lenkungs- und Gestaltungsmittel zu erkennen, mag zunächst die gedankliche Gegenstruktur, das heute unwirklich gewordene

4) M. I m b o d e n, Vertrag, S. 68.

B) G. A n s c h üt z, Kritische Studien zur Lehre vom Rechtssatz und formellen Gesetz, 2. Aufl., 1913, S. 26; F. F l e i n e r, Institutionen des deutschen Verwaltungsrechtes, 8. Aufl., 1928, S. 61/62; Z. G i a c o m e t t i, Schweizerisches Bundesstaatsrecht, 1949, S. 772.

6) E. For s th of 1 , Lehrbuch, S. 186; derselbe, Norm und Verwaltungsakt im geltenden und klinftigen Baurecht, DVBl. 1957, S. 113/15; F. W e r n e r, Zur Kritik an der Verwaltungsgerichtsbarkeit, DVBl., 1957, S. 225; W. B r oh m, aaO., $S$. $59 \mathrm{ff}$; vgl. auch $A, K u t t$ le $r$, Der Plan als Rechtsinstitut in der baselstädt1schen Baugesetzgebung und Praxis, Basler Juristische Mitteilungen 1959, S. $105 \mathrm{ff}$. Kritisch steht dieser Ansicht gegenüber K. O b e r m a y e r, NJW 1856, s. 1850 .

7) Vgl. das (schweizerische) Bundesgesetz betr. die Verbindlichkelt zur Abtretung von Privatrechten vom 1.5.1850, Art. 10. 
Bild ausschließlich normativer Baubeschränikungen gezeichnet werden. Anlage und Ausgestaltung der Siedelungen, Stellung und Form der Häuser werden in einer streng normativen Bauordnung allein durch Maße und Gegebenheiten bestimmt, die auf die konkrete Eigentumseinheit, d. h. auf die einzelne Parzelle, Bezug haben. Die Bauordnung ruht auf den für alle Eigentümer gleichen Abstandsvorschriften und Höhenbeschränkungen, auf einheitlichen Normen über Dachneigung und Fassadengestaltung und auf den dem klassischen Polizeirecht zuzuordnenden Vorschriften über die minimalen Ausmaße der Innenräume. Nach Maßgabe dieser Normen steht jedem Berechtigten die Ausnützung seines Grundeigentums frei; er hat einen unabdingbaren Anspruch darauf, innert der Schranken der für jedermann geitenden Grundeigentumsbeschränkungen bauen zu können.

Charakteristisch für eine derartige Ordnung bleibt, daß die zu treffenden konkreten Verfügungen, die Baubewilligungen und die gegen einen Widerstrebenden zu erlassenden Bauverbote oder Beseitigungsbefehle, durch Rechtssätze vorweggenommen sind. Sieht man von der Institution des Dispenses $\left.a b^{8}\right)$, so ist der Rechtsanwender in allen seinen Entscheidungen determiniert. Wo keine rechtlichen Schranken bestehen, da hat die Behörde nach dem Grundaxiom der Eingriffsverwaltung den Privaten gewähren zu lassen; sie kann die nachgesuchte Bauerlaubnis nicht versagen ${ }^{9}$ ). Erst der feste Anspruch auf Erteilung der Baubewilligung bei Einhaltung der allgemeinen Vorschriften macht die sogenannte Baufreiheit, d. h. die als dem Eigentum inhärent gedachte bauliche Dispositionsbefugnis aus. Gewiß bedürfen die eigentumsbeschränkenden Normen bei ihrer Anwendung der Interpretation. Das kann indessen nicht ausschließen, daß die eigentumsbeschränkenden Rechtssätze im Prinzip als ein lückenloses Ganzes gedacht sind. Spielraum verbleibt der verfügenden Baubehörde nicht in der Erzeugung, sondern nur in der Deutung des Normgefüges.

Im Gegensatz zur normativen Bauordnung stehen die lineargeometrischen Bauvorschriften. Stellung und Ausmaß der zulässigen Baukörper werden nicht durch allgemeine Regeln, durch Abstands-, Richtungs- und Längenbestimmungen festgelegt. Nach dem klassischen Beispiel der Fluchtlinie, der Baulinie oder des französischen „plan d'alignement" werden viel-

8) Vgl. hierzu U. B inds ch ed ler, Die Dispensation, Zürcher Dissertation 1958; E. $\mathrm{Zi} \mathrm{mme} \mathrm{rma} \mathrm{n} \mathrm{m}$, Der Baudispens in der Stadt Zürich, Zürcher Dissertation 1958.

9) F. F l e in e r, Institutionen, S. 408; (schweizerisches) Zentralblatt für Staats- und Gemeindeverwaltung, 1954, S. 401/02. 
mehr Baugrenzen gezogen, die auf einem Grundstücksplan festgehalten sind. Der Plan unterscheidet sich also zunächst als A u sdru cksmit tel vom Rechtssatz. Darin mag für den Juristen eine Äußerlichkeit liegen. Wesentlicher erscheint jedenfalls, wieweit sich mit dem Wechsel des Ausdrucksmittels auch die Sache verändert.

\section{B. Norm und Plan als Determinanten}

Die Stellung des Rechtsanwenders - und das ist von grundlegender Bedeutung - wird durch den Übergang von der normativen zur linear-geometrischen Bauplanung nicht berührt $\left.{ }^{10}\right)$. Auch wenn die rechtsanwendenden Instanzen nicht allein nach Rechtssätzen, sondern mit auf Grund plangebundener linearer Baubeschränkungen zu verfügen haben, sind ihre Entscheidungen vorbestimmt. Jedenfalls tritt keine Lockerung in der Determination der verfügenden Baubehörde ein. Es geht aber auch nicht an, die Folge der Ersetzung der rechtssatzmäßigen Baubeschränkung durch den Plan darin zu sehen, daß der Entscheidungsspielraum en $\mathrm{g}$ e $r$ werde ${ }^{11}$ ). Nochmals sei betont, daß eben im Rahmen einer rein normativen Bauordnung ein eigentlicher „Entscheidungsspielraum “ der Baubehörde nicht zusteht. Das Normgefüge bedarf lediglich der Interpretation. Die Frage kann somit nur sein, ob mit dem Ubergang zu einer linear-geometrischen Determination der zulässigen Bauten für den Rechtsanwender die Auslegungsschwierigkeiten vermindert werden. Wäre dies der Fall, käme also den plangebundenen Eigentumsbeschränkungen gegenüber den rein normativen Baubeschränkungen größere Eindeutigkeit zu, so ließe sich allenfalls in einem übertragenen, freilich aber mißverständlichen Sinne von einer Verschmälerung des Entscheidungsspielraumes - exakter: des Auslegungsspielraumes - sprechen. Indessen dürfte es schwerlich möglich sein, über das $\mathrm{Maß}$ der Auslegungsbedürftigkeit normativer und linear-geometrischer Bauvorschriften allgemein gültige Aussagen zu machen. Wer je praktisch mit der Handhabung von Fluchtlinien zu tun hatte, wei $\beta$, da $\beta$ eine lineare Determination eines Baukörpers keineswegs immer den Vorzug größerer Eindeutigkeit aufweist. Man denke nur an die vielfachen Ungewißheiten darüber, welche Bauteile von der linearen Baubegrenzung erfaßt werden.

Wie der Rechtssatz determiniert somit auch die zum Prototyp des Planes genommene lineare Baubeschränkung die verfügende Behörde. Wer erklärt, der Plan wirke wie eine Norm, ja er sei

10) So das Bundesverwaltungsgericht in DVBl. 1957, S. 536.

11) Was Forsthoff (Norm, S. 116) anzunehmen scheint. 
überhaupt eine Norm, hat stets in erster Linie diese Determinationsfunktion im Auge. Für den Rechtsanwender schafft der Plan wie die Norm Bindungen; der Plan wirkt wie die Norm „in die Zukunft"; er nimmt kommende konkrete Entscheidungen vorweg'12); er verleiht dem Grundeigentümer einen sicheren und greifbaren Anspruch auf eine genau bestimmte bauliche Ausnützung; er orientiert sich in gleicher Weise wie der Rechtssatz am Grundwert der Rechtssicherheit. Betrachtet man die Norm nur als Determinante für die Rechtsanwendung, als bloße Bedingung konkreter Rechtserzeugung, so läßt sich der Plan von ihr nicht als etwas grundsätzlich anderes abheben. In diesem Sinne konnte denn auch der Art. 89 des französischen "Code d'Urbanisme" Gesetz und Alignementsplan zwangslos nebeneinander stellen ${ }^{13}$ ). Im Hinblick auf seine Determinationsfunktion wird der Plan vor allem in Osterreich von Rechtsprechung und Lehre als Verordnung, nicht als Bescheid qualifiziert $\left.{ }^{14}\right)$.

\section{Der Inhalt von Norm und Plan}

Das Bild ändert sich, sobald man den I $\mathrm{n} h$ a $1 \mathrm{t}$ von Norm und Plan ins Auge faßt. In der früheren schweizerischen Rechtsliteratur wird es als Argument für den Norm-Charakter des Planes angeführt, daß die Bildhaftigkeit der Darstellung nur zufällig sei; gedanklich könne jeder Plan durch nicht-plangebundene Aussagen ersetzt werden ${ }^{15}$ ). Dieses Argument ist richtig und unrichtig zugleich. Gewiß läßt sich der Verlauf einer Fluchtlinie auch durch Worte ausdrücken. Nur unter ganz be-

12) K. O b e rma ye $r$, Verwaltungsakt und innerdienstlicher Rechtsakt, 1956, s. 76/77; W. B r o h m, aaO., S. $48 \mathrm{ff}$. Dieses Moment hat vor allem $H$. I s a y (Rechtsnorm und Entscheidung, 1929, S. 3) als wesentliches Kriterium für die Unterscheidung zwischen Norm und Verwaltungsakt bezeichnet.

13) Vgl. Art. 89 Abs. 1 des „Code d'urbanisme“ vom 26. 7. 1954: „Le permis de construire ne peut être accordé que si les constructions projetées sont conformes aux dispositions législatives et réglementaires ainsi qu'à l'alignement....".

14) Sammlung der österreichischen Verwaltungsgerichtshofentscheidungen Nr. 3024, 1953, Adm. Teil, S. 523; Nr. 2258, 1951, Adm. Teil, S. 986; Nr. 1629, 1950, Adm. Teil, S. 1397; W. A n t o n i o 111 , Allgemeines Verwaltungsrecht, 1954, S. 72 Anm. 21; L. A d a movi ch, Handbuch des österreichischen Verwaltungsrechtes, 5. Aufl., Bd. II, S. 141/42.

15) E. K I r c h h of e r, Eigentumsgarantie, Eigentumsbeschränkung und Enteignung, Zeitschrift für schweizerisches Recht, Bd. 58 (1939), S. 146/47: H. K u n 2, Das öffentliche Baurecht im Kanton St. Gallen, Dissertation St. Gallen, 1958, S. 64; B u s e r, in Zentralblatt für Staats- und Gemeindeverwaltung, 1932, s. 355/57. 
sonderen Voraussetzungen kann indessen die die lineare Baubeschränkung ersetzende Wortformel in die logische Form eines Rechtssatzes gebracht werden. Dieser Ausnahmefall ist gegeben, wenn die Fluchtlinie parallel zu einer bestehenden öffentlichen Straße verläuft: durch eine Vorschrift, wonach Gebäude gegenüber dem öffentlichen Grund einen bestimmten Grenzabstand einzuhalten haben, läßt sich unter dieser speziellen Voraussetzung der nämliche Erfolg erzielen wie durch eine dem Grenzabstand folgende Baulinie. Dieser Fall liegt indessen atypisch. In der modernen Stadtplanung werden Baulinien zumeist für andere Zwecke als nur zur gleichmäßigen Verbreiterung bestehender Straßen verwirklicht ${ }^{16}$ ). Für die nicht dem öffentlichen Grund folgenden linearen Baubeschränkungen läßt sich eine Wortformel nur finden, indem auf Grund von Fixpunkten im Gelände deren Verlauf beschrieben wird. Ueber die Einwirkungen der Baubeschränkung auf die einzelnen Grundstücke sagt indessen eine derartige Umschreibung überhaupt nichts aus. Man kennt diese Einwirkungen erst, wenn man um die räumliche Beziehung zwischen der beschriebenen Linie und der Parzelle weiß. Diese Beziehung ist für jedes Grundstück eine andere.

Damit ist der für das Verständnis des Planes vielleicht zentrale, von der französischen Lehre mit Recht in den Vordergrund gerückte Aspekt berührt ${ }^{17}$ ). Er liegt darin, daß die lineare Baubeschränkung ihrer Natur nach für jede Bodenparzelle anders wirkt: bald wird nur ein geringer Teil der Grundfläche der Bebauung entzogen; bald trifft die Belastung den größeren Teil des Grundstückes oder gar dessen volles Ausmaß. Zwar folgt die getroffene Unterscheidung zwischen bebaubarem und unbebaubarem Land einem klar erfaßbaren, in einer räumlichen Grenzlinie ausgedrückten Gesichtspunkt. Von den Normadressaten aus gesehen ist indessen das Kriterium der Baubeschränkung nicht ein gleiches, sondern ein u ngleiches Maß. Die Intensität des Eingriffes ist von der räumlichen Beziehung von Parzelle und Fluchtlinie abhängig. Diese Beziehung ist für jedes Grundstück eine spezifische und einmalige Gegebenheit.

Die Problematik des Planes liegt somit im Verhältnis der Planung zum Gleichheitsmaß. Darin spiegelt sich wider, daß der Planer einem diametral entgegengesetzten Blickpunkt folgt als der Baugesetzgeber, der rechtsatzmäßige Grundeigentumsbeschränkungen verwirklicht. Der Planer betrachtet ein Siede-

16) A. Kuttle r, aaO., S. 106.

17) R. C a p it a nt , Urbanisme, in ,Encyclopédie juridique Dalloz, Droit Administratif", Bd. II, Paris 1958, S. 1024, Nr. 45. 
lungsgebiet als einen eigentumsmäßig nicht differenzierten Raum. Planung heißt Verfügung über eine zur Ganzheit verschmolzene Summe von Gütern. Das einzelne Gut, die konkrete Eigentumseinheit, die Parzelle, ist zunächst kein Bezugspunkt der Planung ${ }^{18}$ ). Die Auswirkungen des Planes auf die subjektiven Eigentumsrechte können deshalb auch keine gleichmäßigen sein. Die plangebundenen Eigentumsbeschränkungen sind nicht auf Masse und Gegebenheiten abgestützt, die den konkreten Eigentumseinheiten inhärent sind.

\section{Das Wesen des Rechtssatzes}

Der Unterschied zwischen planender und rechtssatzääßiger Baubeschränkung verdeutlicht sich weiter, wenn man in eine Analyse des Rechtssatzbegriffes eintritt. In Anlehnung an die französische Lehre, die das Gesetz als "générale et abstraite" kennzeichnet ${ }^{18}$ ), wird der Rechtssatz als "generell-abstrakte Norm" charakterisiert und zur individuell-konkreten Verfügung in Gegensatz gebracht ${ }^{20}$ ).

\section{A. Allgemeinheit des Rechtssatzes im Hinblick auf den Adressatenkreis}

Die postulierte Allgemeinheit des Rechtssatzes hat Bezug auf die Normadressaten: der Kreis der Rechtsträger darf nicht individuell bestimmt $\operatorname{sein}^{21}$ ). Kontrovers ist, ob Unbestimmtheit zugleich auch Unbestimmbarkeit bedeutet. Richtigerweise kann eine Anordnung - ein Amnestieerlaß zum Beispiel -, deren Adressatenkreis zwar nicht individuell bezeichnet wird, aber immerhin von vorneherein feststeht und damit bestimmbar ist, nicht als Rechtssatz gelten ${ }^{22}$ ). Unbestimmtheit des Adressatenkreises bedeutet damit Abhängigkeit der personellen Auswirkungen von einer sich erst in Zukunft vollziehenden Entwicklung, von einer - wie es der Korreferent formuliert hat „immer wiederkehrenden Tatbestandsverwirklichung(23). Die

18) Dazu Forsthoff, Norm, S. 114, Capltant, aaO., S. 1024 Nr. 47; G. G r a u vog e I in DVBl. 1958, S. 76.

19) Vgl. G. Bu rde a u, Essal sur l'évolution de la notion de la loi en droit français. Archives de philosophie du droit, 9. Jahrgang, 1939 , S. 16/17, 44 ff.

20) Statt vieler O. B a c h of, aaO., S. 315; vgl. auch $H$. K op p, Inhalt und Form der Gesetze, Zürcher Dissertation 1958, S. $12 \mathrm{ff}$., $140 \mathrm{ff}$.

21) Statt vieler W. J e 11 i n e k, Gesetz, S. 146; H. K o p p, a.O., S. $383 \mathrm{ff}$.

22) E y e rm a n n-Frö hler, Kommentar zum VGG, 1950, S. 66.

23) K. O b e r m a y e $r$, Verwaltungsakt, $S$. 77 . 
generelle Norm muß an einen nicht geschlossenen Adressatenkreis gerichtet sein. Damit ist jedenfalls, um bei der von T h o m a und $\mathrm{Men}$ ger vertretenen Typologie der atypischen Gesetze zu bleiben, das Einzelpersonengesetz eliminiert ${ }^{24}$ ).

Entgegen einer von mir früher selbst vertretenen These ${ }^{25}$ ) halte ich dafür, daß sich die spezifische Problematik der Raumplanung nicht unter dem Gesichtspunkt der Restriktion des Adressatenkreises verstehen läßt. Schon $W$ a $l$ t h e r J e l l in e k hat dargetan, daß die (hier einmal mit Recht angerufene) „Natur der Sache“ allen grundeigentumsbeschränkenden Rechtssätzen eine besondere Note verleiht ${ }^{26}$ ). Grund und Boden sind nicht veränderbare Größen. Mit der räumlichen Geltung einer rechtssatzmäßigen Grundeigentumsbeschränkung sind daher endgültig auch das sachliche Substrat und in einem zum mindesten stärkeren $\mathrm{Maß}$ als hinsichtlich anderer Vorschriften auch die personell angesprochenen Rechtsträger vorbestimmt ${ }^{27}$ ). Dieses Moment kann indessen nicht entscheidend sein: Das Gleichbleiben des sachlichen Substrates zieht nicht zwingend auch das Gleichbleiben der Rechtsträger nach sich; Parzellen können geteilt und die Rechtsverhältnisse bezüglich der nämlichen Parzelle können verändert werden. Auch die lineare Baubeschränkung wendet sich in diesem Sinne an einen nicht geschlossenen, sich mit der Änderung der Eigentumsverhältnisse ändernden Kreis von Berechtigten ${ }^{28}$ ). Alle gegenteiligen Aussagen sind letztlich wohl bloße Rückprojektionen der Erkenntnis von der Unveränderbarkeit von Grund und Boden.

Nicht haltbar ist daher auch die Auffassung, die Fluchtlinie sei zwar „im allgemeinen" - man beachte die Unbestimmtheit dieser Aussage - eine Norm; sie werde hingegen zur Verfügung, wenn sie nur ganz wenige oder gar nur ein einziges Gründstück belaste ${ }^{2 \theta}$ ). Von rein quantitativen Gegebenheiten kann der Rechtscharakter einer linearen Baubeschränkung ebensowenig abhängen wie die juristische Natur einer allgemeinen Vorschrift durch die Breite des virtuell betroffenen

24) Vgl. hierzu C. F. M e n g e r, Das Gesetz als Norm und Maßnahme, VVDStRL. 15, s. 18 ff.

25) Vgl. M. I mboden, Der Schutz der Eigentumsgarantie, Festschrift Fritzsche, 1952, S. 45.

26) W. J e 11 in e k, Gesetz, S. 153/54.

27) F. Z y g a r t, Der Bebauungsplan nach solothurnischem Recht, Berner Dissertation 1953, S. 39.

28) W. B r o h m, aaO., S. 54; OVG. Münster in DOeV. 1954, S. 185.

29) So ein Urteil des Schweizerischen Bundesgerichtes vom 16. 10. 1944, Monatsschrift für bernisches Verwaltungsrecht, $B d .43$, Nr. 96, S. 253 und die dortigen Verweise auf die schweizerische Rechtsliteratur. 
Personenkreises bestimmt sein kann. Auch die nur noch von wenigen erreichbare Spitzenklasse einer steuerlichen Progressionsskala behält ihren Normcharakter bei. Gewiß stellt sich das Problem des getarnten Einzelpersonengesetzes. Diese Erscheinung, letztlich ein Anwendungsfall des ,détournement du pouvoir", läßt sich indessen nicht durch einen bloßen Quantitäts-Maßstab erfassen.

\section{B. Abstraktheit des Gegenstandes}

Das zweite herkömmliche Erfordernis des Rechtssatzes ist die Abstraktheit des Gegenstandes ${ }^{30}$ ). Hier vor allem häufen sich die Schwierigkeiten; hier vor allem wird das Fehlen einer überzeugenden modernen Gesetzeslehre deutlich. Es ist daher nicht ohne Grund, wenn die Lehre immer wieder die Neigung bekundet, den gordischen Knoten zu durchhauen und das $\mathrm{Ab}$ straktheits-Erfordernis preiszugeben ${ }^{31}$ ).

Hält man sich an das Hergebrachte, so wird durch das Moment der Abstraktheit die Forderung ausgedrückt, die Norm habe eine "Vielzahl von Einzelfällen“ zu erfassen ${ }^{32}$ ). Diese These bedarf der Erläuterung. Muß der Rechtssatz beim $n$ ä m $\mathrm{l}$ i $\mathrm{h}$ e $\mathrm{n}$ Adressaten eine Vielheit von Handlungen motivieren? Oder genügt es, wenn das Gesetz in s g e s a m t auf eine unbestimmte Vielzahl konkreter Sachverhalte Bezug hat? Offenbar trifft das zweite zu - sonst wären Gesetze über einmalige Lebensvorgänge wie Geburt und Tod keine Gesetze im materiellen Sinn. So gesehen fügt nun aber das Erfordernis gegenständlicher Vielzahl nichts Neues zum Erfordernis des offenen Adressatenkreises hinzu. Eine Norm, die einen nicht geschlossenen Kreis von Personen anspricht, motiviert zwangsläufig auch eine unbestimmte Zahl konkreter Fälle. Es ist logisch ausgeschlossen, daß mehrere Rechtsträger Handlungen vollziehen, die absolut identisch sind.

Man kann sich dieser Einsicht fügen und demgemäß die Norm allein durch ihren unbestimmten Adressatenkreis gekennzeichnet sehen $^{33}$ ). Die zwangsläufige Konsequenz liegt darin, daß das in der juristischen Theorie zu Ansehen gekomnene stationäre Verkehrszeichen nicht mehr als Verfügung

30) Statt vieler P. S e li g m a n $\mathbf{n}$, Der Begriff des Gesetzes im materiellen und formellen Sinn, 1886, S. 63/64, Is a y, aaO., S. 3; K o p p , aaO., S. $407 \mathrm{ff}$.

31) A n s c hü t z, aaO., S. 26; A. H a e n s e l, Studien zum deutschen Staatsrecht, Bd. II/2, S. 130.

32) K. R in g e, Zur Rechtsnatur des Wirtschaftsplanes nach dem Wohnsiedelungsgesetz, DVBl. 1954, S. 246.

33) W. Jelline k, Gesetz, S. 148; Antoniolli, aaO., S. 196. 
qualifiziert werden kann. Gegen diese Folgerungen haben Forsth off, Wolff und andere mit Recht Bedenken erhoben $^{34}$ ). Der Gesetzesbegriff würde strapaziert, wollte er auch eine auf einen derart schmalen Wirkungsbereich gestellte $\mathrm{An}$ ordnung wie eine lokale Verkehrsbeschränkung einschließen. Es liegt daher nahe, diese Erscheinung auszunehmen. Das läßt sich dogmatisch nur dadurch vollziehen, daß man voraussetzt, die durch generell abstrakte Normen erfaßten Einzelfälle müssen eine hinlänglich äußere Streuung aufweisen, sie müssen einerseits räumlich und andererseits zeitlich auseinander liegen. Der Mangel des ersten Erfordernisses läßt die Norm zum Einzelfallgesetz, der Mangel des zweiten Erfordernisses zum Zeitgesetz werden. Man gibt sich somit der Vorstellung hin, das räumliche oder zeitliche Zusammenrücken der durch eine Vorschrift bestimmten Handlungen stelle den Rechtssatzcharakter in Frage. Damit wird, richtig besehen, zu den rein formalen Kriterien des Rechtssatzes ein Element der Werthaftigkeit hinzugefügt; räumliche Breite und Dauerhaftigkeit heben den Rechtssatz von der Verfügung ab und geben ihm einen höheren inneren Rang.

Für den Rechtscharakter des Planes bleibt diese Einengung des Gesetzesbegriffes bedeutungslos. Die linearen Baubeschränkungen lassen sich auch unter diesem Gesichtspunkt ebensowenig zu den Verwaltungsakten weisen wie, was neuestens $B$ e t t e r m a n $n^{35}$ ) überzeugend dargetan hat, die Allgemeinverbindlicherklärung eines Tarifvertrages. Sowohl die räumliche wie auch die zeitliche Streuung der determinierten Einzelhandlungen kann dem Plan nicht abgesprochen werden.

In der Formel "Räumliche Breite und Dauerhaftigkeit" erschöpft sich nun aber das Abstraktheits-Erfordernis nicht. Es gehört zu den nicht wegzudenkenden Prämissen der generell abstrakten Norm, daß sie die von ihr erfaßten Tatbestände nach $\mathrm{glei} \mathrm{chem} \mathrm{MaBe}$ mißt. Gleichheit und Gesetz sind seit Rousseaus Gesetzestheorie nicht mehr zu trennen $\left.{ }^{38}\right)$. Der Rechtssatz soll eine Vielzahl konkreter Sachverhalte unter eine einheitliche Regel bringen; er geht von typischen Lagen aus. Um ein gleichbleibendes Beurteilungsmaß zu erhalten, wird in der Formulierung der Norm vom Besonderen

34) For st h off, Lehrbuch, S. 200, Anm. 3; H. J. Wolff, Verwaltungsrecht I, 3. Aufl., S. 236.

35) K. A. B et term a n n, Die Allgemeinverbindlicherklärung eines Tarifvertrages: Rechtsschutz, Rechtskontrolle und Rechtsnatur, erschienen in "Recht der Arbeit“, 1959, Heft 7/8, Separatum, S. 9.

36) Vgl. R o u s s a u, Contrat Social, Buch II. Kap. 11, 1. A.bs. 
„abstrahiert". Darin liegt die ursprünglichste Bedeutung des Abstraktheits-Erfordernisses.

Unter diesem Gesichtspunkt - und erst unter diesem wird die Kluft von Rechtssatz und Plan erkennbar. Der linearen Baubeschränkung ist die „Verallgemeinerung" durch abstrahierende Außerachtlassung des Besonderen fremd. Sie reiht das Partikuläre einfach aneinander. Sie unterstellt jeden Grundeigentümer einem speziellen Statut. Die formale Gleichheit des Beurteilungsmaßes fehlt. Im Hinblick auf die mangelnde Zusammenfügung der getroffenen Anordnungen zu einer einheitlichen Aussage kann die Fluchtlinie kein Rechtssatz sein. Sie bietet sich als Summierung von Einzelverfüg u n g e n dar ${ }^{37}$ ).

IV. Der Raumplan als Mittel der Koordinierung von Ermessensakten

Die durch den Plan summierten Einzelverfügungen werden freilich nicht wahllos aneinander gereiht; sie sind in ihrem Wirken „planmäßig" miteinander verknüpft und inhaltlich aufeinander abgestimmt. Erst von diesem Blickpunkt aus wird es möglich, die Struktur der Planung juristisch zu erfassen und namentlich zu erkennen, wie sich der Plan zwischen Norm und Verfügung stellt. Zweierlei ist für den Plan charakteristisch:

a) Seine Bausteine stellen für sich allein betrachtet Verfugungen đar; sie haften am Partikulären. Als Verfügungen sind die getroffenen Anordnungen aber nicht rechtssatzgebunden. Ihr Inhalt ist nicht durch eine allgemeine Norm determiniert. Sie sind Ermessensakte ${ }^{38}$ ). Sie stehen im Rahmen einer sog. Verfügungsermächtigung ${ }^{39}$ ): die planende Behörde ist ermächtigt, unter Uberspringung der $\mathrm{Zwischenstufe}$ der generellabstrakten Norm unmittelbar das Konkrete zu ordnen. Nach seinen Elementen ist somit der Plan ein dezisionistisches Gestaltungselement ${ }^{40}$ ).

b) Die Einzelverfügungen ergehen indessen nicht isoliert. Sie sind inhaltlich aufeinander bezogen. Diese Bezugnahme vollzieht sich nicht durch Unterstellung unter ein gleichbleibendes Kriterium, sondern durch ein nicht bis zum Rechtssatz verall-

37) L. S c h n e ider, Fluchtlinienpläne und Verwaltungsrechtsweg, DOeV. 1951 , S. 662 ; A. H a m a n n, offentlichrechtliche Bauund Planungsmaßnahmen und die Eigentumsgarantie des Art. 14 GG, DVBl. 1957, S. 514.

38) Vgl. z. B. VGH Bayern, Urteil vom 16. 2. 1954, DVBl. 1954, S. $510 \mathrm{ff}$.

39) Dazu I m b o d e $n$, Vertrag, S. $68 \mathrm{ff}$.

10) $\mathrm{H}$ a m a n n, S. 514 . 
gemeinertes graphisch dargestelltes Maß. Eine räumlich-geometrische Rationalität ersetzt die rechtssatzmäßige Folgerichtigkeit formaler Gleichheit ${ }^{41}$ ).

So mag man den Plan kennzeichnen als ein Instrument nichtrechtssatzmäßiger inhaltlicher Koordinierung von ermessensweise getroffenen Einzelverfügungen. Der Plan unternimmt es, konkrete Anordnungen nach einem andern Gesichtspunkt inhaltlich aufeinander auszurichten als nach dem Kriterium formaler Gleichheit. Im Raumplan tritt an die Stelle des Gleichheitsmaßes eine zweckrationale dezisionistische Folgerichtigkeit nicht anders als im Finanzplan, im Jahresbudget oder im Mehrjahresprogramm der spezifisch finanzpolitische Konnex die Egalitätsbetrachtung ablöst.

Mit der linearen Baubeschränkung, die als klassisches Planungsinstrument bisher als Modell diente, stimmt die "zonengebundene Bauvorschrift" strukturell überein. Unter diesem Terminus soll jene Bauvorschrift verstanden sein, die 2war formal in das Gerüst eines Rechtssatzes gekleidet ist, die indessen räumlich nur einen kleinen Teil eines selbständigen Rechtskreises, zumeist nur einen kleinen Abschnitt eines Gemeindebannes erfaßt. Gegenstände von zonengebundenen Bauvorschriften sind Bildung und Abgrenzung von Nutzungsklassen oder Bauklassen ${ }^{42}$ ). Der strukturelle Aufriß dieser Bauvorschrift wird durch zwei Ausdruckselemente geformt. Einerseits wird durch Worte festgelegt, wie in der Zone gebaut werden kann, d. h. welche Nutzungsarten zugelassen sind, welche allgemeine Höhenbeschränkungen gelten und nach welchen Abstandsvorschriften oder Ausnützungsziffern sich die Baudichte bestimmt. Anderseits wird in einer graphischen Darstellung - im sogenannten Zonenplan - angezeigt, wo im Gelände die Zonengrenzen verlaufen, welchen Zonen m. a. W. die einzelnen Grundstücke zugehören.

Das erste Glied des Baustatuts, der Komplex der durch Worte ausgedrückten Vorschriften über die sogenannte Zonenbauweise, stellt unzweifelhaft ein Gefüge von Rechtssätzen dar. Im Unterschied zur Fluchtlinie haben die Anordnungen ein formal gleiches Beurteilungsmaß zum Inhalt. Das zweite Glied des Baustatutes hingegen, der sogenannte Zonenplan, entspricht

41) Vgl. dazu C a pit a $\mathrm{t}$, aaO., S. 1024, Nr. 47: „... on peut considérer que l'intégration dans un plan exerce, dans le droit moderne, une fonction d'objectivation comparable à celle qui, dans le droit classique, était remplie par la ,forme générale donnée aux définitions réglementaires".

42) H. E g g e r , die Bauzonen der stadtzürcherischen Bauordnung von 1946, Zürcher Dissertation 1948, S. $43 \mathrm{ff}$. 
in seinem inneren Aufriß der linearen Baubeschränkung. Der Zonenplan ist ein Akt gestaltender Auslese. Entsprechend dem als ideal angestrebten Raumbild werden Zonengrenzen gezogen. Damit vollzieht sich eine differenzierende Zuordnung der Grundstücke zu verschiedenen Normgruppen. Für sich allein betrachtet, d. h. auf eine einzelne Parzelle bezogen, bildet jeder Klassifizierungsakt eine Verfügung - nicht anders als auch Akte über die Veränderung von Verwaltungsgrenzen Verfügungen sind ${ }^{43}$ ). Der Einzelakt steht jedoch, gleich wie jeder Teilstrich einer Fluchtlinie, in einem räumlich gestalteten größeren Zusammenhang. Durch den Plan werden die Verfügungen auch hier nach einer nichtrechtssatzmäßigen Folgerichtigkeit, nach einem anderen Kriterium als dem der formalen Gleichheit aufeinander bezogen.

Was früher über den charakteristischen Blickpunkt des Planes gesagt wurde, tritt hier noch deutlicher hervor: Bezugspunkte der Planung sind nicht die gewordenen Eigentumseinheiten, sondern eigentumsmäßig nicht differenzierte Räume. Die Individualität der Sache im Rechtssinn und der sachenrechtlich Berechtigten ist primär ohne Bedeutung.

Nicht ohne Absicht bin ich bisher dem Begriff der All ge me in ve r $f \ddot{u} g u n g$ aus dem Wege gegangen. Der Erkenntniswert dieser Vorstellung scheint mir fraglich; jedenfalls ist der Begriff in höchstem Maße schillernd ${ }^{44}$ ). Welcher Inhalt ihm gegeben wird, hängt in erster Linie von der jeweiligen Rechtssatz-Vorstellung ab. Wer jede generelle Anordnung ohne Rücksicht auf ihren Gegenstand inhaltlich als Gesetz versteht, kann mit "Allgemeinverfügung" nur jenen Akt kennzeichnen, der zwar formal nicht individualisiert ist, der aber doch einen geschlossenen Kreis bestimmbarer Adressaten anspricht ${ }^{45}$ ). Wer umgekehrt das Abstraktheits-Erfordernis nicht preisgeben will, wird dazu neigen, unter "Allgemeinverfügungen" solche Anordnungen zu verstehen, die nach seiner Begriffsbestimmung generell-konkreten Charakter haben ${ }^{46}$ ). Dabei kann freilich der Bereich der unter diesen Terminus gebrachten Erscheinungen ungleich weit umrissen werden. Es läßt sich entweder jede an einen unbestimmten Adressatenkreis gerichtete konkrete Anordnung, also auch der Plan, in diese Kategorie einfügen. Oder

43) So F. S c h a c k, Rechtsverordnung im formellen Sinn? Zur Frage der Rechtsnatur der gebietlichen Organisationsakte, DUeV. 1958, S. 276/77.

44) Abgelehnt wird der Begriff der „Allgemeinverfügung“ von $\mathbf{R}$. Ne b in g e r (Verwaltungsrecht, Allg. Teil, 2. Aufl., S. 164) und für das österreichische Recht von Ant on i olli (aaO., S. 73).

45) $\mathrm{H}$ a m a n n, S. 514.

46) So wohl Forsthoff, Lehrbuch, S. 184. 
aber diese Bezeichnung kann den dem Gleichheitsmaß verpflichteten generell-konkreten Verfügungen vorbehalten werden; Plan und Allgemeinverfügung werden dann zu Gegensätzen; sie werden zu den beiden unterschiedlichen Formen generellkonkreten Anordnens. Diese Terminologie erscheint mir als die sinnvollste. Wie immer man aber sich dazu stelle, jedenfalls wird man die Bedeutung der Klassifizierung nicht überschätzen dürfen. Rien de plus permis que les expressions!

Mit der Kennzeichnung des Planes als eines Mittels zur Koordinierung von Einzelakten soll zugleich auch ausgesagt sein, daß diese Institution nach ihren konstitutiven Elementen jedenfalls der Verfügung näher steht ${ }^{47}$ ). Dieser Erkenntnis gibt, wie im folgenden zu zeigen sein wird, eine Betrachtung der praktischen Aspekte der Planung recht.

\section{Der Erlaß des Raumplanes}

\section{A. Rechtliches Gehör}

Was das auf Erlaß des Planes ausgerichtete Verfahren am sichtbarsten vom üblichen Modell des Normsetzungsverfahrens abhebt, ist die institutionell gesicherte Einflußnahme des Grundeigentümers. In Frankreich, wo das Institut der linearen Baubeschränkung erstmals entwickelt wurde, geht diese Einschaltung des Privaten in das Planverfahren bis auf die vorkonstitutionelle Zeit zurück $\left.{ }^{48}\right)$. Heute vollzieht sie sich mit unterschiedlicher Akzentsetzung: Entweder erfolgt die Einwirkung des Privaten in einem vor dem förmlichen Erlaß liegenden, durch die sogenannte Offenlegung des Planprojektes eingeleiteten $\mathrm{Zwischenverfahren^{49 }}$ ). Oder der Grundeigentümer wird auf ein sich dem förmlichen Erlaß anschließendes mit justizmäßigen Formen durchsetztes Aufsichtsverfahren ver-

47) W. H ït te nhein, Anfechtung von Fluchtlinienplänen, DOeV 1954, S. 166/68; Cap it ant, aaO., S. 1023 Nr. 43; Forst h of $f$, Norm, S. 115 .

48) Nach Ansicht des Conseil d'Etat (avis, 3.11.1885) ist immer noch das Edit von 1607 in Kraft (A. de Laubadère, Traité élémentaire de droit administratif, 2. Aufl., 1957, S. 732, Nr. 1457).

49) So das französische Recht (P. Guérin, Alignement, "Encyclopédle juridique Dalloz, Droit Administratif“, Bd. I, S. 83, Nr. 35), das deutsche Recht (vgl. z. B. das preußische Fluchtliniengesetz \& 8 und das Aufbaugesetz von Nordrhein-Westfalen, \& 7 und $\$ 11$ ), das österreichische Recht (A d a m o vi c h, Bd. II, S. 142, Anm. 1) und das italienische Recht (vgl. z. B. Legge urbanistica vom 17.8.1942, Art. $\theta$ und Art. 15). 
wiesen $^{50}$ ). Nicht uninteressant ist es, daß in der unmittelbaren Kommunaldemokratie der Schweiz die zweite Form vielfach bevorzugt wird: die demokratische Beschlußfassung wird zugleich auch als Möglichkeit zur Geltendmachung der Grundeigentümerinteressen verstanden; sie ersetzt - was freilich nicht unproblematisch ist - das Stadium vorgängiger Anhörung.

Es kommt einer juristischen These um des Reimes willen gleich, wenn diese Einflußnahme als Teilnahme Privater an einem Normsetzungsverfahren oder gar als "Petition" an den Gesetzgeber deklariert wird. Mit der heute üblichen und gelegentlich sogar teilweise institutionalisierten Einwirkung der Interessentengruppen auf die Rechtssetzung hat der Vorgang jedenfalls nichts zu tun; ihn unter den Begriff der „Petition“ zu bringen, dürfte angesichts der stark justizförmigen Gestaltung, die das Einwendungsverfahren teilweise - z. B. in Italien ${ }^{51}$ ) aufweist, schwerlich eine sinnvolle juristische Konstruktion sein. Materiell hat die angegangene Behörde nicht einen allgemeinen Gegensatz von Gruppeninteressen zu beurteilen. Sie muß zwischen sich ausschließenden konkreten Rechten die Wahl treffen: soll die Straßenverbreiterung zu Lasten der links oder der rechts liegenden Grundstücke erfolgen? soll von zwei unbebauten Gebieten dieses oder jenes zur Grünzone erklärt werden? Der im Rahmen des sogenannten planerischen Ermessens zu treffende Entscheid hat oft die Tragweite eines eigentlichen Justizaktes. Das öffentliche Interesse kann bei Gleichwertigkeit mehrerer Lösungsvarianten völlig zurücktreten; alles liegt auf der Abwägung der in Mitleidenschaft gezogenen privaten Rechte.

Wird daher durch den Plan - so wie z. B. durch den französischen „plan d'alignement" oder durch die Fluchtlinienfestsetzung gemäß dem preußischen Gesetz von $1875^{52}$ ) - ein endguiltiger, jedenfalls in der Ermessenshandhabung später nicht wieder in Frage zu stellender Entscheid getroffen, so ist die Anhörung des Eigentümers mehr als nur eine atypische

50) Vgl. z. B. § 15 des zürcherischen Baugesetzes für Ortschaften mit städtischen Verhäitnissen vom 23. Aprll 1893: „Die Pläne über die Bau- und Niveaulinien sind mit den nötigen Erläuterungen öffentlich aufzulegen, unter schriftlicher Mitteilung an die betroffenen Grundeigentümer, die im Inland wohnen, und unter Ansetzung einer Rekursfrist von zwanzig Tagen".

51) A. Cas a i in, Repertorio generale di giurisprudenza amministrativa, Bd. II, 1956, piani regolatori Nr. 1 .

62) Hierzu v. StrauB und Torney-Sass, Straßen- und Baufluchtengesetz, 7. Aufl., 1934. 
Variante des Rechtserzeugungsverfahrens ${ }^{53}$ ). Diese Einwirkung, nicht ohne Grund institutionell gesichert, garantiert das rechtliche Gehör in einem Verfahren, das zwar nicht generell, aber doch im möglichen Extrem vorab der Austragung privater Interessenkonflikte dient. Daraus möchte ich folgern, daß sich auch die Anhörung der betroffenen Grundeigentümer nicht beliebig handhaben läßt, daß sie namentlich in ihrer Effektivität nicht beliebig abgewertet werden darf. In der Heranziehung des Privaten liegt letztlich eine Ausstrahlung der verfassungsrechtlichen Gehörs-Gewährleistung.

\section{B. Die Befugnis zur Planfestsetzung}

Was freilich der zutreffenden juristischen Deutung des Planes entgegensteht, ist der Umstand, daß die Befugnis zur Planfestsetzung vielfach bei den rechtssetzenden Instanzen liegt. Ergeht der Plan f or m e 11 als Gesetz, dann liegt es aus der Sicht des Gewaltenteilungsschemas nahe, ihn auch m a t e ri e 11 als Gesetz zu verstehen.

Demgegenüber wird man sich vergegenwärtigen müssen, daß der moderne Raumplan im kleinen Rechtskreis, vorab in der Gemeinde, entwickelt wurde. Die Kommunalverfassung kennt aber - und das zumal in ihren ursprünglichen Rechtsschichten - keine der modernen Scheidung der Rechtsfunktionen folgende Gewaltenteilung ${ }^{54}$ ). Die Gliederung der Macht erfolgt primär nach anderen Gesichtspunkten. Es ist eine sich vor allem im schweizerischen Gemeinderecht deutlich abzeichnende und auch im deutschen und österreichischen Recht nachweisbare Tendenz, die oberste rechtserzeugende Instanz der Gemeinde immer dann einzuschalten, wenn ein Akt getroffen werden muß, der vermöge seiner Breitenwirkung oder des beanspruchten Ermessensspielraums von besonderem Gewicht erscheint. Dem entspricht es, die Planfestsetzung der nämlichen Intanz zu überantworten, die auch das eigentliche Ortsrecht, $d . h$. die kommunalen Rechtssätze erläßt. So erklärt es sich zwanglos, daß vor allem in den Stadtstaaten (Hamburg,

53) Vgl. hierzu das Urteil des Schweizerischen Bundesgerichtes vom 28.5. 1958, BGE 84 I 172: „La procédure d'opposition à un plan d'extension cantonale est une procédure contradictoire qui permet aux propriétaires intéressés de défendre ceux de leurs droits constitutionnels auxquels le projet porterait atteinte...".

54) M. I m b o de n, Die Organisation der schweizerischen Gemeinden, Zentralblatt für Staats- und Gemeindeverwaltung, 1945, S. 378. 
Wien und Basel) Pläne in den Formen des Gesetzes oder doch qualifizierter Verordnungen erlassen werden ${ }^{55}$ ).

\section{Plan und Rechtsgleichheit}

Die entscheidenden rechtlichen Probleme der Planung liegen indessen nicht im Verfahrensgang, sondern, was im schweizerischen Recht vor allem $\mathrm{H}$ a $\mathrm{n} \mathrm{H}$ u b e $\mathrm{r}$ betont hat, im Inhalt der geplanten Maßnahmen ${ }^{56}$ ). Welche Folgerungen sind aus der Erkenntnis zu ziehen, daß der Plan als ein nichtrechtssatzmäßiges Mittel der Koordinierung von Einzelverfügungen einem anderen Maße als dem der formalen Gleichheit folgt? In der Rechtsprechung und in der Lehre zeichnen sich - mitunter freilich unausgesprochen - zwei Haltungen ab:

Die eine Auffassung will die dem Plane eigene Rationalität gleichwertig neben die rechtssatzmäßige Folgerichtigkeit formaler Gleichheit stellen. Planungsmaßnahmen sollen danach so lange nicht rechtsungleich, $d$. h. nicht willkürlich sein, als sie ihrem eigenen inneren Gesetz treu bleiben, als sie m. a. W. dem Planungszweck entsprechen und nicht durch sachwidrige Motive beeinträchtigt werden ${ }^{57}$ ). Verlangt das städtebauliche Gestaltungsinteresse, daß von zwei objektiv in gleicher Weise geeigneten Grundstücken nur das eine in ein Bauausschlußgebiet einbezogen werde, so wird dem Einwand rechtsungleicher Behandlung durch die These zweischichtiger rechtlicher Bindung, durch die Vorstellung eines ưbereinanderliegens von Pflichtigkeit und Pflicht begegnet. Alle zur Anlegung von Grüngürteln geeigneten Grundstücke - so wurde vom deutschen Bundesgerichtshof gesagt ${ }^{58}$ ) - unterliegen virtuell der Last, Bauverbotszone zu werden; nur bei einigen verdichtet sich indessen diese allgemeine Pflichtigkeit zur festen und durchsetzbaren Pflicht. Entsprechend der verbreiteten, meiner Ansicht nach freilich in dieser Art nicht haltbaren These, der baurechtliche Dispens liege außerhalb des rechtlich $\mathrm{zu}$ Beanspruchenden ${ }^{59}$ ), wird auch gegenüber dem Plan angenommen,

55) Gesetz über den Aufbau der Hansestadt Hamburg in der Fassung vom 12.4.1957, \& 7 und $\S 11$ Abs. 2; Bauordnung für die Stadt Wien vom 25.11.1929, $\S 1$; Baselstädtisches Gesetz über Anlegung und Korrektion von Straßen vom 24.1.1937 \& 8 lit. a.

56) $\mathrm{H}$. H u b e r, Zeitschrift für schweizerisches Recht, Bd. 66, (1947), S. 508a/509a.

ธ7) B r o h m, aaO., S. 70.

58) BGHZ 23 Nr. 4, S. 33. Dazu W. D it t u s, Planung und Sozialgebundenheit des Grundeigentums, DVBI. 57, S. 329 ff.

59) So Brohm, S. 90; kritisch dazu Imboden, Vertrag, S. $190 \mathrm{ff}$. 
kein Grundeigentümer habe im Rahmen des planenden Ermessens ein fest gestaltetes Recht auf eine ihm günstige bauzonenmäßige Einstufung seines Grundbesitzes. Nur dann, wenn im tubergang von der Pflichtigkeit zur Pflicht gegen die innere Folgerichtigkeit der Planung verstoßen wurde, liegt nach dieser Anschauung eine willkürliche Diskriminierung vor.

Die Fragwürdigkeit dieser These ist unverkennbar. Welche Pflichtigkeiten sich zu Pflichten verdichten - und hierin liegt ja gerade das praktisch entscheidende Problem - wird dem planenden Ermessen freigestellt. Der Gleichheitsgesichtspunkt ist durch ein zweckrationales dezisionistisches Kriterium ersetzt.

Die gegenteilige Auffassung sieht in der rechtssatzmäßigen Folgerichtigkeit formaler Gleichheit und in der gestaltenden Rationalität des Planers zwar ebenfalls inkommensurable Größen. Indessen ordnet sie die beiden Maßstäbe einander nicht gleich; sie ordnet vielmehr das planende Ermessen dem Prinzip der Gleichheit unter. Der Plan hat somit nur da Bestand, wo die durch ihn getroffenen Unterscheidungen auch in einer ausschließlich normativen Ordnung begründbar wären. Die Ungleichbehandlung zweier Grundstücke verstößt gegen das Gleichheitsgebot, sobald die getroffene Differenzierung nicht auch als allgemeines Gesetz formuliert aus der Verschiedenheit der Tatbestände gerechtfertigt erscheint. Es liegt auf der Hand, daß diese These praktisch eine weitgehende Lahmlegung, wenn nicht überhaupt eine Verunmöglichung der modernen Stadtund Landesplanung zur Folge haben müßte.

Die Frage stellt sich, ob der Konflikt dieser beiden Anschauungen durch eine strikte Alternative überhaupt lösbar ist. Eine Uberbrückung des Gegensatzes wird möglich, wenn man nach den Unrechtsfolgen zwei Arten von Verstößen gegen das Gleichheitsgebot unterscheidet: einerseits Diskriminierungen, die eine getroffene Anordnung ungültig werden lassen, und andererseits Diskriminierungen, die eine finanzielle Ersatzpflicht begründen $\left.{ }^{60}\right)$. Lineare Baubeschränkungen und Zonengliederungen, die zwar planerisch folgerichtig erscheinen, indessen ungleiche Belastungen zur Folge haben, sind dann zwar gültig; die Diskriminierung muß indessen durch Geldersatz ausgeglichen werden ${ }^{61}$ ). Nur der schon nach seiner immanenten Eigengesetzlichkeit nicht folgerichtige und willkürliche Plan bliebe bereits als Eingriff ungültig.

60) Vgl. hierzu auch G. D î $r$ in $g$, JZ 1954, S. 5.

61) Dieser Gedanke ist erkennbar in der französischen Praxis zum plan d'alignement (vgl. D u e $z-D$ e b e y $r e$. Traité de droit administratif, 1852, S. 787); er klingt auch an in BGHZ 15, S. $268 \mathrm{ff}$. 
Die Annahme zweischichtigen Unrechtes ist der bestehenden Ordnung keineswegs fremd; ja, sie bildet sogar eines der strukturellen Kennzeichen des geltenden Verwaltungsrechtes. Bereits dem Polizeinotstand ist diese Doppelgesichtigkeit eigen: das Vorgehen gegen den "Nichtstörer" ist zwar formal zulässig, mit dem Blick auf die Entschädigungsfolge aber doch Unrecht ${ }^{62}$ ). Nicht anders wird das Schulbeispiel des objektiv zwar unschuldigen, indessen aus haltbaren Gründen der Tat verdächtigten Häftlings behandelt $\left.{ }^{63}\right)$. Vor allem aber ist schon der klassische Tatbestand der Enteignung in nämlicher Weise zweischichtig: formal gilt der Sachentzug als rechtmäßig; materiell ist er indessen eine Beeinträchtigung, die durch Wertausgleich aufgewogen werden muß $\beta^{84}$ ). Die juristische Dogmatik hat sich dieser Gegebenheit dadurch angepaßt, daß die verfassungsrechtliche Eigentumsgewährleistung, soweit es um die Sicherung der individuellen Rechtsstellung geht, zur bloßen W e r t g a r a n t i e abgeschwächt wurde. Wer abweichend vom Nachbar seine Eigentumsrechte in einem Enteignungsverfahren preisgeben muß, behält immerhin den Anspruch auf wertgleiche Behandlung. Der Anspruch auf Fortbestand der geldwertmäßigen Stellung überdauert den Anspruch auf Fortbestand der Realrechte ${ }^{65}$ ).

Ubertragen auf die Verhältnisse des deutschen Rechtes hätte diese These zu bedeuten, daß der Begriff des „enteignungsgleichen Eingriffes" und allenfalls auch derjenige des besonderen Opfers im Rahmen des Aufopferungsanspruches ein weiterer wäre als der Begriff der willkürlichen, vor Art. 3 des Grundgesetzes unhaltbaren Eigentumsbeschränkung. Im schweizerischen Recht läßt sich gestützt auf die verfassungsmäßige Eigentumsgewährleistung das nämliche Ergebnis erzielen. Die neuere bundesgerichtliche Praxis neigt dazu, einen enteignungsähnlichen Eingriff in das Grundeigentum nicht als ungültig hinzunehmen, aber unmittelbar aus der Verfassung, ohne daß es einer besonderen Ersatzklausel bedarf, einen Entschädigungsanspruch herzuleiten ${ }^{66}$ ).

Die Betrachtung des Verhältnisses von Planung und Gleichheit wird jedenfalls zum Ergebnis führen müssen, daß das

62) D r e w s - W a cke, Allgemeines Polizeirecht, 6. Aufl., 1952, S. $206 \mathrm{ff}$.

B3) F l e in e r, Institutionen, S. 297.

64) K. A. Bet termann, Der Schutz der Grundrechte in der ordentlichen Gerichtsbarkeit, in ,Die Grundrechte“, Bd. III/2, S. 866.

65) BGHZ 6, Nr. 37, S. 280: „Der Verstoß gegen den Gleichheitssatz kennzeichnet die Enteignung".

B8) Urteil des Schweizerischen Bundesgerichtes vom 26.10.1955, BGE 81 I Nr. 55, S. $346 \mathrm{ff}$. 
planende Ermessen von den Grundrechten her entscheidenden Grenzen unterstellt sein muß. Mit Recht hat neuestens B a c h of auf die grundsätzliche Bedeutung der ermessensbeschränkenden Verfassungsnormen hingewiesen ${ }^{67}$ ). Mit dem Blick auf den Rechtsschutz ergibt sich daraus die Forderung, die dem betroffenen Privaten zur Verfügung gestellten Rechtsbehelfe so auszugestalten, daß für eine wirksame Einhaltung der verfassungsimmanenten Planungsschranken Gewähr geboten ist.

\section{Die Gestaltung des Rechtsschutzes}

\section{A. Die Uberprüfungsformen}

Damit ist auf jene Frage hingewiesen, die in der neueren deutschen Lehre den Anstoß zur dogmatischen Klassifizierung des Planes gab. Die Öffnung des Rechtsweges hängt in erster Linie von der Natur des Planes ab; sowohl das Bundesverwaltungsgericht wie der österreichische Verwaltungsgerichtshof haben diesen Zusammenhang klar betont ${ }^{88}$ ). Wenn dabei das Bundesverwaltungsgericht den Begriff des Verwaltungsaktes als „Zweckschöpfung“" wertet ${ }^{69}$ ), so bringt es zum Ausdruck, da $B$ die praktische Frage nach Zulassung des administrativen Rechtszuges nicht unbedingt an die aprioristische Scheidung von Rechtssatz und Verfügung gebunden sei. Die Qualifikation erfolgt primär teleologisch und nicht dogmatisch. Allein diese Betrachtung gewährleistet praktisch brauchbare Ergebnisse. Entscheidend muß m. a. W. sein, welches Verfahren am sinnvollsten und wirksamsten eine justizmäßige UUberprüfung des Planes erlaubt; in Ausrichtung auf dieses Endziel ist die Klassifizierung vorzunehmen.

Sieht man von den noch nicht hinlänglich geklärten Möglichkeiten öffentlich-rechtlicher Feststellungsprozesse oder administrativer Unterlassungsklagen ab, so kennt das geltende Recht drei verfahrensmäßige Grundtypen zur Überprüfung des Planes: Der Plan kann Gegenstand dir ekt e r gerichtlicher Anfechtung sein; er kann bei Anlaß seiner späteren Anwendung vorfrageweise überprüt werden; schließlich kann die Nachprüfung in ein Verfahren verwiesen sein, das primär Merkmale der Verwaltungsaufsicht trägt. Die Frage

67) O. B a c h of, Grundgesetz und Richtermacht, 1959, S. 22.

68) BVerwGE. $3 \mathrm{Nr} .70$, S. 259; Sammlung der österreichischen Verwaltungsgerichtshofentscheidungen Nr. 1988, 1951, Adm. Teil, s. 316 .

69) BVerwGE. 3 Nr. 70, S. 262, 6 Nr. 37, S. 151. 
stellt sich, welche Gestalt des Kontrollverfahrens den durch die Natur des Planes bedingten Rechtsschutzbodürfnissen am besten entspricht.

\section{B. Die direkte gerichtliche Anfechtung}

Eine unmittelbare gerichtliche Anfechtung des Planes durch den Privaten ruft Schwierigkeiten im Hinblick auf die Interdependenz aller Planungselemente: einige Grundeigentümer verlangen als isolierte Einzelkläger die Uberprüfung ihrer räumlich begrenzten Situation, während der Plan seinem Wesen nach ein Koordinierungselement darstellt und eine Gestaltung in einem größeren Raum anstrebt $\left.{ }^{71}\right)$. Ob der Planer in $\mathrm{Ab}$ wägung der sich gegenüberstehenden Eigentümer-Interessen eine innerlich haltbare Lösung traf, ob er die planende Auslese überzeugend vollzog, kann der Richter nur entscheiden, wenn er die Freiheit hat, auch Grundeigentümer, die keine Rechtsmittel eingelegt haben, am Verfahren $\mathrm{zu}$ beteiligen. Ist ihm diese Möglichkeit versagt, dann bleibt das planende Ermessen sozusagen vollständig einer rechtlichen Überprüfung und $\mathrm{Be}$ grenzung entrückt. Dehnt aber der Richter durch Beiladung einer großen Zahl weiterer Grundeigentümer das Verfahren aus, kann dieses durch seine Breite den üblichen Rahmen einer justizmäßigen Nachprüfung hoheitlicher Anordnungen sprengen.

In vier deutschen Ländern - Baden-Württemberg, Bayern, Hessen und Bremen - ist freilich mit dieser Qualifikation des Planes der direkte Weg zum Verwaltungsgericht noch nicht verschlossen. Auch Rechtssätze unterhalb der Gesetzesstufe, also Verordnungen, können Gegenstand einer hauptfrageweisen Rechtsprüfung sein. Die praktischen Schwierigkeiten, die sich ergeben, wenn der Plan auf dem Wege der prinzipalen Normkontrolle überprüft wird, sind indessen eher noch größere, als sie sich im Rahmen der verwaltungsgerichtlichen Verfügungsanfechtung ergeben - was vielleicht $z u$ erklären vermag, warum vor allem das Verwaltungsgericht von Baden-Württemberg der These des Bundesverwaltungsgerichts so zähen Widerstand entgegensetzt.

\section{Die vorfrageweise tberprüfung}

Wird der Weg zur direkten verwaltungsgerichtlichen Anfechtung des Planes unter Hinweis auf dessen Norm-Charakter verschlossen, dann ist der Grundeigentümer - sieht man von

70) Brohm, aaO., S. $79 \mathrm{ff}$.

71) Forsth off, Norm, $S .114$. 
der erwähnten verfahrensrechtlichen Besonderheit in einigen deutschen Ländern ab - darauf verwiesen, den Plan bei Anlaß seiner Anwendung vorfrageweise zu beanstanden. Ist der Plan nicht Verwaltungsakt, sondern Norm, muß zu seiner Nachprüfung die für Rechtssätze unterhalb der Gesetzesstufe charakteristische akzessorische Normkontrolle Platz greifen. Ich fürchte freilich, daß die praktische Erprobung dieser Möglichkeit ziemlich enttäuschende Ergebnisse zeitigen werde; liegen einmal aus einem weiteren Bereich Ergebnisse vor, dann wird man vielleicht unter dem Eindruck stehen, mit der Qualifizierung des Planes als Norm sei kaum etwas Wesentliches erreicht worden, es sei denn, daß der schwarze Peter für einmal weitergegeben wurde ${ }^{72}$ ).

Die vorfrageweise Normkontrolle gründet sich auf die Vorstellung, daß die Rechtswidrigkeit eines Rechtssatzes in jedem Anwendungsfall in nämlicher Weise relevant werde, da $\beta$ es somit gleichgültig sei, welcher Sachverhalt zum Anlaß der Normprüfung genommen werde. Jeder Betroffene handelt stellvertretend für alle Normadressaten. Diese Prämisse bleibt bei der vorfrageweisen tuberprüfung des Planes unerfüllt. Der Plan wirkt für jeden Grundeigentümer anders. Auch nicht-beteiligte Grundeigentïmer ins Verfahren einzubeziehen ist aber, da sich das Problem der Planverbindlichkeit nur akzessorisch stellt, prozessual nicht vollziehbar. Incidenter kann der Plan zwar auf gewisse allgemeine Voraussetzungen wie z. B. auf seine formelle Rechtmäßigkeit hin überprüft werden. $O b$ aber die der Planung immanenten Ermessensschranken, vor allem die Schranke der Gleichheit, eingehalten wurden, entzieht sich der Nachkontrolle ${ }^{73}$ ). Die Wiener Bauordnung, die eine individuelle Beanstandung von Fluchtlinien nur im Zusammenhang mit der Bauerlaubnis zuläßt, bestätigt dies besonders eindrücklich. Der Grundeigentümer kann nicht den Plan als Ganzes, sondern nur den sein Grundeigentum belastenden Plan-T e i 1 beanstanden ${ }^{74}$ ). Im Hinblick auf den Rechtsstreit wird der Plan in seine Elemente aufgelöst. Sobald also mit der These vom Normcharakter des Planes ernst gemacht wird, sobald man den Plan wie eine Norm als Ganzes einer incidenter wirksamen Rechtskontrolle unterstellt, ergibt sich, daß er sich nicht als Norm behandeln

72) Aufschlußreich: W. B lu m e 1, Ungereimtheit beim Rechtsschutz gegen Planfeststellungen, DOeV. 1959, S. $665 \mathrm{ff}$.

73) Vgl. preußisches OVG. $25 \mathrm{Nr} .52, \mathrm{~S} .387 \mathrm{ff}$.

74) Wiener Bauordnung, $\$ 10$, Abs. 7. 
läßt. Damit erklärt sich wohl auch, warum Italien die vorfrageweise Plankontrolle überhaupt nicht zuläßt ${ }^{75}$ ).

\section{Plankontrolle im Wege der Verwaltungsaufsicht}

Das preußische Fluchtliniengesetz wies Einwendungen gegen die Zweckmäßigkeit linearer Baubeschränkungen im Anschluß an die sog. Offenlegung in ein administratives Aufsichtsverfahren. Im deutschen Recht wurde diese Möglichkeit der Planprüfung im allgemeinen nicht weiterentwickelt; $j a$, mitunter sind die bestehenden Ansätze zu einer institutionalisierten verwaltungsinternen Plankontrolle wieder abgebaut worden. Die Anfechtung bei der Oberbehörde wurde gelegentlich zur Einsprache bei der Planungsinstanz reduziert ${ }^{76}$ ). Anders haben sich das schweizerische und teilweise auch das italienische ${ }^{77}$ ) Recht entwickelt. Entsprechend der stark betonten Kommunalautonomie obliegt in der Schweiz die Planung im Rahmen relativ weiter kantonalrechtlicher Schranken den Gemeinden. Die lokalen Gebietskörperschaften unterstehen hierbei freilich einer besonders ausgestalteten Aufsicht. Einerseits können die betroffenen Grundeigentümer bei den kantonalen Behörden individuell Beschwerde führen; anderseits bedürfen Fluchtlinienpläne und Bauzonenordnungen zumeist der Genehmigung durch den Kanton. Aus dem Ineinandergreifen von Beschwerdeprüfung und Genehmigungs-Kontrolle hat sich ein Aufsichtsverfahren entwickelt, das bei einigermaßen justizförmiger Sicherung der Parteirechte doch eine freie Nachprüfung des von der planenden Gemeindebehörde vollzogenen Interessenausgleichs erlaubt. Dem Beschluß der letzten kantonalen Aufsichtsinstanz schließt sich der staatsrechtliche Rekurs, d. h. die Verfassungsbeschwerde ans Bundesgericht an. Dieser Rechtsbehelf kann ohne Rücksicht darauf, ob es sich um Verfügungen oder Rechtssätze handelt, ergriffen werden ${ }^{78}$ ). Die Rechtsnatur der angefochtenen Anordnung wird indessen für eine Reihe von prozessualen Fragen von Bedeutung. Nach einigem Schwanken scheint das Bundesgericht nunmehr dazu zu neigen, den Plan

75) Casalin, aaO., Nr. 21. Dagegen ist die Anfechtung des Planes selbst bzw. des Entscheides uber die Plangenehmigung möglich; vgl. Cas a li n, aaO., Nr. 5, Abs. 3.

76) Vgl. z. B. Aufbaugesetz von Nordrhein-Westfalen, $\$ 11$, Abs. 1.

77) Vgl. z. B. Legge urbanistica, Art. 15/16.

78) Gi a c o metti, aaO., S. 887.

79) $\mathrm{Z}$ w y g a r , aaO., S. 41; I m b od e n, Festschrift Fritzsche, s. $46 ; \mathrm{K}$ ut t 1 e r, S. 118 . 
in Ubereinstimmung mit der neueren schweizerischen Literatur ${ }^{79}$ ) wie eine konkrete Anordnung zu behandeln ${ }^{80}$ ).

\section{E. Die Nachprüfung des planenden Ermessens}

Die Übersicht über die Rechtsschutzformen läßt das Grundproblem der Plankontrolle klar erkennen. Wohl ist es ohne Schwierigkeiten möglich, den Plan daraufhin zu prüfen, ob er formell rechtmäßig erlassen wurde und ob er durch seinen Inhalt nicht gegen die durch das Plangesetz aufgestellten materiellrechtlichen Vorschriften verstößt. Gegenüber einfachen Plangebilden wie z. B. Fluchtlinien, wird es allenfalls auch möglich sein, gröbste Fälle sachwidriger Planung im Rechtsschutzverfahren zu korrigieren. In seiner spezifischen Funktion, nämlich als Mittel zur Koordinierung von Einzelverfügungen, entzieht sich indessen der Plan in weitem Maße der Nachprüfung. Die dominierenden Typen des Rechtsschutzes, Verfügungsanfechtung und Normkontrolle, drohen in der Nachprüfung des planenden Ermessens ins Leere zu greifen ${ }^{81}$ ). Nur ein der Natur des Planes angepaßter, besonders gestalteter, Merkmale des Aufsichtsverfahrens tragender Rechtsbehelf vermöchte eine wirksame Plankontrolle zu gewährleisten. Dieses Sonderverfahren sollte jedenfalls in der ersten Stufe eine volle Ermessenskontrolle zulassen; es sollte, wie in Italien, mit der oberbehördlichen Plangenehmigung zusammengehen. Ein auf die Rechtskontrolle beschränktes Gerichtsverfahren hätte den Rechtszug zu beschließen. Das reine Justizverfahren vermag nur dann die Geltung der das planende Ermessen beschränkenden Grundnormen zu sichern, wenn es sich diesem Sonderverfahren a n s hlie $B$ t. Die dem Plan zu Grunde liegenden Interessengegensätze müssen als Ergebnis einer früheren Verfahrensstufe vor dem Richter voll entfaltet sein.

So weist der Plan auf Grenzen des heutigen RechtswegStaates hin. Er ruft in Erinnerung, was namentlich W a lt er Burckhardt immer wieder betonte: daß der Rechtsstaat nicht im Anliegen nach verwaltungsexterner justizförmiger

80) Einer Charakterisierung des Planes als Summe konkreter Verfügungen kommt es gleich, wenn das Bundesgericht einen angefochtenen Plan nur insoweit aufhebt, als sich dieser auf das Grundeigentum des Beschwerdeführers bezieht: BGE 74 I $147 \mathrm{ff}$,, 77 I 211 ff., 78 I $424 \mathrm{ff}$.; Zentralblatt für Staats- und Gemeindeverwaltung, Bd. 53, S. 120 ff., Bd. 58, S. $263 \mathrm{ff}$.; Monatsschrift für bernisches Verwaltugnsrecht, Bd. 43, Nr. 96, S. 253. Diese Praxis des Bundesgerichtes ist aber nicht einheitlich; vgl. BGE 76 I 329 ff., 81 I $26 \mathrm{ff}$.

81) K.H. v. Kö h le r, Fragen des Eigentums im Verwaltungsrecht, DVBl. 1958, S. 196. 
Kontrolle der öffentlichen Gewalt aufgeht, daß er, um Willkür zu unterdrücken, auch Sicherungen innerhalb der Verwaltung notwendig macht ${ }^{82}$ ).

VIII. Programm atischer Leitplan und rechtsgestaltender Durchführungsplan

Um die komplexe Struktur der heutigen Raumplanung zu verstehen, ist eine letzte Differenzierung erforderlich. In Lehre und Praxis werden danach verschiedene Planformen unterschieden, ob der Plan die rechtliche Lage der Grundeigentümer verändere, oder ob er - ähnlich den sog. Normativvorschriften - lediglich Anweisungen an andere Behörden beinhalte ${ }^{83}$ ). Für die Grundeigentümer rechtsgestaltend wirkt der Plan dann, wenn er einen Baubescheid oder eine andere gegenüber dem Privaten zu treffende Verfügung mitzubestimmen vermag ${ }^{81}$ ). Nur als Anweisung an eine Behörde wirkt er, wenn er sich in keiner Richtung als Determinante individuell-konkreter Anordnungen entfaltet. Der rein programmatische, für den Grundeigentümer nicht unmittelbar wirksame Plan - vielfach als sog. Leitplan oder, wie in Italien ${ }^{85}$ ), als Koordinierungsplan bezeichnet - ist seinem Wesen nach eine bloße Vorstufe; er ist ein Element in einem zweistufigen Planverfahren. Durch den rein programmatischen Plan werden nicht individuelle Verfügungen, sondern Pläne zweiter Ordnung koordiniert. In seiner rechtlichen Struktur läßt sich der reine Leitplan zur Verwaltungsverordnung in Parallele bringen; er ist bloße Ermessensdirektive für die nachgehende Planung $\left.{ }^{86}\right)$.

Die klare Scheidung von koordinierendem Planungsprogramm und rechtsgestaltendem Bauplan ist nun freilich in der neueren Gesetzgebung mehr und mehr verwischt worden. Auch der Leitplan hat in einzelnen Beziehungen unmittelbar Gestaltungswirkung. Soweit er noch nicht durch einen Durchführungsplan konkretisiert wurde, wirkt er mitunter als vorläufige Eigen-

82) Wa lter Burckhardt, Die Verwaltungsgerichtsbarkeit in der schweizerischen Eidgenossenschaft, Zeitschrift für die gesamte Staatswissenschaft, Bd. 90 (1931), S. 248: „Wenn es gelingt, dem Verwaltungskörper Kontrolleinrichtungen einzubauen, welche die Gesetzmäßigkeit und die Folgerichtigkeit der Verwaltungspraxis sicherstellen, ohne der Einheit der Verwaltung und der Offizialmaxime Abbruch $\mathrm{zu}$ tun, ist dieses Mittel dem immer etwas künstlichen Mittel der Verwaltungsgerichtsbarkeit vorzuziehen".

83) B roh m, S. 21/22.

84) Preußisches OVG 61, Nr. 86, S. $386 \mathrm{ff} ., 68, \mathrm{Nr} .95, \mathrm{~S} .435 \mathrm{ff}$.

85) Zum italienischen Recht vgl. Legge urbanistica, Art. 5.

86) $H$. R a s n e r, Vorbereitende Bauleitplanung und Enteignung, DVBl. 1956, S. 813; H. G. R ö s s l e r, Zur Nichtigkeit des Aufbaugesetzes von Nordrhein-Westfalen, DVBl. 1957, S. 124. 
tumsbeschränkung, z. B. als Sperre für eine Neubebauung oder eine Nutzungsveränderung. Parallel mit dieser Entwicklung wurde vielfach sogar eine dreistufige Planung verwirklicht: zwischen den rein programmatischen und den rein gestaltenden Plan wurde eine Zwischenform eingeschoben, in deren rechtlicher Struktur Züge der vorangestellten wie der nachfolgenden Planstufe verschmolzen sind. Die Verwirklichung einer mehrstufigen Bauplanung und noch mehr die Vermischung von programmatischem Leitplan und rechtsgestaltendem Durchführungsplan trägt weiter dazu bei, das planende Ermessen einer wirksamen Nachkontrolle $\mathrm{zu}$ entziehen und damit die Effektivität der verfassungsimmanenten Planungsschranken zu entkräften. Der Verfassungsjurist wird daher an den Gesetzgeber die Forderung richten müssen, vor allem nach Klarheit und Evidenz der Planungstypen zu streben.

\section{Plan und Rechtsistat}

Lassen Sie mich an den Beginn meiner trberlegungen zurückkehren. Es ist die Frage nach dem Verhältnis von Plan und Rechtsstaat gestellt.

Versteht man den Rechtsstaat nicht anders denn als eine spezifische Technik im Ineinandergreifen der Rechtsfunktionen, dann mag man in der Tat den Plan als einen nicht assimilierbaren Fremdkörper betrachten. Weder folgt er den zwei Grundstufen der Rechtsverwirklichung "Rechtssatz und Verfügung", noch läßt er sich bruchlos von einem System repressiven verwaltungsinternen Rechtsschutzes erfassen. Ja, es läßt sich sagen, daß sich im Plan wie in keinem anderen verwaltungs. rechtlichen Institut die Regelwidrigkeiten häufen. Im Plan spiegelt sich als erstes die rechtsstaatliche Fragwürdigkeit des Ermessensaktes wider. Soweit es sich um programmatische Pläne handelt, kommt die der Verwaltungsverordnung eigene Problematik hinzu. Im Grenzfall kleinräumiger Planung kann zusätzlich auch der Problemkomplex des öffentlich-rechtlichen Vertrages berührt sein. Mit diesem Aufriß bekannter rechtsstaatlicher Fragwürdigkeiten verbindet sìch schließlich der spezifisch juristische Aspekt der Planung, nämlich die Koordinierung von Einzelakten nach einem anderen Gesichtspunkt als dem der rechtssatzmäßigen Gleichheit. So mag die tbersicht, geht man von einer formal-technisierten Rechtsstaats-Vorstellung aus, in der Tat mit einer hoffnungslosen Unterbilanz schließen.

Aber der Rechtsstaat ist mehr als nur ein kunstvoll eingespieltes Funktionsgefüge. Sein formales Grundaxiom, das Prinzip vom Erfordernis des Rechtssatzes, ist nicht Selbstzweck 
und hat letztlich keinen Eigenwert. Die Einzelrechte und dio Einzelverpflichtungen sollen sich auf allgemeine Normen gründen, weil damit allein die Verwirklichung der Rechtsgleichheit gewährleistet erscheint ${ }^{87}$ ). Die Formtypik des Rechtsstaates steht im Dienste eines doppelten Gerechtigkeitswertes: einmal der Forderung, daß ohne Ausnahme nach Grunidsätzen entschieden werde, und sodann des Postulates, daß keine willkürlichen Unterscheidungen und keine willkürlichen Nicht-Unterscheidungen getroffen werden. Die Verpflichtung zur normativen Grundsätzlichkeit und das Willkürverbot gehören als Manifestationen des Gleichheitsgrundsatzes zu den das staatliche Funktionsgefüge tragenden Grundwerten. $\mathrm{Daß}$ im Plan die eingespielte rechtsstaatliche Formtypik zerbricht, bedeutet nicht die Preisgabe dieser rechtsstaatlichen Fundamentalwerte. Dem Gesetzgeber ist die Aufgabe gestellt, dem Gleichheitsgebot durch Institutionen außerhalb des überkommenen FunktionsGerüstes Nachachtung $z u$ verschaffen. So mag uns eben das Institut des Planes in Erinnerung rufen, da $B$ sich der Rechtsstaat nicht auf ein System formalrechtlicher Automatismen reduzieren läßt. Das rechtsstaatliche Denken bewährt sich im Bestreben, das Institutionelle immer wieder auf die grundlegenden Gerechtigkeitswerte auszurichten.

87) Hans Huber, Niedergang des Rechts und Krise des Rechtsstaates, Festgabe Giacometti, 1953, S. 76. 


\section{Leitsātze der Berichterstatters über: Der Plan als verwaltungsrechtliches Institut}

I.

Der Plan ist in der Gestalt linearer Baubeschränkungen (Fluchtlinien) eine bereits dem klassischen Verwaltungsrecht vertraute Institution. Die linear-geometrische Bauordnung steht im Gegensatz zur normativ-rechtssatzmäßigen Bauordnung. Durch die Aufgliederung der kommunalen Rechtskreise in eine Vielzahl von Bauzonen (Nutzungsklassen und Bauklassen) wurde in den letzten Jahrzehnten eine weitere Form planender Baulenkung entwickelt. Aus der Verbindung der klassischen linearen Baubeschränkung und der Zonengliederung hat sich der moderne Raumplan entwickelt.

II.

Der Plan ist wie der Rechtssatz Determinante für den Rechtsanwender. Er bestimmt spätere Verfügungen. Unter dem Gesichtspunkt seiner bindenden Wirkung für die Baubehörden läßt er sich nicht vom Rechtssatz unterscheiden. Der Ubergang von einer rechtssatzmäßigen zu einer plangebundenen Bauregelung bewirkt weder eine Ausweitung noch eine Einengung des Entscheidungsspielraumes der Baubehörde. In beiden Fällen ist das System der grundeigentumsbeschränkenden Vorschriften als ein lückenloses Ganzes gedacht. Wer den Plan der allgemeinen Norm gleichsetzt, hat in erster Linie dessen DeterminationsFunktion für den Rechtsanwender im Auge.

III.

Das Spezifische des Planes liegt in dessen Inhalt. Die graphische Darstellung läßt sich nur in Ausnahmefällen in rechtssatzmäßige Aussagen umwandeln. Charakteristisch für den Plan ist dessen ungleiche Auswirkung auf die Grundeigentümer. Für jeden betroffenen Privaten wirkt er anders. Der Plan ist, bezogen auf die Normadressaten, nicht ein gleiches, sondern ein ungleiches Maß. Während der Baugesetzgeber, der rechtssatzmäßige Grundeigentumsbeschränkungen verwirklicht, von Gegebenheiten ausgeht, die der konkreten Eigentumseinheit (der Parzelle) inhärent sind, sieht der Planer zunächst über alle eigentumsmäßigen Differenzierungen hinweg. Planung ist stets Verfügung über eine zur Ganzheit verschmolzene Summe von Gütern. 
IV.

Der Rechtssatz als allgemeine Norm ist durch folgende Merkmale gekennzeichnet, die kumulativ erfüllt sein müssen:

1. Er hat sich auf einen nicht-geschlossenen, $d$. $h$. nicht nur unbestimmten, sondern zum voraus überhaupt nicht bestimmbaren "generellen" Adressatenkreis zu beziehen (Gegensatz: das Einzelpersonengesetz);

2. Er hat sich auf einen „abstrakten" Gegenstand zu beziehen, d. h. er hat

a) menschliche Handlungen $z u$ determinieren, die einerseits räumlich (Gegensatz: das Einzelfallgesetz) und andererseits zeitlich (Gegensatz: das Zeitgesetz) auseinander liegen, und er hat

b) die von ihm erfaßten Tatbestände nach gleichem $M a \beta z u$ messen, d.h. unter Abstrahierung vom Partikulären nach einem gleichen allgemeinen Gesichtspunkt zu beurteilen.

V.

Der Plan ist dem Adressaten nach generell. Er weist ferner die für den Rechtssatz ckarakteristische räumliche Breite und Dauerhaftigkeit auf. Hingegen ist dem Plan die Verallgemeinerung durch abstrahierende Außerachtlassung des Besonderen fremd. Er reiht das Partikuläre aneinander, während es im Rechtssatz auf ein gemeinsames Kriterium bezogen ist.

VI.

Die Elemente des Planes sind Verfügungen. Diese werden jedoch in spezifischer Weise miteinander verknüpft. Seinem Inhalte nach ist der Plan ein Instrument nicht-rechtssatzmäßiger Koordinierung von ermessensweise getroffenen Einzelverfügungen. Im Plan tritt an die Stelle des Gleichheitsmaßes eine zweckrationale dezisionistische Folgerichtigkeit.

VII.

Ob man den Plan als "Allgemeinverfügung" bezeichnen will, ist eine Frage der Benennung. Dem Begriff der Allgemeinverfügung werden in der Lehre abweichende Inhalte gegeben; der grundsätzliche Erkenntniswert dieses Konzeptes erscheint fraglich. Am naheliegendsten dürfte es sein, unter Allgemeinverfügung die dem Gleichheitsmaß entsprechenden, im Hinblick auf den Adressatenkreis zwar generellen, im Hinblick auf den Gegenstand aber konkreten Anordnungen zu verstehen (Beispiel: das stationäre Verkehrszeichen). Plan und Allgemeinverfügung werden damit zu den beiden Typen generell-konkreter Anordnungen. 
VIII.

Vielfach werden durch den Plan primär Konflikte zwischen den Anliegen Privater entschieden; das öffentliche Interesse kann bei Gleichwertigkeit von Planungsvarianten gegenüber der Abwägung der in Mitleidenschaft gezogenen privaten Rechte völlig zurücktreten. Wenn in den Planungsgesetzen den betroffenen Grundeigentümern eine Einwirkung auf die Plangestaltung eingeräumt wird, so liegt darin nicht nur eine atypische Variante des Rechtserzeugungsverfahrens. Darin ist vielmehr eine Aktualisierung des verfassungsrechtlichen Anspruchs auf rechtliches Gehör zu erblicken.

IX.

Das fundamentale Rechtsproblem der Planung liegt in der Vereinbarkeit der spezifisch planenden Auslese mit dem verfassungsrechtlichen Gebot der Rechtsgleichheit. Die Antinomie von planender Rationalität und formaler Gleichheit ist im Rahmen einer strikten Alternative überhaupt nicht lösbar; der eine Gesichtspunkt läßt sich nicht grundsätzlich dem anderen unterordnen. Entsprechend den Unrechtsfolgen sind vielmehr zwei Arten des Verstoßes gegen den Gleichheitsgrundsatz zu unterscheiden:

1. Lineare Baubeschränkungen und Zonengliederungen, die unter dem Gesichtspunkt der Planung folgerichtig (d. h. planerisch nicht willkürlich) erscheinen, sind gültig. Diskriminierungen von Grundeigentümern, die nicht auch im Rahmen einer rechtssatzmäßigen Ordnung haltbar wären, sind indessen als besonderes Opfer zu qualifizieren und durch Geldersatz auszugleichen.

2. Nur der schon nach seiner immanenten Eigengesetzlichkeit nicht folgerichtige und daher willkürliche Plan bleibt bereits als Eingriff ungültig.

$X$.

Der Plan weist auf Grenzen des reinen Rechtsweg-Staates hin. Zur rechtlichen Kontrolle des Planes, namentlich zur Überprüfung der verfassungsimmanenten Planungsschranken, eignet sich ein direktes gerichtliches Anfechtungsverfahren nicht. Noch stärker greift eine vorfrageweise Planprüfung ins Leere. Nur ein der Natur des Planes angepaßter, besonders gestalteter, Merkmale des Aufsichtsverfahrens tragender Rechtsbehelf vermag einen wirksamen Rechtsschutz zu garantieren. Dieses Sonderverfahren sollte jedenfalls in der ersten Stufe eine volle Ermessensprüfung zulassen. Ein auf die Rechtskontrolle beschränktes Justizverfahren hätte den Rechtszug zu beschließen. 
$X I$.

Die verfassungsimmanenten Planungsschranken sind heute auch dadurch entkräftet, daß die Grenzen zwischen der rein programmatisch-koordinierenden und der unmittelbar rechtsgestalteten Planung immer mehr verwischt werden. An den Gesetzgeber ist die Forderung zu richten, vermehrt nach Klarheit und Evidenz der Planungstypen zu streben.

$X I I$.

Im Plan häufen sich die bereits am öffentlichrechtlichen Vertrag, am Ermessensakt und an der Verwaltungsverordnung in Erscheinung tretenden Irregularitäten gegenüber Rechtssatz und Verfügung, den beiden klassischen Elementen der öffentlichrechtlichen Verhaltensordnung. Dennoch bewirkt der Plan nicht zwangsläufig eine Beeinträchtigung des rechtsstaatlichen Prinzips. Der Rechtsstaat ist mehr als nur ein kunstvoll eingespieltes Funktionsgefüge und ein System formalrechtlicher Automatismen. Seine spezifische Formtypik - die Gegenüberstellung von Rechtssatz und Verfügung - steht im Dienst eines doppelten Gerechtigkeitswertes: einmal der Forderung, daß ohne Ausnahme nach Grundsätzen entschieden werde, und sodann des Postulates, daß keine willkürlichen Unterscheidungen und keine willkürlichen Nicht-Unterscheidungen getroffen werden. Es ist möglich, diesen grundlegenden Gerechtigkeitswerten auch außerhalb des überkommenen Funktionsgerüstes von allgemeiner Normsetzung, konkretem Normvollzug und justizmäßiger Rechtskontrolle Ausdruck zu geben. 


\section{Der Plan als verwaltungsrechtliches Institut}

\section{Mitbericht von Privatdozent Dr. Klaus Obermayer, München}

I. Um die verwaltungsrechtliche Bedeutung des Planes zu untersuchen, ist es zunächst erforderlich, den B e griff des Planes klar herauszustellen.

1. Jeder Begriff verlangt präzise Kriterien und es soll nicht verkannt werden, daß ihrer Ermittlung im Falle des verwaltungsrechtlichen Planes b e s ondere S ch wierigkeiten im Wege stehen.

a) Einmal ist $z u$ bemerken, daB das Wort "P la n " ein Allerweltsausdruck ist, der im Hinblick auf Entstehung, Entwicklung und Gebrauch keine ursprüngliche jurist ische Affinität aufweist. Es gehört der Umgangssprache des Alltags genauso an wie der Nomenklatur der verschiedenen Fachdisziplinen. Nach Brochhaus ist unter einem Plan ein „Entwurf“ zu verstehen, „in dem eine beabsichtigte Handlung gedanklich vorweggenommen wird mit dem Ziel, den gewünschten Effekt möglichst sicher und ohne Umwege zu erreichen" ${ }^{\prime \prime}$.

b) Sicher gibt es auch im Verwaltungsbereich schon seit langer Zeit Pläne ${ }^{2}$ ). So werden z. B. die Fluchtlinien- bzw. Bebauungspläne, die Enteignungspläne und die Haushaltspläne der Selbstverwaltungskörperschaften bereits im vergangenen Jahrhundert bekann $t^{3}$ ). Die Raumordnungspläne haben eine 50 jährige Geschichte hinter sich $^{4}$ ). Die Wirtschaftspläne wurden im Jahre 1933 durch das Wohnsiedlungsgesetz gesetzlich verankert ${ }^{5}$ ). Aber alle diese Pläne standen doch mehr oder minder beziehungslos nebeneinander. D e $r$ verwaltungsrechtliche Plan ist erst nach 1945 "entdeckt" worden, als es galt, unsere bis ins Mark er-

1) Der Große Brockhaus, 16. Aufl. 1956, 9. Bd., S. 221. - Uber die Geschichte des Wortes "Plan" (im Sinne von "Vorhaben") vgl. Friedrich Maurer und Fritz Stroh, "Deutsche Wortgeschichte, 2. Bd., 1949, S. 400.

2) Vgl. W e r n e r DVBl. 57 S. 225.

8) Vgl. $§ 2$ Pr FluchtlG v. 2. 7. 1875 (GS S. 561) und $\S 15$ ff. Pr EnteignG v. 11. 7. 1874 (GS S. 221).

4) Vgl. K l a m r o th, Organisation und rechtliche Grundlagen der Landesplanung in der Bundesrepublik Deutschland und in Berlin, 1954, S. $10 \mathrm{ff}$.

5) $\S 2$ des Gesetzes über die Aufschließung von Wohnsiedlungsgebieten (WSG) v. 22. 9. 1933 (RGBl. I S. 659). 
schütterte Sozialordnung neu aufzubauen. Die umfassende und intensive Planungstätigkeit der öffentlichen Gewalt machte einen neuen Schwerpunkt verwaltungsrechtlichen Handelns sichtbar, der eine rechtsstaatliche Einordnung und eine rechtswissenschaftliche Bewältigung verlangte. F o rs th of $f$ lenkte mit Nachdruck unsere Aufmerksamkeit auf diesen Verwaltungssektor ${ }^{\theta}$ ), der auf einmal eine zentrale Rolle im Rahmen der öffentlichen Daseinsvorsorge eingenommen hatte.

War nun der $\mathrm{Plan}$ ein gängiger verwaltungsrechtlicher Fachausdruck geworden, so doch ein solcher, der $\mathrm{k}$ e in e $\mathrm{dog}-$ $\mathrm{m}$ a t i s c he Vergangen he it besitzt ${ }^{7}$ ). Der Verwaltungsakt, um dessen begriffliche Neubildung wir in den letzten Jahren auch nachhaltig bemüht waren, konnte immerhin auf eine Geschichte von mehreren Dezennien zurückblicken. So lagen schon viele von Rechtslehre und Rechtsprechung herausgearbeitete Ansatzpunkte vor, als nach Einführung der Generalklausel eine Neubesinnung auf die dem Rechtsstaat adäquaten Kriterien des Verwaltungsaktes geboten war. Der Plan hingegen ist kein vorgeprägter Begriff. Zum ersten $\mathrm{Mal}$ soll er unter verwaltungsrechtlichen Aspekten theoretisch geformt und mit wissenschaftlich verwertbaren Merkmalen ausgestattet werden.

c) Nicht zu übersehen ist schließlich, daß sich das Ringen um die Bestimmung des verwaltungsrechtlichen Plan-Begriffs unter einer gewissen rechtsideologischen Belastung vollzieht. Wir stehen sehr stark im Banne der klassischen verwaltungsrechtlichen Institute, die jedenfalls heute vorwiegend unter dem Gesichtspunkt des Rechtsschutzes betrachtet werden. Daher rührt die Neigung, den Plan von vornherein auf e in e Ebene mit dem Verwaltungsakt und der Rechtsverordnung zu stellen, sei es, daß er einem dieser Rechtinstitute zugeordnet oder daß er als ein aliud mit ihnen konfrontiert wird $\left.{ }^{8}\right)$. Durch eine nicht geprüfte Prämisse wird so das Untersuchungsergebnis von vornherein in einem entscheidenden Punkte festgelegt.

2. Soll trotz aller Schwierigkeiten ein verwaltungsrechtlicher Plan-Begriff gewonnen werden, so sind folgende $\mathrm{meth}$ od i s chen Erwägungen zu berücksichtigen. Es kommt einmal darauf an, Einverständnis darüber zu erzielen, welche Pläne dieser Begriff erfassen soll. Sodann muß versucht werden, ohne Seitenblick auf die bereits erwähnten klassischen verwal-

6) Lehrbuch des Verwaltungsrechts, I. Band, 7. Aufl. 1958 (zit. Verwaltungsrecht), S. 185 ff. und DVBl. 57 S. 113 ff.

7) Deshalb wird man auch in den früheren verwaltungsrechtlichen Lehrbüchern vergeblich nach einer Erörterung des Planes suchen.

B) Vgl. F or s t h of f DVBl. 57 S. 114 und Verwaltungsrecht S. 186 sowie Werner DVB1. 57 S. 225. 
tungsrechtlichen Hoheitsakte von allen in Betracht gezogenen Plänen Merkmale zu abstrahieren, die ihnen gemeinsam sind.

a) Bei einem sinnvollen teleologischen Vorgehen können nur solche Pläne berücksichtigt werden, die die Gestaltung einer bestimmten Ordnung zum Ziele haben.

(1) Damit $s \mathrm{ch}$ eiden von vornherein alle Pläne a $\mathrm{u} s$, die nichts anderes als bloße Absichten zur Vornahme oder Unterlassung von Handlungen bekunden. Ferner sind jene Pläne auszunehmen, die wie die Geschäftsverteilungspläne lediglich die Eigenschaft einer Ubersicht oder einer organisatorischen Einteilung besitzen.

(2) Die dem Plan-Begriff zu unterstellenden Pläne können schon aus technischen Gründen nicht ausnahmslos angeführt werden. Aus der bunten Fülle bundes- und landesrechtlicher Verwaltungspläne sollen daher nur einige besonders charakteristische herausgegeriffen werden.

An erster Stelle sind die wichtigsten auf die Gestaltung und Nutzung des Raumes gerichteten Pläne zu nennen, nämlich

die Raumordnungspläne ${ }^{\vartheta}$ ),

die L e it plä n e ${ }^{10}$ ) einschließlich der Wirtschafts-11), Flächennutzungs-12), Ubersichts-13), Baugebiets-14), Generalbebauungs- ${ }^{15}$ ), Generalbaulinien-16) und (Gesamt-)Aufbaupläne ${ }^{17}$ ),

die Bebau ngsplän $\mathrm{e}^{18}$ ) einschließlich der Fluchtlinien-19), Baulinien-20), Ortsbau- und Durchführungspläne ${ }^{22}$ ),

9) § 3 nw.LandesplanungsG v. 11. 3. 1950 (GV S. 41) und Art. 11 bay.LandesplanungsG v. 21. 12. 1957 (GVBl. S. 323).

10) $\$ 5$ nwAufbauG v. 29. 4. 1952 (GV S. 75).

11) § 2 WSG, § 4 rh.pf.AufbauG v. 1. 8. 1949 (GVBl. S. 317).

12) $\S 5$ nds. AufbauG v. 9. 5. 1949 (GVBl. S. 107), $\$ 3$ hess. AufbauG v. 25. 10. 1948 (GVBl. S. 139) und $\S 5$ EntwBundesbauG (Bundestagsdrucksache 336 ).

13) $\S 4$ wü.-bad. AufbauG v. 18. 8. 1948 (Reg. Bl. S. 127) und $\S 6$ bad. AufbauG v. 25. 11. 1949 (GVBl. 1950 S. 29).

14) $\S 5$ hess. AufbauG.

15) $\$ 4$ hess. AufbauG.

16) §59 Abs. 1 bay. BauO v. 17. 2. 1901 (GVBl. S. 87).

17) §10 EntwBundesbauG; vgl. auch die Aufbaupläne nach $\$ 6$ Hamb. AufbauG v. 11.4. 1949 (GVBl. S. 45) und \$ 6 rh. pf. AufbauG.

18) $\$ 6$ hess. AufbauG.

19) 82 pr. FluchtlG v. 2. 7. 1875 (GS S. 561).

20) $\$ 4$ bay. BauO v. 17. 2. 1901 (GVBl. S. 87).

21) Art. 7 wü. BauO v. 28. 7. 1910 (Reg. Bl. S. 333).

22) $\$ 10 \mathrm{nw}$. und nds. AufbauG sowie $\$ 18 \mathrm{rh}$. pf. AufbauG.

23) § 4 BauRegVO v. 15. 2. 1936 (RGBl. I S. 104). 
die Baustufen-28) und A ufbauplän ${ }^{24}$ ),

die Umlegungs-25) und Flurbereinigungs$\mathrm{p} l$ än e $\left.{ }^{26}\right)$,

die im Rahmen eines Planfeststellungsverfahrens aufgestellten Pläne (Enteignungs-27), Straßenbau-28), Wasserausbau- ${ }^{29}$ ) und Bundesbanbaupläne ${ }^{30}$ ),

die Landbeschaffungsplän ${ }^{31}$ ) und

die wasserwirtschaftlichen Rahmenpläne ${ }^{32}$ ).

In diesem Zusammenhang sind auch

die Wohnungsbauprogramme nach dem zweiten Wohnungsbaugesetz ${ }^{33}$ )

vorzumerken. Sie sind zwar im Gesetz nicht ausdrücklich als „Pläne" bezeichnet. In ihrem Wesen entsprechen sie aber dem auf der Gesetzesstufe in Vorbereitung befindlich "Lücke-Plan". Ferner sollen noch

die Haushaltspläne der Selbstverwaltungskörperschaften besondere Beachtung finden.

b) Es kommt nun darauf an, bei den genannten Plänen g e meinsame Merkmale aufzufinden.

(1) Zunächst ist festzustellen, daß es sich um A u s a r b e i tungen von Verwaltungsbehörden handelt, die e in em bestimmten $Z$ we ck dienen. Eine zwecklose Planung wäre ja auch an sich schon eine contradictio in adiecto. Die Zweckbedingtheit kann aber nicht als hervorstechendes

24) $§ 2$ Abs. 3 BauGestVO v. 10.11. 1936 (RGBl. I S. 938).

25) Art. 30 bay. BaugeländeerschlG v. 4. 7.1923 (BayBS II S. 419), $\S 16$ bad. AufbauG,

§ 26 wï.-bad. BaulandG i. d. F. v. 24. 9.1948 (Reg. B1. S. 157),

$\S 31$ wü.-ho. BaulandG v. 28. 11.1949 (Reg. Bl. 1950 S. 1),

\$ 25 nw. AufbauG,

$\$ 28$ nds. AutbauG und

$\S 60$ Erstes BundesbauG.

20) $\$ 56$ FlurbG.

27) § 15 pr. EnteignG v. 11. 7. 1874 (GS S. 221),

Art. 16 wü. EnteignG v. 20.12.1888 (Reg. Bl. S. 466) und

Art. 18 old. EnteignG v. 21. 4. 1897 (GBl. Bd. 31 S. 541).

28) §17 FStrG, § 2 bad. OrtsstrG v. 15. 10. 1908 (GVBl. S. 605), bay.

StrWG v. 11. 7. 1958 (GVBl. S. 147).

29) $\$ 163$ pr. WasserG v. 7.4.1913 (GS S. 53).

so) $\$ 36$ BundesbahnG.

s1) § 31 LBG.

s2) $\S 36$ WasserhaushG.

s3) $\$ 29$ 2. WohnungsbauG. 
Kriterium gerade des Planes angesehen werden. SchlieBlich ist jede Verwaltungsmaßnahme, sofern sie nicht ausgesprochen unvernünftig ist, auf einen $Z$ weck ausgerichtet.

(2) $\mathrm{Zu}$ erwägen wäre, ob sich der Plan-Zweck vielleicht dahingehend eingrenzen ließe, daß er sich auf die Verwirklichung eines bestimmten Ordnungszustan$d$ e ${ }^{34}$ ) erstrecken muß. So könnte man darauf verweisen, $d a B$ die baurechtlichen Pläne auf die Errichtung von Baukomplexen mit genau festgelegten Ausmaßen und die Haushaltspläne auf die Ausgeglichenheit des Etats am Ende des Haushaltsjahres abzielen; daß sie damit unter einem Ordnungsaspekt bestimmte Situationen gestalten sollen, die noch nicht vorhanden sind. Indessen ist es sehr wohl möglich, daß auch Hoheitsakte ohne Plancharakter eine solche Qualität besitzen. Es sei nur erinnert an die verschiedenen Vorschriften zum Schutz von Landschaftsteilen und Gewässern, die bisher übliche Beeinträchtigungen der Natur untersagen, um dadurch einen Zustand der Unberührtheit wiederherzustellen.

Das Ziel der Verwirklichung eines bestimmten Ordnungszustandes allein wird also dem Plan-Begriff nicht gerecht. Es muß vielmehr noch ein Kriterium gesucht werden, das für den Plan typisch ist und ihn unzweideutig von anderen Verwaltungshandlungen abhebt.

(3) Auf die Regelung des Totalablaufs eines künftigen Geschens ${ }^{35}$ ) oder auf die Vorwegnahme freier Einzelentscheidungen ${ }^{36}$ ) kann man bei dem hier zu entwickelnden Plan-Begriff wohl $n i c h t$ abstellen. Der "Totalablauf" ist schon an sich ein relativer Begriff, weil sich immer die Frage erhebt, an welcher Stelle der Ablauf beginnt. Im übrigen können die Raumordnungs- und die baurechtlichen Leitpläne sicher nicht als Regelungen von Totalabläufen betrachtet werden, weil sie als „Pläne für die Planer' ${ }^{\text {(37) }}$ noch der Ausfüllung durch weitere Pläne bedürfen. Und mit der „Feststellung“ von Straßenbau- und Wasserausbauplänen wird

34) Für das Gebiet der Betriebswirtschaft bestimmt $\mathrm{G}$ u t e $\mathrm{n}$ b e r g (Grundlagen der Betriebswirtschaftslehre, I. Bd., 4. Aufl. 1958, S. 121) die Planung als einen ordnenden Akt, „der, zunächst gedanklicher Art, das betriebliche Geschehen in eine ganz bestimmte Bahn drängt, die für richtig und zweckmäßig befunden wird".

35) so Forst h of f DVBl. 57 S. 114 - Vgl. auch Guten berg (Ztschr. f. Betriebsw. 1952, S. 671), der die betriebliche Planung u. a. als „Vorwegnahme einer künftigen Form des Ablaufs bestimmter Geschehnisse" beurteilt.

36) so Werner DVBl. 57 S. 225.

37) Vgl. P eters, Handbuch der kommunalen Wissenschaft und Praxis, 2. Bd., 1957 (zit. Peters), S. 493. 
der Ablauf rechtlichen Geschehens auch nicht anders geregelt als mit jeder ohne Plan erteilten Konzession, die eine belegene Sache zum Gegenstand hat. Was weiter die Vorwegnahme von Einzelentscheidungen anlangt, so ist sie bei allen nicht planartigen rechtssatzmäßigen Regelungen insoweit gegeben, als ein Tatbestand aufgestellt ist und jeder diesen Tatbestand erfüllende Lebenssachverhalt die im Rechtssatz ausgesprochene Rechtsfolge auslöst. Sollte man jedoch im Hinblick auf die Bebauungspläne die $\mathrm{k}$ on $\mathrm{krete}$ Art der vorweggenommenen Einzelentscheidung wegen ihrer Bindung an ein be st i m mte s Stück B od e n hervorheben, so würde selbst damit nicht eine typische Planeigenschaft angeführt. Auch bei Landschaftsschutzverordnungen und Bausperren, die doch niemand als Pläne beurteilen dürfte, werden unter Bezugnahme auf konkrete Grundstücke Einzelentscheidungen vorweggenommen, so z. B. die Versagung einer Baugenehmigung oder ihre Erteilung unter bestimmten Auflagen.

(4) Das wesentliche Merkmal des Planes ist darin zu erblicken, daß er e in e $R$ eihe von $M$ a $B n$ ahmen vorsieht, die zueinander in e in e m un ös baren Verhält$n$ is gegenseitiger Ergänzung und Abhängig$k$ e it stehen, die also - wie bereits der Erstberichterstatter hervorgehoben hat - aufeinander „abgestimmt" sind. Diese Voraussetzung ist dann gegeben, wenn die verschiedenen Maßnahmen den gewünschten Erfolg nur durch ihr Zusammenwirken gewährleisten; und wenn sie derart aufeinander angewiesen sind, daß die Änderung oder der Wegfall einer einzigen Maßnahme eine Kettenreaktion auslöst, die die gesamte Konzeption in Frage stellt.

Einige Beispiele mögen diesen Sachverhalt der „planmäßigen“ Abstimmung verdeutlichen:

Würde die Baubehörde lediglich für ein einziges neu zu errichtendes Bauwerk den Verlauf des vorderen Hausrandes bestimmen, so könnte man nicht von der Aufstellung eines Planes sprechen. Der Baulinien p I a n (bzw. der Fluchtlinienbestandteil des Bebauungsplanes ${ }^{38}$ ) entsteht erst dadurch, daß unter Berücksichtigung des für e in Grundstück festgelegten vorderen Bauverlaufs dieser auch für die anschließenden Grundstücke festgelegt wird, daß also eine Gebäudefluchtlinie - als Summe aufeinander abgestimmter Teillinien - gezogen wird. Der Plan erweitert sich dann dadurch, daß dieser $\mathrm{e}$ i n e $\mathbf{n}$ Baulinie noch andere Baulinien - z. B. die Vorgartenlinie und die seitlichen und rückwärtigen Bebauungsgrenzen - hinzugefügt werden,

s8) Vgl. B r o h m, Rechtsschutz im Bauplanungsrecht, 1959, S. 23. 
die ihrerseits einmal auf die Gebäudefluchtlinie und zweitens untereinander abgestimmt sind. Der Bebauungsplan ist noch umfassender als der reine Baulinienplan, weil er in einem „planmäBigen" Verhältnis zu den am Boden verlaufenden Baulinien noch andere Linien bzw. Beschränkungen aufnimmt, etwa hinsichtlich der Höhenlage im Gelände oder der Anzahl und Höhe der Stockwerke ${ }^{30}$ ). Soll nun eine Baulinie für ein einziges Grundstück geändert werden, so wird die ganze Linienführung unterbrochen. Soll eine Baulinie in vollem Umfang vor- oder zurückverlegt werden, so ergeben sich Rückwirkungen auf das gesamte Liniengefüge.

Der Wirtschafts- bzw. Flächennutzungsplan sucht die sinnvolle Entwicklung eines Gebietes dadurch sicherzustellen, daß er verschiedene Nutzungsräume - Baugebiete, Industriegebiete, Agrargebiete usw. - festlegt. Die Erweiterung e in e s Gebietes bedingt die Verkleinerung a $\mathrm{n} d \mathrm{er}$ e $\mathrm{r}$.

Der Haushaltsplan verteilt die öffentlichen Einkünfte auf die einzelnen Ressorts in einer unterschiedlichen, durch die jeweiligen Ressortbedürfnisse veranlaßten Art und Weise, um dadurch einen Gesamtausgleich zu erwirken. Beansprucht e in Ressort einen größeren Betrag, so kann der Gesamtausgleich nur dadurch aufrecht erhalten werden, daß die für andere Ressorts bestimmten Mittel gekürzt werden.

Das Zusammentreffen mehrerer, aufeinander abgestimmter Festsetzungen kennzeichnet - wie unschwer einzusehen ist auch alle übrigen vorher genannten Pläne. Jeder von ihnen trägt die Züge eines Ordnungsbildes, in dem verschiedene Teileffekte eine zentripetale Ordnungsfunktion erfüllen.

3. Nach diesen Uberlegungen kann der verwaltung srechtliche Plan definiert werden als

Ausarbeitung eines Verwaltungsorgans, die durch verschiedene aufeinander abgestimmte MaBnahmen die Verwirklichungeinesbestimmten Ordnungsustandes anstrebt.

II. Ist der Begriff des verwaltungsrechtlichen Planes ermittelt, so soll nun weiter versucht werden, unter systematischen Gesichtspunkten einzelne Planarten aufzustellen. Im

so) Es wird hier unter Berücksichtigung der bayerischen Verhältnisse zwischen dem Baulinienplan gemäß \& 4 Abs. 2 bayBauO (der nur die am Boden verlaufenden Baulinien bestimmt) und dem gesetzlich nicht vorgesehenen aber in der Praxis entwickelten Bebauungsplan (der weitere Baubeschränkungen festlegt) unterschieden. 
Zuge dieser Einteilung ist auch die Frage nach der Rechtsnatur des Planes - oder genauer gesagt der verschiedenen Pläne - aufzugreifen, eine Frage, deren Klärung wiederum für die Lösung des Rechtsschutzproblems von Bedeutung ist.

1. Eine Einteilung der Pläne könnte zunächst unter Berücksichtigung des $\mathrm{Ge} g$ e n $\mathrm{s}$ t a ndes vorgenommen werden. Sie bietet sich von selbst an und ist hier nicht weiter zu verfolgen.

2. Gleichfalls nur angedeutet werden soll die Möglichkeit, die Pläne rein deskriptiv nach der A r t i h re r A u s a r b e i t ung zu unterscheiden. Dabei wäre z. B. zu berücksichtigen, ob bzw. inwieweit ein Plan durch eine Skizze oder durch das geschriebene Wort festgelegt ist.

3. Von größerem dogmatischen Wert ist es schon, als Unterscheidungsmerkmal das zeitliche Verhältnis heranzuziehen, in dem die a ufeinander abgestimmten Maßnahmen zur Auswirkung gelangen sollen. Seine Beachtung vermittelt die Erkenntnis, daß die Pläne einmal auf ein zeitliches Zusammentreffen verschiedener Effekte abstellen, das andere $\mathrm{Mal}$ aber eine sukzessive Verwirklichung des erstrebten Erfolges vorsehen.

Die Umlegungs- und Flurbereinigungspläne, die Straßenbau-, Wasserausbau- und Bundesbahnbaupläne können ihr Ziel nur dann erreichen, wenn die von ihnen intendierten Rechtsänderungen allen Betroffenen gegenüber gleichzeitig eintreten.

Für eine andere Gruppe von Plänen spielt das Zeitmoment keine entscheidende Rolle. Die in einem Bebauungsplan getroffenen Anordnungen überlassen die Planbefolgung einer vielleicht in großen Zügen absehbaren, im einzelnen aber doch ungewissen künftigen Entwicklung. Es hängt hier von der Initiative der Grundstückseigentümer ab, wann ein Bauwerk errichtet wird und wann deshalb die geplanten Linien und Baubeschränkungen in der Rechtswirklichkeit relevant werden.

Wieder andere Pläne stellen gerade auf eine sukzessive Erfüllung des Planzwecks ab. Sie legen zeitliche Etappen fest, in denen die einzelnen Maßnahmen zur Auswirkung gelangen sollen. Die Raumordnungspläne, die baurechtlichen Leitpläne, vor allem aber die Wohnungsbauprogramme nach dem 2 . Wohnungsbaugesetz sind sehr oft durch ein solches zeitliches Abstimmungsmoment gekennzeichnet. Das Planziel wird dann bei diesen Plänen dadurch erreicht, daß bestimmte Gestaltungsmaßnahmen in einer zeitlichen Reihenfolge vorgenommen werden.

4. Eine weitere Einteilung der Pläne kann die Ge n a u i gkeit zum Prüfstein nehmen, mit der die verschiedenen Einzelmaßnahmen festgelegt sind. Die Bebauungspläne z. B. schreiben die Gestaltung der zu errich- 
tenden Bauwerke regelmäßig mit dreidimensionaler Exaktheit vor. Die Umlegungs- und Flurbereinigungspläne sowie die im Rahmen eines Planfeststellungsverfahrens aufgestellten Pläne weisen die beabsichtigten Rechtsänderungen bis in das kleinste katastermäßig faßbare Detail aus. Demgegenüber enthalten die Raumordnungspläne meist nur ungefähre Angaben, mit denen sie allgemeine Entwicklungsziele andeuten. Oft sind nicht einmal die einschlägigenRäume klar abgegrenzt sondern nur "symbolisch" bezeichnet. Das kommt dann zeichnerisch darin zum Ausdruck, daß Umgrenzungslinien fehlen und dafür Richtungsoder Schwerpunktpfeile verwendet werden.

5. Die sicher wichtigste Einteilung der Pläne ist unter dem Gesichtspunkt ihrer r e ch t li chen A u s wirkung zu treffen. Dabei sind von vornherein zwei Gruppen voneinander zu unterscheiden: die unverbindlichen und die verbindlichen Pläne.

a) Als unverbindli che P läne sind jene Pläne zu betrachten, die ein förmliches Feststellungsverfahren nicht durchlaufen oder noch nicht durchlaufen haben. Sie sind Arbeits- bzw. Beurteilungsgrundlagen der Verwaltungsorgane, die den Erlaß rechtsverbindlicher Maßnahmen erst vorbereiten. Die Aufstellung solcher Pläne läßt sich außerdem dann als verfahrensrechtlicher Teilakt beurteilen, wenn sie die unabdingbare Voraussetzung für den Erlaß eines verbindlichen Hoheitsaktes darstellt. Manche Pläne - wie die Wohnungsbauprogramme und die wasserwirtschaftlichen Rahmenpläne - behalten stets ihren vorbereitenden Charakter, so daß sie niemals eine Verbindlichkeit erlangen können. Andere zunächst noch unverbindliche Pläne werden gerade zu d e m Zweck entworfen, daß sie eines Tages - vielleicht nach der Vornahme gewisser Korrekturen mit verbindlicher Kraft versehen werden. Das ist bei der Masse der hier behandelten Pläne der Fall, so bei den Bebauungsplänen, den Umlegungs- und Flurbereinigungsplänen und allen im Rahmen eines Planfeststellungsverfahrens aufgestellten Plänen. Wieder andere Pläne - nämlich die nordrhein-westfälischen und bayerischen Raumordnungspläne - $\mathrm{k}$ ö $n \mathrm{n}$ e $\mathrm{n}$ für verbindlich erklärt werden, ohne daß dies zwingend erforderlich ist.

Da die unverbindlichen Pläne weder gegenüber Verwaltungsorganen noch gegenüber außenstehenden Personen eine Rechtswirkung entfalten, können sie nicht als hoheitliche Rechtsakte gewertet werden. Das schließt nicht aus, daß gewisse unverbindliche Pläne - wie die bayerischen Flächennutzungs- und Generalbaulinienpläne - mittelbar dadurch eine rechtliche Bedeutung gewinnen, daß sie intern als Ermessensrichtlinien für den Erlaß verbindlicher Hoheitsakte - z. B. für Entscheidungen über die Festsetzung von Baulinien - verwendet werden. 
b) Die eigentliche Rechtsakt-Problematik bezieht sich auf die verbindlichen Pläne, die auf Grund eines bestätigenden Hoheitsaktes das Stadium des reinen Entwurfs verlassen haben. Der Eintritt der Verbindlichkeit kann bewirkt werden durch eine ausdrückliche Verbindlichkeits-Erklärung seitens der Behörde, die den Plan aufgestellt hat, durch Genehmigung oder Prüfung (im Sinne einer Nichtbeanstandung) seitens der Aufsichtsbehörde oder durch Erlaß im Verordnungs- bzw. Satzungsverfahren. Als Beispiele solcher verbindlichen Pläne wären zu nennen die für verbindlich erklärten Raumordnungspläne, alle förmlich festgestellten Bodenpläne sowie die als Satzungen erlassenen Haushaltspläne.

(1) Vor einer Entscheidung über die Rechtsnatur dieser Pläne müssen die Kategorien feststehen, die $\mathrm{f} \ddot{\mathrm{u}} \mathrm{r}$ d i e E r m it t l ung der Rechtsnatur verwaltungsrechtlicher $\mathrm{H}$ oheits akt e verfügbar sind $\left.{ }^{40}\right)$. Sie werden durch die beiden Fragen bestimmt, we $r$ von einem Hoheitsakt rechtlich betroffen ist und in welcher Form diese Betroffenheit rechtlich relevant wird.

(a) Der Betroffenenkreis ist unter zwei Gesichtspunkten festzulegen:

aa) Zunächst ist zu klären, ob sich die Rechtswirkung auf Verwaltungsorgane beschränkt oder ob sie - gegebenenfalls a u c h - den Rechtskreis anderer der öffentlichen Gewalt unterworfener Rechtssubjekte berührt. Damit wird eine $\mathrm{Abg} \mathrm{r}$ e $\mathrm{n}$ zung zwischen den rein organisatorischen A k t e $\mathrm{n}$ - die sich lediglich auf den internen Sektor der öffentlichen Gewalt erstrecken - und den Rechtsakten g e genüber Personen ermöglicht. Mag die Unterscheidung zwischen einem Innen- und einem Außenverhältnis nach wie vor im einzelnen problematisch sein ${ }^{41}$ ), daß sie prinzipiell möglich und darüber hinaus notwendig ist, wird heute wohl nicht mehr bezweifelt werden können.

bb) Ferner ist zu prüfen, ob der Betroffenenkreis bestimmt bzw. bestimmbar oder unbestimmt ist. Damit wird auf den

40) Die Problematik des „Verwaltungsfabrikates“ kann hier unberücksichtigt bleiben. Darüber vgl. Z e i d l e r, Uber die Technisierung der Verwaltung, 1959 (insbes. S. 10).

41) Vgl. hierzu vor allem: H e r b e r t $\mathrm{K}$ r üg e r „Rechtsverordnung und Verwaltungsanweisung " in Festgabe für Rudolf Smend, 1952, S. 211 ff., B a c h of „Verwaltungsakt und innerdienstliche Weisung " in Verfassung und Verwaltung in Theorie und Wirklichkeit (Festschrift für Wilhelm Laforet), 1952, S. 285, O b e r m a y e r, Verwaltungsakt und innerdienstlicher Rechtsakt (zit. Verwaltungsakt), 1956, S. 124 ff. und $M$ a u n z-D ü ri g, Grundgesetz (zit. MaunzDürig), Art. 19 Abs. IV S. 19 ff. 
Unterschied $z$ wischen Einzelakt und Norm abgestellt, der jedoch nicht mit den Gegensätzen von „abstrakt" und "konkret" sowie von "generell" und ,individuell" identifiziert werden darf.

Wichtig ist die Erkenntnis, daß sich die Rechtserheblichkeit des Einzelaktes für die Betroffenen in einem einzigen Augenblick - nämlich im Zeitpunkt des Erlasses - erschöpft. Dabei spielt es keine Rolle, ob die Betroffenen namentlich genannt oder gattungsmäßig mit abstrakten Merkmalen bezeichnet werden. Wenn beispielsweise ein Polizeibeamter eine Versammlung auflöst und "alle anwesenden Personen" zum Verlassen des Versammlungsraumes auffordert, so setzt er trotz der abstraktgenerellen Formulierung einen Einzelakt, der hic et nunc gegenüber den gerade anwesenden und damit abschließend bestimmbaren Personen rechtserheblich ist.

Die Norm als eine weiterer Konkretisierung zugängliche Regel weist dagegen in die Zukunft ${ }^{42}$ ). Sie ist ein Teil einer vor der Rechtsgemeinschaft aufgerichteten, „währenden" Ordnung; sie ist dazu geschaffen, das - wie Goethe einmal gesagt hat - ,in der Mittelhöhe des Lebens w i e d e r k e h r e n d Schwebende "43) zu bewältigen. Und darum leuchtet der in ihr enthaltene rechtserhebliche Funke immer wieder auf, wenn jemand irgendwann während ihrer Geltung den normmäßigen Tatbestand erfüllt. Die Zahl der von einer Norm ${ }^{44}$ ) Betroffenen ist demnach unbestimmt und unbestimmbar.

Diejenigen Normen, die als Rechtsakte gegenüber Personen eine Außenwirkung besitzen, werden herkömmlicherweise als „Rechtsnormen" bezeichnet. Die nur intern wirkenden Normen treten in der Fachsprache als „Verwaltungsnormen“, „Verwaltungsvorschriften" und "Organisationsnormen" auf.

(b) Die rechtliche Betroffenheit kommt for$\mathrm{m}$ a $\mathrm{l}$ in unterschiedlicher Weise zur Geltung. Es stehen sich zwei Verfahrensarten gegenüber: Das gewöhnliche Verwaltungsver-

42) Vgl. O be rm a y e r, Verwaltungsakt S. $76 \mathrm{ff}$.

43) G o e the, Die natürliche Tochter, 4. Aufzug, 2. Auftritt.

44) Der Normbegriff wird hier in einem weiteren Sinne verstanden ohne Rücksicht darauf, ob es sich um eine Norm mit einer vollen Tatbestands- und Rechtsfolgeseite oder um eine (hinsichtlich der Tatbestands- oder Rechtsfolgeseite) ausfüllungs- bzw. ergänzungsbedürftige Norm handelt. Uber die Bedeutung des "Teilrechtssatzes" vgl. O berma yer BayvBl. 58 S. 69. - Wegen der Abgrenzung zwischen Norm und Einzelakt vgl. auch $\mathrm{J}$ a h $\mathrm{r}$ re i B (Mensch und Staat, 1957, S. 33), der der „Normsetzung“ jenen Vorgang gegenüberstellt, der ,in einem bestimmten Lebensfalle oder in mehreren abschließend aufzählbaren Lebensfällen, in ,konkreten' Lagen entschieden" wird. 
fahren, das mit einer Eröffnung des Rechtsaktes an die jeweils betroffenen Personen oder Organe seinen Abschluß findet; und das Verordnungsverfahren, das durch eine Kundmachung an die Allgemeinheit beendet wird. Einzeleröffnung und allgemeine Publikation sind die grundlegenden Unterscheidungsmerkmale beider Verfahrensarten. Ein innerer Zusammenhang zwischen dem Verfahren und dem Betroffenenkreis besteht insofern, als alle an einen unbestimmten Betroffenenkreis gerichteten Normen nur in dem zu einer öffentlichen Bekanntmachung hinführenden Verordnungsverfahren erlassen werden können, da eine Einzeleröffnung an alle jemals Betroffenen nicht möglich ist. Steht also fest, daß ein Hoheitsakt inhaltlich eine Norm ist, dann $\mathrm{mu} B$ er im Verordnungsverfahren ergehen. Wie dieses im einzelnen abzuwickeln und welches Publikationsorgan dem Betroffenenkreis adäquat ist, muß jeweils besonders entschieden werden. Liegt ein Einzelakt vor, so ist grundsätzlich das Verwaltungsverfahren mit einer Einzeleröffnung an die bestimmten oder jedenfalls bestimmbaren Betroffenen geboten. Freilich sind Einzelakte auch ausnahmsweise in das "Gewand einer Verordnung “45) eingekleidet. Die Frage, wann eine solche Verfahrensgestaltung auch bei Einzelakten gegenüber Personen zulässig ist, rührt an die Problematik der Maßnahmegesetze. Sie kann in diesem Zusammenhang nicht weiter untersucht werden.

(c) Für bestimmte regelmäßige Verbindungen der soeben aufgeführten sachlichen und formalen Rechtsakt-Elemente sind die klassischen verwaltungsrechtlichen Rechtin s t it u t e entwickelt worden.

aa) Der im Verwaltungsverfahren und nicht im Verordnungsverfahren erlassene Einzelakt mit Außenwirkung ist der $\mathrm{V}$ e $\mathrm{r}$ w a l $t$ ung s a $t$ mit dem Unterfall der Allgemeinverfügung bei einer gattungsmäßig genannten bestimmbaren Personenmehrheit.

bb) Die als Verordnungen erlassenen Normen mit einer Rechtswirkung gegenüber Personen sind als $\mathrm{Rechtsver-}$ ordn ung e n-im Sinne rechtssatzmäßiger Verordnungenbekannt.

cc) Die organisatorischen Akte, die in der Form einer Verordnung auftreten, werden als Verwaltungs verordn u n g e $\mathrm{n}$ bezeichnet.

(d) Bei der Erörterung der vorgenannten Rechtsbegriffe und Rechtsinstitute sind Fragen einer inneren Werthaftigkeit unberücksichtigt geblieben. Sie haben

45) Vgl. hierzu Urt. d. BayVGH v. 20.1. 1956, BayVBl. 56 S. 121 ff. 
- das darf nicht verkannt werden - auch für das Verwaltungsrecht eine eminent wichtige Bedeutung. Auf einer Stufe verwaltungsrechtlicher Betrachtung, auf der lediglich rechtslogische und rechtstechnische Fragen zur Diskussion stehen, sind sie jedoch noch nicht einschlägigit).

(2) Die bekannten, an der rechtlichen Betroffenheit ausgerichteten Kategorien nehmen alle verwaltungsrechtlichen Hoheitsakte auf. Sie müssen deshalb auch berücksichtigt werden, wenn es darum geht, die $R$ e chtsnaturder verbindlichen $P l a ̈ n$ e festzulegen.

(a) Die Merkmale eines $R$ echtsaktes gegenüber $P$ e $r s$ o n e tragen neben einigen verbindlichen Leitplänen die verbindlichen Bebauungs-, Baustufen- und Aufbaupläne, ferner die verbindlichen Flurbereinigungs- und Umlegungspläne sowie die in einem Planfeststellungsverfahren festgestellten Enteig-

46) Selbstverständlich wäre es denkbar, eine begriffliche Festlegung des Rechtssatzes vorzunehmen, die auf wertgebundenen Kriterien beruht. Ein solcher Rechtssatz hätte jedoch nichts gemein mit jenem Rechtssatz, um dessen Bestimmung seit langer Zeit unter dem Gesichtspunkt der rechtlichen Betroffenheit gerungen wird. Dieser Gesichtspunkt allein war ausschlaggebend, wenn der Unterschied zwischen einer (rechtssatzmäßigen) Verordnung und einem Verwaltungsakt erörtert wurde. Typisch hierfür waren z. B. die mannigfachen Uberlegungen, die im preußischen Polizeirecht über die $\mathrm{Ab}$ grenzung zwischen Polizeiverordnung und Polizeiverfügung angestellt wurden, um die für das Zustandekommen oder die gerichtliche Nachprüfung einer polizeilichen Maßnahme geltenden Regeln zu ermitteln. Stehen nun die Art der rechtlichen Betroffenheit, die Modalitäten des Erlasses einer Maßnahme und die Möglichkeiten ihrer gerichtlichen Anfechtung im Vordergrunde, so erstrecken sich die wissenschaftlichen Bemühungen eben auf rechtslogische und rechtstechnische Fragen. Es darf dann auch - bei Anerkennung der genannten methodischen Voraussetzungen - nicht plötzlich der „Dienst an der Gerechtigkeit" als Kriterium des Rechtssatzes, sei es auf der Gesetzes- oder der Verordnungsstufe, eingeführt werden (vgl. $\mathrm{Br}$ o h m S. 49. unter Bezugnahme auf $\mathrm{F}$ or $\mathrm{s}$ th of $\mathrm{f}$ ). Freilich soll nicht übersehen werden, daß die Verwaltungsrechtswissenschaft jenseits der vordergründigen formaldogmatischen Probleme noch andere zu bewältigen hat, die ein tieferes Eindringen in Wesen und Aufgabe des Rechtes erfordern. Sie spielen z. B. eine Rolle, wenn die Rechtmäßigkeit der Akte (im Sinne ihrer juristischen Geltung) und ihre Zweckmäßigkeit (im Sinne einer optimalen Erfüllung ihrer Ordnungsfunktion) zur Debatte stehen. Sie sind weiter von Bedeutung, wenn festzustellen ist, welchen Rechtsakten für die Erzielung der verschiedenen rechtlichen Effekte der Vorzug zu geben ist (ob beispielsweise gewisse Handlungsverbote für die Allgemeinheit normativ oder jeweils für bestimmte Personen auf Grund eines Rechtssatzes durch Verwaltungsakt zu erlassen sind). Auch das Problem einer (inhaltlichen) Rangordnung der Rechtssätze wäre in diesem Zusammenhang zu nennen. In diesen Fällen gibt dann sicher der „Dienst an der Gerechtigkeit" nicht nur einen geeigneten sondern auch einen notwendigen Prüfungsmaßstab ab. 
nungs-, Straßenbau-, Wasserausbau- und Bundesbahnbaupläne. Alle diese Pläne sind für Personen, die zur öffentlichen Gewalt in einem Verhältnis der Subordination stehen, von unmittelbar rechtserheblicher Bedeutung. Die Bebauungspläne verankern erstmals die Pflicht, Bauwerke in einer ganz bestimmten Art und Weise - mit einem bestimmten Grenzverlauf, einer bestimmten Höhe im Gelände usw. - aufzuführen. Die anderen Pläne schaffen neue Rechtsverhältnisse am Grundeigentum. Die Außenwirkung ist also unbestreitbar. Zu klären bleibt nur, inwieweit Einzelakte oder Normen gegeben sind.

aa) Als Einzelakte treten deutlich hervor die förmlich festgestellten Flurbereinigungs-, Umlegungs- und sonstigen Bodenpläne, soweit sie für bestimmte am (Plan-)Verfahren beteitigte Grundstückseigentümer rechtserheblich sind. Der Flurbereinigungsplan z. B. wendet sich an die derzeitigen Grundstückseigentümer des Bereinigungsgebietes, indem er die von ihnen zu duldenden Rechtsänderungen am Grundeigentum einschließlich der zu gewährenden Entschädigungsabfindungen festlegt.

Durch die Planfeststellung nach § 17 FStrG werden „alle öffentlich-rechtlichen Beziehungen zwischen dem Träger der Straßenbaulast und den durch den Plan Betroffenen rechtsgestaltend geregelt". Regelmäßig werden hierbei den angrenzenden Grundstückseigentümern oder anderen wegeunterhaltspflichtigen Personen Duldungs- oder Unterhaltungspflichten auferlegt.

Die genannten Pläne werden im Verwaltungsverfahren erlassen und den Betroffenen einzeln eröffnet. Sie werden dementsprechend von Rechtsprechung und Schrifttum auch fast einhellig als Verwaltungsakte qualifiziert $\left.{ }^{47}\right)$.

bb) Die Rechtsnaturdes (verbindlichen) Be$\mathrm{b}$ a u u $\mathrm{ng} \mathrm{s} \mathbf{l}$ a nes ist keineswegs rechtslogisch in einer bestimmten Richtung zwingend vorgeschrieben ${ }^{48}$ ). Er kann gesetzlich sowohl als Einzelakt wie auch als Rechtsnorm ausgestaltet sein. Ein Einzelakt liegt vor, wenn sich die Festsetzung der Baulinien und sonstigen Baubeschränkungen nur an diejenigen Personen richtet, die im Zeitpunkt der Festsetzung die Verfügungsmacht über die vom Plan betroffenen Grundstücke besitzen. Dann sind die Baulinien und sonstigen Baubeschränkungen gewissermaßen als öffentliche Last den Grundstücken aufgedrückt

4) Vgl. Forsth of $\mathrm{f}$ Verwaltungsrecht S. 185 und die Rechtsprechungsübersicht bei B lü m el Dơv 59 S. 669 .

48) Vgl. die Zusammenstellung der verschiedenen zur Rechtsnatur des Bebauungsplanes vertretenen Ansichten bei B roh m S. $27 \mathrm{ff}$.; vgl. ferner Urt. d. OVG Hamburg v. 19.5. 1958, MDR 59 S. 874 f. 
mit der Folge, daß alle Rechtsnachfolger diese Last in gleicher Weise übernehmen, wie eine in das Grundbuch eingetragene privatrechtliche Belastung. Der Bebauungsplan ist als Rechtsnorm zu betrachten, wenn er jedem, der einmal auf der mit den Baulinien und sonstigen Baubeschränkungen versehenen Grundfläche bauen will, die Pflicht zu ihrer Beachtung auferlegt. Eine solche Verpflichtung resultiert dann nicht daraus, daß die Baulinien und sonstigen Baubeschränkungen am Grundstück haften. Sie ergibt sich vielmehr $u \mathrm{n} \mathrm{m}$ i t $t$ e $\mathrm{l}$ b a $r$ aus dem Bebauungsplan, der damit die gleiche Wirkung auslöst wie eine rechtssatzmäßige Naturschutzverordnung, die allen möglichen Bauwerbern - und nicht nur den de r z e i ti g e n Grundstückseigentümern - für die Errichtung von Bauwerken im Interesse des Naturschutzes bestimmte Auflagen macht.

Nach den in den einzelnen Bundesländern geltenden Bauvorschriften muß dem Bebauungsplan jedenfalls überwiegend ein normativer Charakter zugesprochen werden. Einer besonderen Betrachtung bedarf jedoch die bayerische und $z$. $T$. auch die württembergische Regelung. Entgegen meiner früheren Ansicht ${ }^{40}$ ) möchte ich heute den bayerischen Baulinienplan wegen seiner Ausrichtung auf die derzeitigen Grundstückseigentümer als Verwaltungsalkt - oder genauer gesagt: als eine Summe von Verwaltungsakten - beurteilen. Damit pflichte ich wenigstens im Ergebnis der vom Bayer. Verwaltungsgerichtshof ${ }^{50}$ ) und vom Bundesverwaltungsgericht ${ }^{51}$ ) vertretenen Ansicht bei. Desgleichen sehe ich im württembergischen Ortsbauplan einen Verwaltungsakt, sofern er nur die Feststellung einer Baulinie von beschränkter Ausdehnung enthält ${ }^{52}$ ).

cc) In gleicher Weise wie die meisten Bebauungspläne sind auch die Baustufenpläne nach der Bauregelungsverordnung und die Aufbaupläne nach der Baugestaltungsordnung als Rechts $\mathrm{s}$ ä $\mathrm{z}$ e zu beurteilen ${ }^{53}$ ). Normative Akte sind weiterhin die für verbindlich erklärten Raumordnungsplän $e^{54}$ ); sie binden die nachgeordneten Behörden bei ihrer Plantätigkeit, stellen aber gleichzeitig im Außenverhältnis rechtserheblich fest, daß eine

49). Verwaltungsakt S. 80 und NJW 56 S. $1849 \mathrm{ff}$.

50) Urt. d. BayVGH v. 3. 6. 1955, BBBl. 55 S. 127.

51) Urt. d. BVerwG v. 24. 8. 56, BVerwGE 4. Bd. S. 68.

52) Art. 11 Abs. 2 wü. BauO.

5s) Vgl. $\S 4$ Abs. 1 BauRegVo und $\S 2$ Abs. 3 BauGestVo, wonach bestimmte Baubeschränkungen sowohl in rechtssatzmäßiger Formulierung als Ortssatzungen wie auch in der Form von Baustufen- bzw. Aufbauplänen angeordnet werden können.

54) Uber die Rechtsnatur und Problematik der Verbindlichkeitserklärung von Raumordnungsplänen vgl. S e e g e r „Grundfragen des Landesplanungsrechts" in Raumforschung und Raumordnung 1956 S. 193 ff. (196 ff.). 
die Raumverhältnisse berührende Genehmigung nicht erteilt werden darf, wenn sie dem Raumordnungsplan widersprechen würde. Eine rechtssatzmäßige Bedeutung haben auch die verbindlichen Wirtschaftspläne als Ausfüllungsnormen zu \& 6 Nr. 1 des Wohnsiedlungsgesetzes (wonach die Genehmigung zu einem Grundstücksgeschäft $z u$ versagen ist, wenn anzunehmen ist, daß das Grundstück bebaut werden soll und daß die Bebauung dem Wirtschaftsplan widersprechen würde) ${ }^{55}$ ); ferner die nordrheinwestfälischen Leitpläne und die niedersächsischen Flächennutzungspläne, da nach ihrem Erlaß eine Änderung der bisherigen Nutzungsart von Grundstücken nur bei einer Übereinstimmung mit dem festgestellten Planungsziel zulässig ist ${ }^{56}$ ).

Als Rechtssätze sind schließlich auch diejenigen Bestimmungen eines Flurbereinigungsplanes zu werten, die eine Auswirkung gegenüber einer unbestimmten Personenmehrheit besitzen, wie z. B. Hütungsverbote oder sonstige Nutzungsbeschränkungen für bestimmte Grundstücksflächen ${ }^{57}$ ). \& 58 Abs. 4 FlBerG sieht deshalb auch ausdrücklich vor, daß der Flurbereinigungsplan für derartige Festsetzungen die Wirkung von Gemeindesatzungen hat. Sie werden im Gesetz nicht gerade sehr korrekt als "Festsetzungen" bezeichnet, „die im gemeinschaftlichen Interesse der Beteiligten oder im öffentlichen Interesse getroffen werden". Für Rechtssatz-Bestimmungen eines Flurbereinigungsplanes ist dann freilich eine öffentliche Bekanntmachung geboten.

(b) Rein organis a torische Rechtsakte sind die verbindlichen Flächennutzungspläne, denen eine Außenwirkung fehlt.

Eine rein interne Wirkung entfalten ferner die in der Form einer Satzung (Verordnung) erlassenen Haushaltspläne der Selbstverwaltungskörperschaften, weil sie nur nachgeordneten Verwaltungsorganen für die Verwendung der öffentlichen Geldmittel Schranken auferlegen. Die Vorschrift des $\S 24$ RHO, wonach durch den Haushaltsplan Rechte und Verbindlichkeiten Dritter nicht begründet werden, gilt auch für diese Haushaitspläne. Die Feststellung des Bundesverwaltungsgerichts, daß die etatmäßige Bereitstellung von Mitteln wenigstens für Subventionsmaßnahmen eine hinreichende Legitimation verwaltungs-

s5) Vgl. W i e d e m a n n BayVBl. $59 \mathrm{~S}$. $78 \mathrm{ff}$.

56) $\$ 8$ nw. und nds. AufbauG; vgl. auch Peters S. 495 und B r o h m S. $21 \mathrm{f}$.

b7) Vgl. S t e u e r, Kommentar zum Flurbereinigungsgesetz, 1956, S. 213. 
mäßigen Handelns darstelle $e^{58}$ ), kann nicht gebilligt und demnach auch nicht für das Haushaltsrecht der Selbstverwaltungskörperschaften anerkannt werden. Einmal widerspricht sie schon eindeutig dem $\S 24$ RHO. Weiter ist zu bedenken, daß nur der Gesamtplan des Haushaltsplanes mit den Schlußzahlen der Einzelpläne verkündet wird. Die Einzelpläne hingegen mit ihren verschiedenen in Kapitel und Titel eingeordneten Ansätzen, die die eigentliche Grundlage der Finanzwirtschaft sind, werden nicht veröffentlicht. Deshalb können sie auch nicht von der formellen Gesetzes- bzw. Verordnungs- (Satzungs-)Kraft erfaßt werden. Wollte man nun einen publizierten Gesamtplan als genügende Ermächtigung für die Ausschüttung von Subventionsmitteln betrachten, so widerspräche dies dem rechtsstaatlichen Grundsatz der Bestimmtheit einer jeden Rechtsgrundlage. Wollte man aber in den nicht veröffentlichten Einzelplänen eine rechtliche Deckung der erwähnten Maßnahmen erblicken, so wäre das Gesetzmäßigkeitsprinzip an sich mißachtet, weil insoweit eben kein für den Staatsbürger evidenter Rechtsetzungsakt gegeben ist.

III. Nach den Erörterungen über den Begriff des Planes und über die verschiedenen Planarten kann nunmehr die $\mathbf{E}$ in o $\mathbf{~ d ~ - ~}$ nung des Planes indas rechtsstatliche Norm en $\mathrm{g}$ e $\mathrm{f}$ ü g e aufgegriffen werden ${ }^{50}$ ). Damit wird die Frage nach der Rechtmäßigkeit des Planes und dem gegen ihn eingeräumten Rechtsschutz zur Diskussion gestellt.

1) Wenn der Begriff des Planes keine die Rechtsnatur der Hoheitsakte bestimmenden Kriterien enthält, so darf er auch nicht als Ausgangspunkt für die Erörterung der Rechtmäßigkeits- und Rechtsschutzfragen herangezogen werden. Die P r oblemstellung kann also nicht lauten, in welchen Fällen d e $\mathbf{r}$ Plan als solcher rechtmäßig bzw. gerichtlich nachprüfbar ist. Vielmehr müssen die einzelnen nach den Merkmalen der rechtlichen Betroffenheit unterteilten Planarten jeweils gesondert in dieser Richtung geprüft werden. Sie folgen hinsichtlich ihrer rechtmäßigen Aufstellung und ihrer richterlichen Nachprüfbarkeit denselben Regeln wie jene Rechtsinstitute, denen sie auf Grund ihrer rechtlichen Auswirkung zuzuordnen sind.

2) Die $R$ e chtmä $B$ igkeit eines Planes hängt davon $a b$, daß seine Aufstellung durch eine ausreichende rechtsstaatliche Ermächtigung gedeckt ist.

b8) Urt. d. BVerwG v. 21. 3. 1958, BVerwGE 6. Bd. S. 282 ff. (287).

59) Wegen der rechtsstaatlichen Problematik des Planes vgl. F or s th of $f$ DVBl. 57 S. 115 ff. und Werner DVBl. 57 S. $225 \mathrm{f}$. 
a) Die Ermächtigung muß zunächst dem allgemein in Art. 20 Abs. 3 GG verankerten $G r u n d s$ a tz der Gesetz $\mathrm{mäB}$ i g-

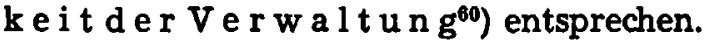

(1) Dieser Grundsatz ist für Verwaltungsakte, untergesetzliche Rechtsnormen und rein organisatorische Maßnahmen verschiedenartig ausgestaltet.

(a) V e r w a l t u n g s a t e benötigen eine Rechtsgrundlage, die grundsätzlich in einem förmlichen Gesetz enthalten sein oder doch auf ein solches zurückgehen muß. Eine gewohnheitsrechtliche Grundlage kann in unserer zwangsläufig durch das ius srciptum geprägten Rechtsordnung nur noch ausnahmsweise anerkannt werden, so z..B. in formalgesetzlich überhaupt nicht geregelten besonderen Gewaltverhältnissen auf dem Gebiete des Unterrichts- und Bildungswesens. Die Rechtsgrundlage muß für den Erlaß bestimmter Verwaltungsakte eindeutige - allenfalls durch einen Beurteilungsspielraum aufgelockerte - Tatbestandsvoraussetzungen festlegen und auch Ermessensmaßnahmen durch einen tatbestandlichen Rahmen binden.

(b) Untergesetzli che Rechts normen bedürfen sofern sie nicht "autonome" Satzungen ${ }^{61}$ ) sind - einer b e s o n d e r e n gesetzlichen Ermächtigung, die nach Inhalt, Zweck und Ausma $B$ bestimmt sein muB $^{62}$ ).

(c) Rein organ is a toris che $M$ a $B n$ a h me n verbindlicher und unverbindlicher Art $k$ ö $n n$ e $n$ durch einen besonderen Rechtsetzungsakt vorgeschrieben sein, ohne daß sie hinsichtlich ihrer Rechtmäßigkeit auf einen solchen a n g e w i es e n sind. Im übrigen ist unmittelbar aus der Verfassung eine (verfassungs-)gesetzliche Ermächtigung der Exekutive zur Vornahme nur intern bedeutsamer Handlungen abzuleiten. Sie ist

60) Uber Entwicklung und Wesen dieses Grundsatzes vgl.: R o o s „Der Grundsatz der gesetzmäBigen Verwaltung und seine Bedeutung für die Anwendung des Verwaltungsrechts" in Berner Festgabe für den Schweizerischen Juristenverein 1955, S. $117 \mathrm{ff}$; $S \mathrm{ch}$ e u ner „Der Bereich der Regierung“ in Festgabe für Rudolf Smend, 1952, S. 203 ff.; G y g i , Interventionsrecht und Interventionsverwaltung, 1958, S. $31 \mathrm{ff}$.

1) innerhalb des eigenen Wirkungskreises von Selbstverwaltungskörperschaften (bzw. -Anstalten).

62) Art. 80 Abs. 1 Satz 2 GG enthält ein allgemeines rechtsstaatliches Postulat unter ausdrücklicher Bezugnahme auf den Erlaß von Rechtsverordnungen auf Grund bundesrechtlicher Ermächtigung. Er bindet jedoch im Hinblick auf Art. 28 Abs. 1 GG auch die Länderorgane. Demzufolge ist z. B. Art. 55 Nr. 2 Satz 3 Bay Verf (wonach für Rechtsverordnungen eine besondere gesetzliche Ermächtigung erforderlich ist) im Sinne des Art. 80 Abs. 1 Satz 2 auszulegen. 
lediglich beschränkt durch den Vorrang des Gesetzes und durch den Vorrang der auf einer höheren Verwaltungsstufe erlassenen organisatorischen Anordnungen ${ }^{(3)}$ ).

(2) Úberprüft man die $\mathrm{R}$ e chtsgrundlagen der verschiedenen $P l a ̈ n e$, so wird man regelmä $B$ ig feststellen dürfen, da $B$ sie $m i t$ em Grundsatz der Gesetzmäßigkeit der Verwaltung übereinstimme n. Eine durchaus rechtsstaatliche Bindung der für die Aufstellung des Baulinienplanes verantwortlichen Behörde kommt z. B. in $\S 3$ bay. BO zum Ausdruck, wonach bei der Festsetzung der Baulinien „auf Sicherheit und Bequemlichkeit des Verkehrs gesehen sowie den Wohnungsverhältnissen, den Anforderungen der Gesundheit, der Feuersicherheit und Schönheit tunlichst Rechnung getragen werden" muß. Die bisher genannten internen Pläne gehen fast ausnahmslos auf eine besondere gesetzliche Ermächtigung zurück, die dann freilich nicht in einem Rechtssatz (mit Außenwirkung) sondern in einer Organisationsnorm (Verwaltungsvorschrift in Gesetzesform) gegeben ist.

b) Die Ermächtigung zur Aufstellung eines Planes hat neben dem Gesetzmäßigkeitsprinzip die sonstigen rechts staatlichen Prinzipien zu berücksichtigen. So sind enteignende Pläne an die Voraussetzungen des Art. 14 Abs. 3 GG gebunden. Auch müssen die Grundsätze der Rechtsklarheit und der Rechtssicherheit befolgt sein. In dieser Hinsicht erwecken die Rechtsgrundlagen mancher Pläne, die die Festsetzung der Baulinien und die Zulässigkeit der Enteignung durch Verwaltungsakt verfügen, erhebliche Bedenken. Ergehen die genannten Maßnahmen gegenüber den derzeitigen Grundstückseigentümern als Verwaltungsakte, so muß die Gewähr gegeben sein, daß sich die Rechtsnachfolger über die Grundstücksbelastungen eindeutig unterrichten können. Deshalb ist es erforderlich, die Bebauungspläne und die für Zwecke der Enteignung festgestellten Pläne als grundbuchähnliche Urkunden auszugestalten oder aber die durch sie verfügten Maßnahmen in Baulastenbücher eintragen zu lassen, die einen öffentlichen Glauben genießen und jedermann zur Einsichtnahme zugänglich sind. Die einschlägigen Vorschriften der bayerischen und württembergischen Bauordnung sowie des Bundesfernstraßengesetzes $^{\text {b4) }}$ lassen diese Notwendigkeit unbeachtet.

63) Nur in diesem Rahmen kann von einer (allgemeinen) Organisationsgewalt der Exekutive gesprochen werden. $\mathrm{Zu}$ diesem Problemkreis vgl. vor allem S p a n n e r DOV $57 \mathrm{~S}$. $640 \mathrm{ff}$., $\mathrm{K}$ o e $t \mathrm{t}$ g e n und E r m a c o r a in VVDStL Heft $16 \mathrm{~S}$. $154 \mathrm{ff}$. und $191 \mathrm{ff}$.; vgl. ferner O berm a y e r DOV 59 S. 355 und AöR 84. Bd. S. 118.

64) Wegen der bindenden Wirkung des Planfeststellungsverfahrens nach § 18 FStrG für ein nachfolgendes Enteignungsverfahren vgl. M a r s h a 11, Bundesfernstraßengesetz, 1954, S. 245. 
3) Für die Entscheidung der Frage, ob ein Plan dem $\mathrm{R}$ e $\mathrm{ch} \mathrm{t} \mathrm{s} \mathrm{-}$ $\mathrm{s} \mathrm{c} \mathrm{h} \mathrm{u} \mathrm{t} \mathrm{z}$ unterfällt, ist gleichfalls seine Rechtsnatur maßgeblich.

a) Gegen unverbindliche und nur intern wirkende Pläne kommt eine Rechtskontrolle auf Grund der verfassungsrechtlichen und der verwaltungsgerichtlichen Generalklausel nicht in Betracht.

b) Die Bestimmung des zulässigen Gerichtsweges gegen

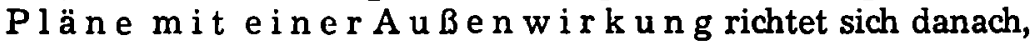
ob sie Verwaltungsakt- oder Rechtsnorm-Pläne sind.

(1) Von den verbindlichen Plänen unterliegen die V e r w a l t ung a k t-P läne dem verwaltungsgerichtlichen Anfechtungsverfahren.

(2) R e chts n orm-Pläne sind dem verwaltungsgerichtlichen Normenkontrollverfahren in jenen Bundesländern zugänglich, deren Verwaltungsgerichtsgesetze eine Nachprüfung untergesetzlicher Rechtsetzungsakte ausdrücklich vorsehen. $\mathrm{Ob}$ sie auch im Geltungsbereich der MRVO 165 justitiabel sind, hängt von der Tragweite des Art. 19 Abs. 4 GG ab.

Die bislang herrschende Meinung will die verfassungsrechtliche Generalklausel nur auf Verwaltungsakte erstrecken. Sie läßt sich dabei von der Vorstellung leiten, daß Rechtsnormen stets eines Vollzugsaktes bedürfen $\left.{ }^{65}\right)$. Demzufolge erblickt sie im Normenkontrollverfahren ein vorbeugendes Rechtsschutzmittel. Freilich darf nicht verkannt werden, daB sich in der Beurteilung des Art. 19 Abs. 4 vor allem dank der Arbeiten F or $s$ th of $\left.f s^{86}\right)$ und $\mathrm{D}$ ï $\mathrm{r}$ i $\mathbf{g ~ s}^{67}$ ) ein grundlegender Wandel vollzieht. In diesem

65) Vgl. F or s th of $f$ DVBl. 57 S. 113 und Brohm S. $43 \mathrm{f}$.

66) Forst h of $f$ DVBl. 57 S. 117.

67) $\mathrm{M}$ a u n z - D ür i g Art. 19 Abs. IV S. 8 ff.

88) Es ist erstaunlich, mit welcher Hartnäckigkeit an der Feststellung festgehalten wird, da $\beta$ Rechtsnormen erst durch Vollzugsakte relevant werden. Dabei ist die unmittelbar wirkende Rechtsnorm nicht etwa ein Phänomen, das seine Existenz irgendwelchen abnormen wirtschaftlichen oder sozialen Verhältnissen unserer Gegenwart verdankt. Sowohl auf der Gesetzes- wie auf der Verordnungsstufe gab es schon immer unmittelbar wirkende, auf keinen Vollzugsakt angewiesene Normen, deren Rechtsfolge „kraft Gesetzes“ eintrat. Es sei nur auf die beamtenrechtlichen Bestimmungen verwiesen, nach denen ein Beamter mit Erreichung der Altersgrenze in den Ruhestand tritt. Auch normative Handlungsverbote zählen hierher. Wenn rechtssatzmäßig gewisse gewerbliche Tätigkeiten untersagt sind, so ist für diejenigen, die ein solches Gewerbe betreiben oder betreiben wollen, der Effekt genau derselbe, als wenn ihnen einzeln ein entsprechendes Verbot auferlegt würde. Der Eingriff wiegt gleich schwer, ob er nun allgemein durch unmittelbar wirkende Rechtsnorm oder durch Verwaltungsalkt vorgenommen wird. Er muß deshalb unter der Geltung des Art. 19 Abs. 4 GG in jedem Falle einer richterlichen Nachprüfung zugänglich sein. 
Zusammenhang soll nur auf die Tatsache verwiesen werden, $\mathrm{da} B$ es auch unmittelbar wirkende, auf keinen Vollzugsakt abzielende Rechtsnormen gibt $^{68}$ ). Werden sie im Verwaltungsbereich erlassen, so muß ihnen derselbe Rechtsschutz zuteil werden, dem die Verwaltungsakte unterliegen. Eine andere Auffassung würde zu unhaltbaren Ergebnissen führen, die mit dem Sinngehalt des Art. 19 Abs. 4 unvereinbar wären.

(3) Besondere Rechtsschutzprobleme ergeben sich bezüglich der B e bau ung p län e.

(a) Zunächst kann es zweifelhaft sein, ob die $n$ or $m$ a $t$ i v e $n$ Bebau ungs äne bereits unmittelbare Rechtswi $r$ k u n g e $n$ entfalten. Formal betrachtet gewinnen sie eine unmittelbare Rechtserheblichkeit erst dann, wenn die von ihnen betroffenen Grundstücke bebaut werden. Doch ist zu berücksichtigen, daß die auf einem Grundstück verlaufende Baulinie regelmäßig in einem unlösbaren Zusammenhang mit einem ganzen System von Baulinien steht. Sollte nun ein Grundstückseigentümer den Rechtsschutz erst im Rahmen eines Baugenehmigungsverfahrens in Anspruch nehmen dürfen, so könnten andere durch dasselbe Bauliniensystem gebundene Bauwerber mit einem früheren Baubeginn Fakten schaffen, die einen späteren Rechtsschutz praktisch illusorisch machen. Deshalb ist es wohl geboten, die normativen Bebauungspläne hinsichtlich der gerichtlichen Nachprüfung den unmittelbar wirkenden Rechtsnormen gleichzusetzen ${ }^{69}$ ) und sie schon aus diesem Grunde dem Schutz des Art. 19 Abs. 4 GG anzuvertrauen. In welcher Weise dann dieser verfassungsrechtlich garantierte Rechtsschutz in den Ländern der ehemaligen britischen Besatzungszone zu bewerkstelligen ist, kann hier nicht näher erörtert werden ${ }^{70}$ ).

(b) Mit allem Nachdruck ist aber darauf hinzuweisen, daß es sehr unzweckmä $B$ ig ist, wenn Bebauungspläne a l s Normen erlassen werden und deshalb als Normen dem Rechtsschutz unterworfen sind. Wird eine Rechtskontrolle frühzeitig in Gang gebracht, so besteht die Möglichkeit, daß rechtswidrige Baulinien beseitigt werden. Stellt ein Bauwerber einen Normenkontrollantrag erst Jahre später, nachdem bereits andere Grundstückseigentümer in Ubbereinstimmung mit den nunmehr angefochtenen Baulinien Bauwerke errichtet haben, dann ergibt sich eine sehr schwierige Situation. Sollte die Baulinienfestsetzung seinerzeit rechtswidrig gewesen sein, so müßte sie

69) Da der Bebauungsplan stets auf eine Umsetzung durch einen Verwaltungsakt (Baugenehmigung) angewiesen ist, kann er nicht als (unmittelbar wirkende) "Vollzugsnorm" beurteilt werden (so Brohm S. 61).

70) Hierzu vgl. O be r m a ye r BayvBl. 58 S. 71. 
für nichtig erklärt werden. Aber im Hinblick auf die inzwischen errichteten neuen Bauten kann es sehr leicht möglich sein, daß die Baulinie $\mathrm{n} \mathrm{un} \mathrm{m} \mathrm{e} \mathrm{hr}$ aus Gründen des öffentlichen Interesses $r$ e $\mathrm{htm} \ddot{\mathrm{a}} \mathrm{B} \mathrm{ig}$ in derselben Weise festzusetzen ist, die se in e rze it - als noch keine Grundstücke bebaut waren re ch t s wi d rig war. Der Kläger würde also sein Ziel, eine andere Baulinienführung durchzusetzen, nicht erreichen. Bestenfalls könnte er einen Schadenersatzanspruch geltend machen.

(c) So wäre de lege ferenda einer Ausgestaltung des Bebaungsplanes als Verwaltungsakt unbedingt der Vorzug zu geben. Die Festsetzung der auf dem Boden und im Luftraum verlaufenden Baulinien umgreift die nachhaltigsten öffentlich-rechtlichen Beschränkungen für die wirtschaftliche Nutzung des Bodens zum Zwecke der Bebauung. So besteht ein dringendes Bedürfnis, hinsichtlich der Wirksamkeit dieser Baubeschränkungen baldmöglichst klare Rechtsverhältnisse zu schaffen. Das ist nur dann möglich, wenn sich der Bebauungsplan als eine Summe von Verwaltungsakten an bestimmte Personen richtet, denen für die Einlegung eines Rechtsmittels eine Frist gesetzt ist. Verwaltungsakt-Bebauungspläne erwachsen - von den seltenen Fällen ihrer Nichtigkeit abgesehen - in formelle Rechtskraft. Sie werden damit auch bei einer Fehlerhaftigkeit endgültig wirksam. Fehlerhafte Rechtsnorm-Bebauungspläne sind und bleiben immer nichtig, da das deutsche öffentliche Recht bei Rechtsnormen keinen Fehlergrad kennt, der der Anfechtbarkeit bzw. Aufhebbarkeit eines rechtswidrigen Verwaltungsaktes entspricht.

(d) Freilich bleibt auch dann, wenn Bebauungspläne als Verwaltungsakte dem Rechtsschutz unterliegen, noch ein weiteres Problem zu lösen. Es handelt sich um die Frage, inwieweit die Anfechtung der für ein Grundstück festgesetzten Baulinie durch einen Grundstückseigentümer einen $S u s p e n s$ i veffekt auslöst. Bei der engen Verzahnung der verschiedenen Baulinien untereinander wird man die Anfechtung einer einzigen Baulinie als einen Angriff auf alle übrigen Baulinien betrachten müssen, die mit der angefochtenen Baulinie in einem unlösbaren Zusammenhang stehen. Insoweit wird dann die Verbindlichkeit des gesamten Bebauungsplanes aufgeschoben. Die Verwaltungsbehörde hat freilich vorbehaltlich einer entgegengesetzten verwaltungsgerichtlichen Entscheidung die Möglichkeit, die Vollziehung des angefochtenen Bebauungsplanes anzuordnen, wenn sie dies im öffentlichen Interesse für geboten hält. Damit übernimmt sie aber ein großes Risiko, weil sie bei einer den Bebauungsplan ganz oder zum Teil beseitigenden Gerichts- 
entscheidung in erhebliche Haftungen geraten kann ${ }^{71}$ ). So wird sie von dem Mittel der Anordnung der Vollziehung nur dann Gebrauch machen dürfen, wenn die eingelegten Rechtsmittel offensichtlich unbegründet sind.

IV. Eine abschließende Betrachtung hat noch $\mathrm{zu}$ prüfen, welche $B$ e de u t ung dem im ersten Teil dieser Ausführungen entwickelten Begriff des verwaltungsrechtli c hen Planes zukommt.

Auf den ersten Blick erscheint der dogmatische Ertrag dieses Begriffes recht gering. Läßt sich der Plan wirklich - so möchte man fragen - als ein besonderes Rechtsinstitut qualifizieren, wenn man es ablehnt, ihn im Verhältnis zu den klassischen Hoheitsakten als ein aliud zu behandeln; wenn man ihn seiner Rechtsnatur nach in mehrere Arten aufspaltet, von denen jede hinsichtlich der Rechtmäßigkeit und des Rechtsschutzes besonderen Regeln folgt?

Wir erinnern uns jener Feststellung $\mathrm{K}$. $\mathrm{rm}$ an $\mathrm{ns}$, wonach ein Rechtsbegriff "nur insoweit wissenschaftlichen Wert" hat, "als er praktische Bedeutung hat"72). Diese Worte sind sicher auch heute noch beherzigenswert, da die dogmatische Durchformung des Verwaltungsrechts immer noch nicht jene klare Geschlossenheit erlangt hat, die die Zivilistik seit langer Zeit auszeichnet. Aber das Postulat der „Praktikabilität" darf nicht auf den rechtstechnischen Bereich beschränkt bleiben. Und es darf nicht in einen Antagonismus gesetzt werden zu jenem - aller wissenschaftlichen Betätigung immanenten - Bedürfnis, eine Einsicht in das Wesen der Phänomene zu gewinnen und sie "theoretisch" zu erfassen.

Unter diesen Aspekten erweist sich auch der Plan-Begriff als ein "praktischer" Begriff, weil er die Erkenntnis verwaltungsrechtlich relevanter Vorgänge erleichtert und deren typische Merkmale hervorhebt; weil er als Rahmenbegriff Ausarbeitungen aufnimmt, die sich trotz ihrer Verschiedenartigkeit in einem wesentlichen Punkte gleichen. Der eigentliche Sinn des PlanBegriffs aber dürfte darin zu suchen sein, daß er unsere Aufmerksamkeit auf Zusammenhänge lenkt, die durch die vordergründige Rechtsakt- und Rechtsschutzproblematik oft verdeckt werden.

Die „regula aurea" des Art. 19 Abs. 4 GG ist sicher ein unabdingbarer Bestandteil unserer rechtsstaatlichen Ordnung. Und es ist gut und richtig, daß seine Konsequenzen für das Verwal-

71) Vgl. M a n g BayVBl. 59 S. 373.

72) Kormanns Einführung in die Praxis des Deutschen Verwaltungsrechts, 2. Aufl. 1930 (herausgegeben von Friedrich List), S. 12. 
tungsrecht gründlich erwogen werden. Aber ein verwaltungsrechtliches Denken, das sich allzu ausschließlich von der Frage nach einer erfolgreichen Jurisdiktion der Verwaltungshandlungen leiten ließe, würde der Erstarrung anheimfallen. Im rein technischen Vollzugsbereich mögen die meisten Hoheitsakte in die Alternative "Rechtmäßigkeit" und „Rechtswidrigkeit" hineingestellt sein. Ist eine Konzession unter ganz bestimmten, durch deskriptive Rechtsbegriffe festgelegten Tatbestandsvoraussetzungen zu gewähren, dann ist ihre Erteilung tatsächlich ein Vollzugsakt, dessen Probleme beim Rechtsschutz auslaufen. Neben dem technischen Vollzugsbereich gibt es aber eine andere Verwaltungssphäre, die vom sogenannten freien Ermessen beherrscht wird. Gewiß sollte man die hier den Behörden vorbehaltene Freiheit grundsätzlich nicht allzu hoch veranschlagen. Die Ausfüllung eines tatbestandlichen Beurteilungsspielraumes und die Anwendung des Handlungsermessens sind doch weitgehend vorgezeichnet bzw. eingeschränkt, und zwar in te r $n$ durch Erfahrungsgrundsätze und Verwaltungsvorschriften und e $x$ t e $r \mathrm{n}$ durch das Gebot pflichtmäßiger Ermessensbetätigung und durch den Gleichheitssatz. Die p l a n e n d e Verwaltungstätigkeit aber ist trotz aller rechtlichen Abschirmung immer noch auf freie dynamische Impulse angewiesen. Hier gibt es noch eine Fülle von Aktionsmöglichkeiten, die mit den Kategorien der „RechtmäBigkeit" und der „Rechtswidrigkeit" keineswegs erschöpfend festgelegt werden können. Die Unterlassung einer Planaufstellung oder eines Planvollzugs braucht noch lange nicht "rechtswidrig“ zu sein. Und auf der anderen Seite kann das Verwaltungsgericht einen seiner Nachprüfung unterworfenen Plan sehr wohl als "rechtmäßig“ bestehen lassen, obgleich er einer eklatanten Fehlentwicklung Vorschub leistet.

Jeder Plan erfordert konstruktive Kräfte, die in gewissem Maße rechtlich g e l e $\mathrm{n} \mathrm{t}$, aber doch nicht mit juristischen Mitteln e r z e $\mathrm{g} \mathrm{t}$ werden können. Sie müssen bereits im Planverfahren zur Auswirkung gelangen. Vor allem aber sind sie erforderlich für jenen intelligiblen Akt, mit dem die leitenden Planer das sachliche Ergebnis konzipieren. Hierbei muß sich ein synthetischer, das Wesentliche erfassender Blick bewähren, der die vorhandenen Beurteilungsgrundlagen verwertet und die maßgeblichen Einfluß- und Entwicklungstendenzen in Rechnung stellt; der die verschiedenen Faktoren aufeinander abstimmt und sie zu einem geschlossenen Ordnungsbild vereint. Je weiter die Pläne in die Dimensionen von Zeit und Raum hineinreichen, je umfangreicher die eingesetzten Mittel, je wichtiger die erstrebten Zwecke und je vielseitiger die tangierten Probleme sind, desto größer ist die Verantwortung, die auf den 
Schultern aller Planenden lastet. Die weitschichtigen Auswirkungen planender Verwaltungstätigkeit gewahren wir wohl am besten, wenn wir die Gesamtheit der auf den Raum bezogenen Pläne ins Auge fassen. Sie stellen ein organisch abgestuftes Plangefüge dar, das sich von den umfassenden Raumordnungsplänen über die baurechtlichen Leitpläne bis zu den auf wenige Grundstücke beschränkten Bodenplänen erstreckt ${ }^{73}$ ). Im Hintergrund dieser Pläne, die alle um die Bezwingung menschlicher Zukunft ringen, taucht dann die uralte Frage nach dem Verhältnis von Mensch und Raum ${ }^{74}$ ), von Mensch und Erde auf. Die verwaltungsrechtlich greifbaren Planungen erweisen sich plötzlich als Vorgänge von schicksalhafter Intensität, die den einzelnen und die Gemeinschaft in ihrem existenziellen Kern berühren. Sie wollen geistig bewältigt werden. Und deshalb mag uns das Rechtsinstitut des Planes nicht zuletzt daran erinnern, daß die Verwaltung ihre großen lebensformenden Aufgaben nur erfüllen kann, wenn sie von einem Hauch schöpferischen Geistes beseelt ist.

73) Vgl. die Feststellung Fors th of is (DVBI. 57 S. 114), daß sich das Planungsgeschehen "in Akten fortschreitender Konkretisierung" vollzieht.

74) Vgl. B ü l ow , Zur Philosophie und Soziologie des Raumes und der Raumordnung, in Raumforschung und Raumordnung 1953 S. 69 ff. 


\title{
Leitsātze des Mitberichterstatters über: Der Plan als verwaltungsrechtliches Institut
}

\author{
I. Der Begriff des Planes
}

1. Die Begriffsbestimmung des verwaltungsrechtlichen Planes begegnet Schwierigkeiten, weil a) das Wort "Plan" ein Allerweltsausdruck ist und keine ursprüngliche juristische Affinität aufweist;

b) die im Verwaltungsrecht seit langer Zeit bekannten Pläne dogmatisch beziehungslos nebeneinander standen, so daß der $P$ la $n$ - anders als der Verwaltungsakt-keinvorgeprägter Rechtsbegriff ist;

c) unter der Vorherrschaft der klassischen verwaltungsrechtlichen Rechtsinstitute die $N$ eigung besteht, d e $n$ P la n von vornherien a uf eine Ebene mit dem Verwaltungsakt und der Rechtsverordnung zu stellen.

2. Für die Ermittlungeinesverwaltungsrechtlichen Planbegriffs kommt es darauf an, Einverständnis über die dem Begriff zu unterstellenden Pläne zu erzielen und dann von diesen Plänen gemeinsame Merkmale zu abstrahieren.

a) Dem Planbegriff sind alle Pläne $z u$ unterst ell e $n$, die die Gestaltung einer bestimmten Ordnung zum Ziele haben, wie $z$. B.

die Raumordnungspläne, die Leitpläne einschl. der Wirtschafts-, Flächennutzungs-, Ubbersichts-, Baugebiets-, Generalbebauungs-, Generalbaulinien- und Gesamtaufbaupläne, die Bebauungspläne einschließl. der Fluchtlinien-, Baulinien-, Ortsbau- und Durchführungspläne, die Ba ustufen-und Aufb a u pläne, die Umlegungs-und Flurbereinigungspläne, die im Rahmeneines Planfeststellungsverfahrens aufgestellten $P$ läne (Enteignungs-, Straßenbau-, Wasserausbau- und Bundesbahnbaupläne), die Land beschaffungs. pläne, die wasserwirtschaftlichen $R$ ah menpläne, die Wohnungsbauprogramme und die Haushaltspläne der Selbstverwaltungskörperschaften: 
b) Das wesentliche Merkmal der genannten Pläne besteht darin, daß sie eine Reihe von Maßnahmen vorsehen, die zueinander in einem unlösbaren Verhältnis gegenseitiger Ergänzung und Abhängigkeit stehen.

3. Der verwaltungsrechtliche Plan ist begrifflich festzulegen als Ausarbeitung eines Verwaltungsorgans, die durch verschiedene aufeinander abgestimmte Maßnahmen die Verwirklichung eines bestimmten Ordnungszustandes anstrebt.

\section{Die einzelnen Planarten}

1. Die Einteilung nach dem Gegenstand bietet sich von selbst an und ist nicht weiter zu verfolgen.

2. Rein descriptiven Wert hat auch eine Unterscheidung nach Art der Ausarbeitung (z. B. Planskizze oder geschriebenes Wort).

3. Ein dogmatisch wertvolleres Unterscheidungsmerkmal ist das zeitliche Verhältnis, in dem die a ufeinander abgestimmten Maßnahmen zur Auswirkung gelangen sollen.

4. Eine weitere Einteilung kann die Genauigkeit zum Prüfstein nehmen, mit der die verschiedenen Einzelmaßnahmen festgelegt sind.

5. Die wichtigste Einteilung ist unter dem Gesichtspunkt der rechtlichen Auswirkung zu treffen, wobei zunächst die unverbindlichen von den verbindlichen Plänen $z u$ unterscheiden sind.

a) Unverbindliche Pläne sind jene Pläne, die ein förmliches Feststellungsverfahren nicht bzw. noch nicht durchlaufen haben.

b) Verbind liche und damit der Rechtsakt-Problematik unterworfene $P l a ̈ n e$ sind jene Pläne, die auf Grund eines ausdrücklich bestätigenden Hoheitsaktes das Stadium des reinen Entwurfs verlassen haben.

(1) Vor einer Entscheidung über die Rechtsnatur der verbindlichen Pläne müssen die $K$ a t e gor $i$ e $n$ feststehen, die für die Ermittlung der Rechtsnatur verwaltungs$r e c h t l i c h$ er $H$ oh eitsakt e verfügbar sind. Sie werden durch die beiden Fragen bestimmt, wer von einem Hoheitsakt rechtlich betroffen ist und in welcher Form diese Betroffenheit rechtlich relevant wird.

(a) Unter dem Gesichtspunkt des Betroffenen$k$ reises gibt es 
aa) Rechts a kte (mit einer "Außenwirkung") ge genüber Personen und rein organisatorische Akte (mit einer "Innenwirkung" gegenüber Verwaltungsorganen);

bb) Einzelakte (als Rechtsakte gegenüber einem bestimmten bzw. bestimmbaren Kreis von Personen bzw. Verwaltungsorganen), deren Rechtserheblichkeit sich im Zeitpunkt des Erlasses erschöpft, und Normen (als Rechtsakte gegenüber einer unbestimmten Zahl von Personen bzw. Verwaltungsorganen), die einer weiteren Konkretisierung zugänglich sind.

Normen mit einer Außenwirkung gegenüber Personen werden herkömmlicherweise als „Rechtsnormen" bzw. „Rechtssätze“ bezeichnet.

Die nur intern wirkenden Normen treten in der Fachsprache als "Verwaltungsvorschriften", „Verwaltungs-" oder "Organisationsnormen" auf.

(b) Die rechtliche Betroffenheit kommt for mal

entweder im gewöhnlichen Verwaltungsverfahren durch Einzeleröffnung

oder im Verordnungsverfahren durch Kundmachung an die Allgemeinheit (,allgemeinverbindliche" Publikation) zum Ausdruck.

Alle Normen müssen im Verordnungsverfahren (mit der dem jeweiligen Betroffenenkreis adäquaten Publikation) erlassen werden. E i $n z$ e $l$ a $k$ t e sind regelmäßig dem $V$ e rwaltungsverfahren (mit Einzeleröffnung) vorbehalten.

(c) Für bestimmte regelmäßige Verbindungen sachlicher und formaler Rechtsakt-Elemente sind die klassischen verwaltungsrechtlichen Rechtsinstitute entwickelt worden.

aa) Verwaltungsakte sind die im Verwaltungsverfahren (und nicht im Verordnungsverfahren) erlassenen Einzelakte;

bb) Rechtsverordnungen (im Sinne rechtssatzmäßiger Verordnungen) sind die im Verordnungsverfahren erlassenen Normen mit einer Außenwirkung gegenüber Personen;

cc) Verwaltungsverord nungen sind die im Verordnungsverfahren erlassenen organisatorischen Akte.

(d) Bei der Festlegung aller auf die rechtliche Betroffenheit gemünzten Rechtsbegriffe und Rechtsinstitute müssen $F$ r a- 
gen einer inneren Werthaftigkeit unbe$r \ddot{u} c k s i c h t i g t$ bleiben, da sie für die Behandlung lediglich rechtslogischer und rechtstechnischer Probleme noch nicht einschlägig sind.

1. Unter Berïcksichtigung der unter (1) dargestellten Rechtsbegriffe ist auch die Rechtsnatur der verbindlichen Pläne festzulegen.

(a) Als Rechtsakte gegenüber Personen erweisen sich neben einigen verbindlichen Leitplänen die verbindlichen Bebauungs-, Baustufen- und Aufbaupläne, ferner die verbindlichen Flurbereinigungs- und Umlegungspläne sowie die in einem Planverfahren festgestellten Enteignungs-, Straßenbau-, Wasserausbau- und Bundesbahnbaupläne.

aa) Einzelakte (Verwaltungsakte) sind die förmlich festgestellten Flurbereinigungs-, Umlegungs- und sonstigen Bodenpläne, soweit sie für bestimmte am (Plan-)Verfahren beteiligte Grundstückseigentümer rechtserheblich sind.

bb) Die Rechtsnatur des Bebauungsplanes ist rechtslogisch nicht in einer bestimmten Weise vorgeschrieben.

Er enthält Einzelakte (Verwaltungsakte), wenn sich die Festsetzung der Baulinien nur an diejenigen Personen richtet, die im Zeitpunkt der Festsetzung die Verfügungsmacht über die vom Plan erfaßten Grundstücke besitzen.

Er enthält $R$ e ch $t s$ n or $m$ e $n$, wenn er jedem, der einmal auf der mit den Baulinien versehenen Grundfiäche bauen will, die Pficht zu ihrer Einhaltung auferlegt.

Nach den in den einzelnen Bundesländern geltenden Bauvorschriften muß dem Bebauungsplan jedenfalls üb erwiegend ein normativer Charakter zugesprochen werden.

cc) Normative Akte sind weiterhin die für verbindlich erklärten Raumordnungspläne, die Baustufen-und Aufbaupläne, die Wirtschaftspläne (als Ausfüllungsnormen zu $\S 6$ Nr. 1 WSG), einige Leit- bzw. Flächennutzungspläne (soweit sie die künftige Nutzungsart von Grundstücken regeln). (b) Rein organisatorische Rechtsakte (ohne Außenwirkung) sind die verbindlichen Flächennutzungspläne, denen eine Außenwirkung fehlt, außerdem die Haushaltspläne der Selbstverwaltungskörperschaften.

Die Auffassung des Bundesverwaltungsgerichts, wonach die etatmäßige Bereitstellung von Mitteln wenigstens für Subventionsmaßnahmen eine hinreichende Legitimation verwaltungsmäßigen Handelns darstelle, ist abzulehnen, da nur der 
Gesamtplan (mit den Schlußzahlen der Einzelpläne), nicht aber die Einzelpläne mit den verschiedenen Ansätzen von der formellen Gesetzes- bzw. Verordnungs-(Satzungs-)Kraft erfaßt werden.

\section{Die Einordnung des Planes in das rechtsstaatliche Normengefüge}

1. Die Problemstellung kann nicht lauten, in welchen Fällen der Plan als solcher rechtmäßig bzw. gerichtlich nachprüfbar ist. Maßgeblich für die Lösung der mit der Rechtmäßigkeit und dem Rechtsschutz zusammenhängenden Fragen ist die jeweilige Rechtsnatur der verschiedenen Pläne.

2. Die Rechtmäßigkeit eines Planes hängt davon ab, daß seine Aufstellung durch eine ausreichende rechtsstaatliche Ermächtigung gedeckt ist.

a) Die Ermächtigung muß dem Grundsatzder Gesetzmäßigkeit der Verwaltung entsprechen.

1. Dieser Grundsatz ist für Verwaltungsakte, untergesetzliche Rechtsnormen und rein organisatorische Maßnahmen verschiedenartig ausgestaltet.

(a) Verwaltungsakte benötigen eine Rechtsgrundlage, die grundsätzlich (von den wenigen Fällen noch gültigen Gewohnheitsrechtes abgesehen) in einem förmlichen Gesetz enthalten sein oder doch auf ein solches zurückgehen muß. Die Rechtsgrundlage muß für den Erlaß bestimmter Verwaltungsakte eindeutige Tatbestandsvoraussetzungen festlegen und auch Ermessensmaßnahmen durch einen tatbestandlichen Rahmen binden.

(b) Untergesetzliche Rechtsnormen (mit Ausnahme "autonomer" Satzungen) bedürfen einer besonderen, nach Inhalt, Zweck und Ausmaß bestimmten gesetzlichen Ermächtigung.

(c) Rein organisatorische $M a \beta n a h m e n$ (verbindlicher und unverbindlicher Art) können durch einen besonderen Rechtsetzungsakt vorgeschrieben sein. Im übrigen ist unmittelbar aus der Verfassung eine (verfassungs-)gesetzliche Ermächtigung der Exekutive zur Vornahme nur intern bedeutsamer Handlungen abzuleiten. Sie ist lediglich beschränkt durch den Vorrang des Gesetzes und den Vorrang der auf einer höheren Verwaltungsstufe erlassenen organisatorischen Anordnungen.

2. Für die Aufstellung der verschiedenen Pläne steht jedenfalls regelmäßig eine dem Grundsatz der 
Gesetzmäßigkeit der Verwaltungentsprechende Rechtsgrundlage zur Verfügung.

b) Die Ermächtigung hat auch die sonstigen rechtsstaatlichen Prinzipien zu berücksichtigen. U. a. müssen die Grundsätze der Rechtsklarheit und der Rechtssicherheit befolgt sein. In dieser Hinsicht erwecken die Rechtsgrundlagen jener Pläne Bedenken, die die Festsetzung der Baulinien und die Zulässigkeit der Enteignung als Verwaltungsakte verfügen, ohne die betreffenden Belastungen des Grundeigentums in Urkunden mit öffentlichem Glauben für die Rechtsnachfolger evident werden zu lassen.

3. Für die Entscheidung der Frage, ob ein Plan dem $R$ e ch $t s$ schutz unterfällt, ist gleichfalls seine Rechtsnatur maßgeblich.

a) Gegen unverbindliche und nur intern wirkende Pläne kommt eine Rechtskontrolle auf Grund der verfassungsrechtlichen und der verwaltungsgerichtlichen Generalklausel nicht in Betracht.

b) Die Bestimmung des zulässigen Gerichtsweges gegen $P l a ̈ n e ~ m i t$ einer $A u \beta$ e $n w$ i $r k u n g$ richtet sich danach, ob sie Verwaltungsakt- oder Rechtsnorm-Pläne sind.

1. Verwaltungsakt-Pläne unterliegen dem verwaltungsgerichtlichen Anfechtungsverfahren.

2. $R$ echts n or $m-P l a ̈ n$ e sind dem verwaltungsgerichtlichen Normenkontrollverfahren in jenen Bundesländern zugänglich, deren Verwaltungsgerichtsgesetze eine Nachprïfung untergesetzlicher Rechtsetzungsakte ausdrücklich vorsehen. Im übrigen werden sie von der Rechtsschutzgarantie des Art. 19 Abs. 4 GG jedenfalls dann erfaßt, wenn sie "unmittelbar" wirken und zur Entfaltung ihrer Rechtserheblichkeit nicht auf einen Vollzugsakt angewiesen sind.

3. Besondere $R$ echtsschutzprobleme ergeben sich bezüglich der Bebauungspläne.

(a) Formal betrachtet gewinnen die Rechtsnorm-Bebauungspläne eine unmittelbare Rechtserheblichkeit erst dann, wenn die von ihnen betroffenen Grundstïcke bebaut werden. Sollte ein Grundstückseigentümer den Rechtsschutz aber erst im Rahmen eines Baugenehmigungsverfahrens in Anspruch nehmen dürfen, so könnten andere durch dasselbe Bauliniensystem gebundene Bauwerber mit einem früheren Baubeginn Fakten schaffen, die einen späteren Rechtsschutz illusorisch machen. Deshalb sind di e normativen Bebauungsplänehinsichtlich dergerichtlichen 
Nachprüfung den unmittelbar wirkenden Normengleichzusetzen.

(b) Aus Gründen des Rechtsschutzes ist es $z$ we c $k m \ddot{a} \beta i g$, Bebauungspläne als Normen zu erlassen.

(c) De lege ferenda ist die Ausgestaltung der Beba u ungspläne als Verwaltungsakte (Summe von einzelnen Verwaltungsakten) $z u$ ford er $n$. Da die Bebauungspläne die nachhaltigsten öffentlich-rechtlichen Beschränkungen für die wirtschaftliche Nutzung des Bodens zum Zwecke der Bebauung enthalten, besteht ein dringendes Bedürfnis, hinsichtlich ihrer Wirksamkeit baldmöglichst klare Rechtsverhältnisse zu schaffen. Das ist nur dann möglich, wenn der Bebauungsplan als ein der formellen Rechtskraft fähiger Verwaltungsakt erlassen wird.

(d) Wird eine als Verwaltungsakt erlassene Baulinienfestsetzung angefochten, so e rstrecktsich der $S u s p$ ensiveffekt aufalle Baulinien, die mit der angefochtenen in einem unlösbaren Zusammenhang stehen.

IV. Die Bedeutung des Planbegriffes

Die Bedeutung des Planbegriffes liegt darin, daß er

1. die Erkenntnis verwaltungsrechtlich relevanter Vorgänge erleichtert und deren typische Merkmale hervorhebt;

2. als Rahmenbegriff Ausarbeitungen aufnimmt, die sich trotz ihrer Verschiedenartigkeit in einem wesentlichen Punkte gleichen;

3. Zusammenhänge deutlich werden läßt, die durch die vordergrïndige Rechtsakt- und Rechtsschutz-Problematik oft verdeckt werden. 


\title{
Der Plan als verwaltungsrechtliches Institut
}

\author{
Aussprache und Schlußworte
}

Peters: Nach Rücksprache mit den Referenten habe ich folgenden Plan für die Diskussion aufgestellt. Das Gesamtthema der Diskussion wäre in vier Gruppen zu teilen:

Punkt 1: „Wesen und Rechtswirkungen des Plans“; dazu würde gehören: Ziel des Plans, Zweck, Arten und Typen der Pläne, die Rechtsnatur des Plans und die rechtlichen Folgen einer Planaufstellung. Lediglich aber das materielle Recht; der Rechtsbehelf wird später unter 4 behandelt.

P u n k t 2: "Normen für die Planaufstellung". Dazu kommen die Frage der Ermessensbeschränkung. Willkürverbot, Gleichheitsdurchbrechung und allgemein positiv-rechtliche Vorschriften, etwa Verfahrensvorschriften usw., wie sie auf manchen Gebieten bestehen.

Punkt 3: „Entschädigungsansprüche aus Planungen, Rechtsentziehungen, wirtschaftliche Schäden".

Punkt 4: „Die Rechtsbehelfe gegen Pläne“, also die Frage: „Entziehen sich manche Arten von Plänen wesensmäßig der Nachprüfung?" Da das freie Ermessen für sie typisch ist, entsteht das Problem der Ermessenskontrolle durch die Gerichte. Dann kämen die Fragen, die Herr Kollege Imboden behandelt hat. Dabei fällt wohl auf, daß wir das Thema als solches auf den Plan als Verwaltungsrechtsinstitut beschränkt haben. Mir ist jedoch während des Referats klar geworden, daß es eigentlich eher hätte heißen müssen: „Der Plan als Rechtsinstitut"; denn ein großer Teil der Planfragen tritt genauso auf bei anderen Typen von Plänen (wie der „Grüne Plan"), bei denen dann sogar an den Gesetzgeber bestimmte Forderungen gerichtet werden, nicht nur an die Verwaltung. Aber der Vorstand hat das Thema begrenzen müssen, und so ist es wohl richtig, daß wir die Diskussion auch darauf beschränken. Das hindert natürlich nicht, daß dort, wo Parallelerscheinungen zu finden sind, sich auch die Diskussion außerhalb dieser Begrenzung bewegt.

Forsthoff: Ich möchte kurz einen allgemeinen Eindruck andeuten, den ich aus den gestrigen und heutigen Vorträgen und Besprechungen gewonnen habe. Mir ist erst in diesen Tagen deutlich geworden, wie sehr die scheinbar getrennten Themen, 
die wir auf den verfassungsrechtlichen und den heutigen Tag verteilt haben, in ihrer Problematik zusammenhängen. Die transnationalen Gemeinschaften sind administrative Gebilde. Sie stehen im Dienste einer Einigung Europas und es werden ihnen, wenn die Einigung fortschreiten soll, weitere folgen. Die Aufgabe einer solchen Einigung stellt sich im 20. Jahrhundert offenbar wesentlich anders als im 19. Jahrhundert. Auch das 19. Jahrhundert hat ja große Einigungsbewegungen hervorgebracht, insbesondere auf dem Boden des deutschen Verfassungsrechts: den Einigungsversuch des Jahres 1848, den Norddeutschen Bund, die Reichsgründung. Zu dieser Zeit war das Mittel der Einigung selbstverständlich die gemeinsame Verfassung. Heute einigt man sich durch Schaffung gemeinsamer Administrationen. In dieser Tatsache drückt sich, wie ich glaube, eine für die moderne, industriell-technische Welt charakteristische Verschiebung der Gewichte aus, in denen wir unsere Hauptmaterien, das Verfassungsrecht und das Verwaltungsrecht einander zugeordnet finden.

Auch innerhalb des Verfassungsrechtes selbst haben sich die Gewichte, wie der gestrige Tag gezeigt hat, eindeutig verschoben. Das alte Zentralproblem der Verfassung: wie ist die Staatswillensbildung organisiert? tritt mehr und mehr hinter dem Problem des Rechtsschutzes zurück. Das hat natürlich gute Gründe. Denn in dem Maße, in dem das administrative Element im modernen Staat zunimmt, gewinnt auch der Rechtsschutz an Bedeutung.

Stellt sich das Problem der Einigung Europas vorzüglich als das Problem der gemeinsamen Administration dar, so tritt die Frage auf, wieviel wir von den Errungenschaften unserer Verfassungsentwicklung in die gemeinsamen administrativen Gebilde hineintragen können. Oder wird das Grundgesetz in seiner Rechtsstaatlichkeit, wie sie in den Artikeln 1-19 zum Ausdruck kommt, von den administrativen Einigungen vermöge der Auslegung des Art. 24 GG gewissermaßen unterlaufen? Das heutige Thema hat damit eine charalteristische Verwandtschaft. Ebenso wie die transnationale Administeration ist der Verwaltungsplan eine Rechtserscheinung, die sich der Struktur unseres öffentlichen Rechts nicht reibungslos einfügen will. Von unserem Verfassungsrecht her haben wir nur die Alternative, den Verwaltungsplan zur Norm oder zum Verwaltungsakt zu erklären, obgleich der Verwaltungsplan $\mathrm{m}$. E. etwas anderes, ein aliud ist, das sich dieser Alternative entzieht.

Ubrigens habe ich bedauert, daß der zeitgebundene Plan in den Vorträgen unberücksichtigt geblieben ist: der Fünfjahresplan oder der Vierjahresplan, wie man sie aus der Sowjetunion 
und dem nationalsozialistischen Staat kennt. Es wäre interessant und wichtig, einmal des näheren darzulegen, daß, warum und inwiefern der Plan, sobald er an die Zeit gebunden wird, sein Wesen vollkommen verändert. Dazu bedürfte es wahrscheinlich auch einer philosophischen Erfassung des Wesens der Zeit. Jedenfalls ist der Plan in der modernen Staatswirklichkeit ein Phänomen von besonderer Stoßkraft, das unser Sozialleben immer stärker bestimmt.

Die verfassungsrechtlichen Probleme, die der Plan als ein unserer Rechtstypik im Grunde fremdes Rechtsinstitut aufwirft, sind im Grunde die gleichen wie sie bei der dem Plan insoweit verwandten transnationalen Administration auftreten. Es sind Rechtsschutzfragen. Art. 19 Abs. 4 GG ist zur Zentralnorm des gesamten öffentlichen Rechts geworden. Ich sehe darin eine charakteristische, aber unausweichliche Minderung der verfassungspolitischen und verfassungsrechtlichen Substanz im Rahmen unseres öffentlichen Rechts. Auf diese allgemeine Bemerkung möchte ich mich zunächst beschränken.

Merk: Ich möchte mich beschränken auf die Behandlung von Ortsbau- und Straßenbauplänen. Man sollte hier von der Festsetzung der Fluchtlinien für ein bestimmtes Grundstück ausgehen. Daß das eine Verwaltungsverfügung ist, kann nicht in Zweifel gezogen werden. Ein Ortsbauplan weist nun die Eigentümlichkeit auf, daß es sich hier um eine Summierung von planmäßig miteinander verknüpften Einzelverfügungen handelt. Daß eine Wesensänderung eintritt dadurch, daß man nicht nur für ein Grundstück die Fluchtlinien festsetzt, sondern für mehrere bestimmte Grundstücke, vermag ich nicht einzusehen. Ich würde diese Fragestellung deshalb nicht so fassen, wie es von Herrn Obermeyer unter Ziff. II, 5,2$)$ bb geschehen ist. Dicse Fluchtlinien beziehen sich auf bestimmte Grundstücke und haben - ganz ähnlich wie eine Verwaltungsverfügung eine bestimmte Gestaltung für diese Grundstücke im Auge. Um Rechtssätze würde es sich handeln, wenn ganz allgemein bestimmt werden könnte, z. B. daß die Baufluchten hinter den Straßenfluchten immer um 2 Meter zurückbleiben müßten, etwa so wie in Baugesetzen bestimmt wird, daß nur Dreiviertel oder die Hälfte eines Grundstücks bebaut werden darf, was eben für alle Grundstücke grundsätzlich gilt. So etwas kann bei den Fluchtlinienplänen praktisch nicht gemacht werden. Aber es ist eben doch wichtig, daß man bei den Verwaltungsverfügungen - sei es nun eine Einzel- oder Allgemeinverfügung - nicht in erster Linie auf den Personenkreis, sondern darauf abhebt, ob ein bestimmter verwaltungsrechtlicher Sachverhalt gestaltet wird. Ich vermag also mit Bezug auf den sachlichen Gehalt 
keinen Rechtssatz in der Festsetzung von Straßen- und Baufluchten zu erblicken. Es werden hier bestimmte Grundstücke unmittelbar in genau bestimmter und im allgemeinen in ganz verschiedener Weise erfaßt, und es ist da nicht von einer allgemeinen, abgezogenen Regelung von Tatbeständen die Rede. $\mathrm{Daß}$ die jeweiligen Eigentümer erfaßt werden, ist lediglich eine Folgeerscheinung der Rechtsverhältnisse an dem Grundstück; das ergibt aber keinen unbestimmten Personenkreis. Was die Kundmachung betrifft, so ergibt sich, daß, wenn die Festsetzung von Fluchtlinien als Verwaltungsverfügung aufzufassen ist, es genügt, daß sie den Beteiligten bekanntgemacht wird, soweit nichts Besonderes, wie z. B. ortsübliche Bekanntmachung, bestimmt ist; eine Verkündung, wie bei Rechtssätzen, ist nicht erforderlich. Diese Pläne mögen gegenüber sonstigen Verwaltungsverfügungen gewisse Besonderheiten aufweisen. Aber gegenüber einem Rechtssatz überwiegt $m$. E. doch die Verwandtschaft mit einer Verwaltungsverfügung. Es handelt sich - jedenfalls in sachlicher Hinsicht - um eine Sammelverfügung, die im Hinblick auf die einheitliche Zielrichtung der Linienführung als Allgemeinverfügung aufgefaßt werden kann. Im übrigen kann freilich das Gesetz auch eine besondere Form vorsehen, z. B. eine Satzung.

Wenn sodann Herr Obermayer in Ziff. II seiner Leitsätze die Auffassung des Bundesverwaltungsgerichts bekämpft, daß die Bereitstellung von Mitteln im Haushaltsplan eine genügende Rechtsgrundlage für die Gewährung von Finanzbeihilfen, den sog. Subventionen, bildet, weil beim Haushaltsplan die Einzelpläne mit ihren Einzelanforderungen nicht von der förmlichen Gesetzeskraft erfaßt werden, so vermag ich ihm darin nicht zu folgen. Allerdings werden die Einzelanforderungen nicht in das förmliche Haushaltsgesetz aufgenommen und im Gesetzblatt veröffentlicht; aber gleichwohl werden in den Einzelplänen der Verwaltung nur begrenzte Ermächtigungen zur Verwendung der bewilligten Mittel nach bestimmter Richtung gewährt, ohne daß dies nach außen veröffentlicht werden müßte und unbeschadet dessen, daß die Einzelanforderungen von der förmlichen $\mathrm{Ge}$ setzeskraft nicht erfaßt werden. Das zeigt sich insbesondere darin, daß ohne besondere Bestimmung Mittel nicht beliebig auf eine andere Einzelanforderung übertragen oder für sonstige Zwecke verwendet werden dürfen. Die Behauptung aber, daß die Verwaltungsverfügungen - abgesehen von der in der Verfassung oder in Gesetzen der Verwaltung erteilten allgemeinen Ermächtigung zum Handeln - jeweils einer besonderen Rechtsgrundlage in einem förmlichen Gesetze bedürfen, trifft nach deutschem Recht wohl für die belastenden Verwaltungsver- 
fügungen zu, nicht aber in gleicher Weise für die begünstigenden, wie gerade für die Finanzbeihilfen.

Winkler: Die Thesen, die von den beiden Referenten vorgetragen worden sind, widerstreiten einander anscheinend. Und zwar sagt Herr Imboden, daß der Plan ein Verwaltungsakt sui generis ist, ein Typus des Verwaltungsakts in einem weiteren Sinne. Herr Obermayer hingegen löst den Plan in verschiedene rechtliche Formen auf, obwohl er ihn nach einem sehr reichhaltigen Anschauungsmaterial doch in e in e $n$ Begriff zusammengefaßt sieht. Irgendwie scheinen sich aber diese beiden entgegengesetzten Standpunkte dennoch zu begegnen. Angesichts dessen erinnere ich mich an die Ausführungen Tezners in seinem Administrativverfahren. Tezner hat in dieser Arbeit verschiedene Typen des Verwaltungsakts in ganz außerordentlicher Vielfalt nach durchaus heterogenen Gesichtspunkten geschildert. So hat er z. B. die Beurkundungen, die Verordnungen, die Mitteilungen, die Gestaltungen, die Verfügungen, die Bescheide, die Polizeiverwaltungsakte usw. aufgezählt. Die Gesichtspunkte der Typisierung haben durchaus unterschiedliche Qualität. Einmal sind es Gesichtspunkte des Inhaltes, zum anderen Gesichtspunkte der Erscheinungsform, dann aber auch Gesichtspunkte der Funktion, aber auch solche des Urhebers. Tezner unterscheidet, ohne eigentlich seiner Unterscheidung eine gemeinsame Unterscheidungsbasis zugrundezulegen.

Mit diesem Hinweis möchte ich aber nicht sagen, daß von einem einheitlichen Typus „Plan“ nicht gesprochen werden darf, sondern nur darauf hinweisen, daß man, stellt man den Plan als einen Typus sui generis heraus, auf den Betrachtungsgesichtspunkt besonders achthaben muß. Der äußeren Erscheinungsform nach weist der Plan zweifellos Eigenheiten auf. Er liegt eben nicht im üblichen sprachlichen Ausdruck vor, sondern in einer lineargeometrischen Beschreibung. Auch seine Funktion zeigt bestimmte Eigenheiten, die eigentlich nur ihm zukommen. Die rechtlichen Auswirkungen des Plans hingegen sprengen diese Einheit der äußeren Erscheinungsform, wie Herr Obermayer sehr schön gezeigt hat. Ein Plan kann nämlich, auch vom österreichischen Recht her gesehen, durchaus die Rechtswirkungen einer Verordnung, also einer Norm oder eines Rechtssatzes, er kann aber auch die Rechtswirkungen eines Verwaltungsakts im engeren Sinne haben. Der Plan kann aber darüberhinaus genauso als Verwaltungsverordnung qualifiziert und er kann auch als bloße unverbindliche Mitteilung angesehen werden. Der Plan entfaltet demnach, so scheint mir, keine ihm spezifisch, d.h. ihm allein eigene Art von Rechtsverbindlichkeit, er kann nur seiner äußeren Erscheinung nach, nicht seiner 
Funktion nach, nicht seinen Rechtswirkungen nach oder der Rechtsverbindlichkeit nach als eigener Typus betrachtet werden.

Und nun noch eine Bemerkung am Rande. Rechtssatz und linear-geometrische Bauplanung sind keine echten Gegensätze, weil die Vergleichbarkeit fehlt. Das liegt auf derselben Linie wie die Typologie Tezners. Der Gegensatz ist vielmehr: wörtlicher, sprachlicher Ausdruck einerseits und linear-geometrische Zeichnung andererseits. Daher ist vielmehr zu fragen, ob überhaupt und wenn ja, welcher normative Sinn dem Plan abgewonnen werden kann, obwohl oder weil er uns im lineargeometrischen Erscheinungsbild entgegentritt. Erst dann wäre eine Gegenüberstellung mit dem Rechtssatz möglich. Bloß deshalb, weil der Plan in dieser Erscheinungsform auftritt, kann man nicht sagen, daß ihm die normative Eigenschaft fehlt. Außerdem darf der Plan wohl nicht ganz isoliert für sich allein betrachtet werden, sondern er muß einerseits im Zusammenhang mit den ihn determinierenden Rechtssätzen gesehen werden und andererseits im Zusammenhang mit dem Sachbezug der Materie, in der er steht und für die er Aussagen abgeben soll. Von dorther werden sich dann zusätzliche Kriterien finden lassen, die für den Plan nach seinen Rechtswirkungen die Zuordnung zur Verordnung, zum Bescheid oder Verwaltungsakt im engeren Sinn oder zu anderen Typen verwaltungsmäßigen Handelns ermöglichen.

Ipsen: Zu dem ersten Punkt der Diskussion nenne ich das Stichwort einer möglichen Typologie der Pläne und knüpfe ich zunächst an die ersten Bemerkungen von Herrn Forsthoff an. Wir haben nach den Referaten unseren Blick im wesentlichen konzentriert auf die Bodenordnung, die Grundordnung und die Stellung des Eigentümers oder des Gewerbetreibenden, die sich im Zusammenhang mit dem Boden entfaltet. Ich frage mich ebenso wie Herr Forsthoff, ob wir bei der Betrachtung des Plang nicht über diesen engen, sachlichen Bereich und auch den des Verwaltungsrechts hinausgreifen müßten. Es wird ja auch "geplant" (zeitlich bemessen) zur Bewältigung bestimmter öffentlicher Aufgaben, sagen wir: der Versorgung. So dient, um nur ein Beispiel zu nennen, der Beschaffung des nötigen Brotgetreides unsere Getreidegesetzgebung mit allem, was damit zusammenhängt, angefangen von der Preisfestsetzung oder weiteren Beschränkungen bis zur regulierten Offfnung von Importschleusen mit Kontrollen zur Anhebung oder Absenkung der Preise, mit einer hoheitlich planenden Apparatur, die den daran Beteiligten (den Landwirt, den Importeur, den Händler), grundrechtlich gesprochen, in seinen Rechten aus den Artikeln 2, 12 und 14 berühren kann. Hier gibt es Zusammenhänge mit 
dem Plan, der den Grund und Boden betrifft. In dem Augenblick, in dem eine „Einplanung“ oder „Verplanung" stattfindet (man nennt sie ja z. T. sonst „Planfeststellung“), werden alle, die mit ihrer beruflichen Funktion, mit ihrer Stellung als Grundeigentümer oder sonstwie davon tatbestandsmäßig erfaßt werden, durch die Verplanung in eine Art rechtlicher "Schicksalsgemeinschaft" eingeordnet. Diesen ersten entscheidenden Akt sollten wir besonders ins Auge fassen, und seine Justitiabilität wird die entscheidenden Fragen aufwerfen. Sie müssen unterschieden werden von den späteren Auswirkungen z. B. für den einzelnen Baulustigen, der dann, nachdem er "verplant" worden ist, feststellt, er dürfe nur zweigeschossig oder hier gar nicht bauen, weil ein Kinderspielplatz, eine Freifïche entstehen soll. Für ihn muß dann seine spätere Betroffenheit ermittelt und gefragt werden, ob er gegenüber der Versagung des Baubescheides Rechtsmittel bei den Verwaltungsgerichten ergreifen oder liquidieren darf, weil ihn ein Schaden trifft. Er befindet sich dann aber bereits in der vorher vollzogenen Einplanung und Verplanung. Dieser erste Akt (um die Grenzen seiner Justitiabilität $\mathrm{zu}$ erfassen) wird uns im wesentlichen im letzten Punkt unseres Diskussionsprogramms beschäftigen. Das hängt damit zusammen, daß es Sinn und Zweck des Plans ist, nivellierend zu wirken und die Besonderheiten, die der einzelne in seiner Grundstückslage aufweist, dem Planzweck unterzuordnen. Wenn davon gesprochen worden ist - ich glaube, von beiden Referenten -, der Plan bewirke per se die nivellierende Verplanung, nur potentiell Ungleichbehandlung und Differenzierung, dann ist das genau das, was ich dem Wesen dieses Vorgangs entnehmen möchte. Die Betroffenen befinden sich nun einmal im Nexus dieser Verplanung und sind ihr unterworfen, wobei es mir unter Eigentumsgesichtspunkten nicht schwerfällt, die gedankliche Brücke zu schlagen zu Formen einer Art „Vergemeinschaftung" des Eigentums unter Vorstellungen, die zwar nicht gerade in Art. 15 GG unterzubringen sind, diesen Vorgang der Verplanung das Eigentum aber doch als einen solchen der Gemeinschaftsordnung charakterisieren.

Peters: Wir gehen davon aus, als ob der Plan primär aus juristischen Gründen aufgestellt werde; er dient aber den allerverschiedensten Stellen dazu, sich in irgendeiner Weise auf ein bestimmtes kommunales oder politisches Ziel zu koordinieren. Der Plan hat gewöhnlich finanzielle Bedeutung. Zunächst wird rein formal das Ziel, das man erreichen will, herausgestellt. Es wird herausgearbeitet, welche technischen Mittel dazu erforderlich sind. Bei den Zeitplänen ist die Zeit der pri- 
märe Maßstab, während sonst bei den anderen Plänen die Zeit auch ein Falktor sein kann. Wenn man z. B. einen Universitätsplan für den Aufbau einer Universität aufstellt, so wirken, auch soweit es keine Zeitpläne sind, zeitliche Momente hinein. Man will etwa in 10 Jahren bestimmte Institute aufbauen. Dann kommt die Finanzplanung, und schließlich folgt die Bodenplanung, und gerade bei der letzteren können die Rechte Dritter beeinträchtigt werden. Wir Juristen müssen uns von der Vorstellung freimachen, als ob der Plan in erster Linie zum Gegenstand habe, wie Eingriffe in die Rechte Dritter irgendwie vorgenommen oder verhindert werden sollen. Diese Fragen sind eigentlich das, was, vom Plan aus gesehen, letztlich nebenher mit dranhängt. Ich habe daher Bedenken dagegen, daß man von den Eingriffen her die ganzen Fragen des Plans als Verwaltungsinstitut aufwirft. Sicher, es gibt Entschädigungsansprüche, es muß irgendwelche Rechtsbehelfe geben; denn auch der Plan bewegt sich im Rechtsstaat und kann daher nicht einfach über fremde Rechte hinweggehen. Aber wir müssen wirklich doch zuerst klar herausstellen, was das Wesen des Plans ist, und das ist m.E. ungefähr richtig von Herrn Kollegen Obermayer definiert worden. Der Plan besteht darin, da $B$ er Richtlinien für zukünftige Maßnahmen der Behörden enthält, daß durch ihn die Koordinierung verschiedener Maßnahmen innerhalb der Verwaltung erfolgt, daß die Zeit irgendwie als ein das Ganze zusammenfassender Faktor auftritt und daß letztlich die zugrundeliegenden bestimmten politischen Bewertungen ins Spiel gebracht werden. Man will z. B. Wohnungen bauen und entscheidet sich bereits durch den Plan für oder gegen Eigenheime. So werden, das wurde noch nicht gesagt, nun auch die verschiedenen politischen Wertmaßstäbe eingeplant. Ich glaube, daß der Jurist, dem es darauf ankommt, nachher die Rechte des Einzelnen sicherzustellen, erst in zweiter Linie auf das Planungsgeschäft einzuwirken berufen ist.

Forsthoff: Das scheint mir eigentlich das Aufregende an der Sache zu sein: daß alles, was innerhalb der Planung geschieht, schließlich auch der ergehende, den einzelnen betreffende Verwaltungsakt, in einem kontinuierlichen Ablauf steht. Das unterscheidet etwa den Plan von der Bauverfügung; diese bleibt eine bestimmte Zeit bestehen, aber unverändert. Das Planungsgeschehen geht bei uns deduktiv vor sich. Beim größeren Raum fängt es an, etwa bei der Landesplanung, und es verengt sich dann bis zum Ortsbebauungsplan. Das Ganze aber ist ein kontinuierliches Geschehen, in das Herr Obermayer nach dem geltenden Recht durchaus zutreffend die Zäsur der unverbindlichen und der mit Außenwirkung ausgestatteten 
Pläne hineinlegt. Diese Zäsur machen wir als Juristen; ob wir sie mit gutem Gewissen machen können, ist die Frage. Aber da steckt das Problem; denn in den unverbindlichen Flächennutzungsplänen, Generalbebauungsplänen usw., liegen schon die Vorgriffe, die alles Weitere, Spätere bestimmen. Es scheint mir das Fundamentalproblem des ganzen Rechtsschutzes zu sein, daß er meistens zu spät kommt. Unsere etwas mechanische Zäsur zwischen Innenwirkung, bei Flächennutzungsplänen und beim Generalbebauungsplan usw. einerseits und dem Ortsbebauungsplan mit Außenwirkung andererseits ist dogmatisch vielleicht noch ganz schön, aber unter dem Gesichtspunkt des Rechtsschutzes ist sie höchst problematisch.

Und dann das zweite. Darf ich noch eine Frage an Herrn Obermayer stellen? Mir ist nicht ganz klar geworden, Herr Obermayer, Thre Unterscheidung innerhalb der Rechtsnatur der Bebauungspläne, zwischen den Einzelakten, von denen Sie sagen, daß sie sich nur an bestimmte Personen richten und deren Rechtsnachfolger, und den Rechtsnormen. Haben Sie das abgehoben aus dem bayer. Baurecht, wo man das vereinfachte Fluchtlinien- und Baulinienfestsetzungssystem ohne Auslegung und ohne öffentliche Mitteilung durch Zustellung an die Eigentümer kennt, und den anderen Fall: der publizierten satzungsmäßigen Festlegung?

Obermayer: Ja, darauf habe ich abgestellt.

Forsthoff: Mir ist der Unterschied nicht klar. Ich sehe keinen Unterschied in der Rechtswirkung, ob eine Baulinie durch Einzelakt oder durch Satzung festgelegt wird. Für das betroffene Grundstück ist die Rechtslage in jedem Falle die gleiche. Ich würde meinen, daß die dem Grundstück auferlegte Bindung in jedem Falle eine öffentliche Last ist. Ich habe bis heute noch nicht begriffen, warum diese Bindung generell sein soll. Sie unterscheidet sich doch in nichts von einer eingetragenen Servitut, die ebenso gegenüber dem Rechtsnachfolger wie jedem Dritten wirksam ist, die wir aber wegen dieser dinglichen Wirkung nicht als etwas Normatives ansehen. Mit dem Gesichtspunkt des Generellen kann man deshalb m. E. hier nicht operieren. Würden Sie Ihre Unterscheidung noch näher verdeutlichen?

Obermayer: Ich glaube, wir müssen unterscheiden zwischen dem Effekt, der in der Rechtswirklichkeit ausgelöst wird und dem juristisch-technisch gestaltenden Akt, der diesen Effekt auslöst. Es ist möglich, Bauverbote normativ festzulegen, etwa durch Naturschutz- oder Landschaftsschutzverordnungen, die es jedermann verbieten, in einem bestimmten Gebiet zu bauen. 
Dann wird der Effekt „Bauverbot" erreicht durch eine Norm. Es ist aber genauso gut möglich, daß dieser gleiche Effekt durch einen Verwaltungsakt erreicht wird. Das ist dann der Fall, wenn eine Verwaltungsbehörde gegenüber einzelnen Grundstückseigentümern ein Bauverbot verfügt auf Grund einer allgemein publizierten Norm, die eine solche Befugnis gewährt.

Mehrere Stimmen: Ein Bebauungsplan in der Form von Einzelverfügungen? Entscheiden soll also die rein formale Unterscheidung zwischen der Einzelzustellung in einem Fall, und dem Erlaß durch Beschluß der Gemeindevertretung im anderen Fall?

Obermayer: Nicht ganz so! Ich gehe davon aus, daß die Bebauungspläne rechtlich ausgeformt wurden in einer Zeit, der unsere heutigen, strengen rechtsstaatlichen Grundsätze fremd waren und die auch nicht die scharfe Unterscheidung zwischen Verwaltungsalkt und Norm kannte. Deshalb möchte ich die Publikation als Indiz für das Vorliegen einer Norm und die Einzeleröffnung als Indiz für das Vorliegen eines Verwaltungsaktes werten. Entscheidend aber scheint mir die Erkenntnis zu sein, da $\beta$ bestimmte rechtliche Wirkungen, die sich für den Betroffenen im Ergebnis gleich auswirken, sowohl durch einen Verwaltungsakt wie auch durch eine Norm erreicht werden können. Die generellen Verbotsnormen und die Einzelverbote, die auf Grund einer Norm ergehen, bedeuten praktisch für den Betroffenen das gleiche. Wenn eine Naturschutzverordnung die Nutzung der Grundstücke in einem bestimmten Gebiet untersagt, dann wirkt sich diese normative Beschränkungsanordnung für den Eigentümer eines Steinbruchs genau so aus, als wenn ihm durch Verwaltungsakt auf Grund einer Norm die Nutzung untersagt worden wäre.

Ule: Ich habe doch Bedenken dagegen, daß das Thema durch die Bezeichnung „Der Plan als verwaltungsrechtliches Institut“ in gewisser Weise, und zwar in doppelter Hinsicht, möchte ich sagen, verengt worden ist, da mir scheint, als ob dadurch der Zugang zum Wesen des Plans erschwert wird. Einmal fragt man sich bei dieser Beschränkung auf das verwaltungsrechtliche Institut, was denn überhaupt der Gegensatz dazu ist. Ich würde etwa den „Grünen Plan“ oder die „Vierjahrespläne“ und dgl. nicht unbedingt als Gegensatz zu einem verwaltungsrechtlichen Institut verstehen können. Aber die entscheidende Frage ist, glaube ich, die, daß hier von einem Rechtsinstitut die Rede ist, und insofern möchte ich das, was Herr Peters ausgeführt hat, noch etwas schärfer zum Ausdruck bringen. Ist der Plan nicht 
im Grunde genommen ein v or rechtliches und $a \mathrm{u} B$ e $\mathrm{r}$ rechtliches Institut, das nur in einer ganz bestimmten Situation ver rechtlicht wird? Ich meine, jedes Verwaltungsgesetz, soweit es sich nicht um Organisationsnormen, Verfahrensnormen und dgl. handelt, will doch einen Plan verwirklichen, auch wenn dieser Plan nicht in irgendwelchen Rechtssätzen festgelegt ist. Und wenn beispielsweise ein Staat sich dazu entschließt, eine Wehrmacht aufzustellen, oder wenn für die Erziehung der Jugend ein ganz bestimmter Plan aufgestellt wird (der Bundes-Jugendplan ist bisher noch nicht genannt worden), dann muß man sich doch die Frage stellen, wie dieser Plan nun verwirklicht werden kann, und das heißt im Rechtsstaat mit rechtlichen Mitteln. Das ist ein Sonderproblem unserer staatsrechtlichen Situation, aber wohl kein allgemeines Problem des Planes. Im Rechtsstaat erfolgt die Verwirklichung des Plans dann im Wege der Norm oder durch Einzelakte auf Grund einer Norm. Würde man den Anschauungsbereich noch weiter ziehen, als das hier geschehen ist, und würde man sich von den Bauplänen stärker lösen, so käme wohl der Gesichtspunkt sehr viel mehr heraus, daß der Plan das erste ist und daß alles weitere aus der Notwendigkeit, den Plan auszuführen, folgt. Diese Notwendigkeit erfordert es im Rechtsstaat, Rechtssätze zu erlassen. Also mir scheint, daß man im Plan nicht nur ein verwaltungsrechtliches Institut sehen sollte, sondern ein, im Grunde genommen, technisches Institut, ein Verwaltungsinstitut, wenn Sie wollen.

Bachof: Ich möchte nochmals auf die Frage zurückkommen, die Herr Forsthoff eben an Herrn Obermayer gestellt hat und die ich hiermit, anders formuliert, ebenfalls stelle. Herr Obermayer hat in seinen Leitsätzen - II, $5, \mathrm{~b}(2), \mathrm{a}, \mathrm{bb}$ - ausgeführt: „Der Bebauungsplan enthält E i n z e l a k te (Verwaltungsakte), wenn sich die Festsetzung der Baulinien nur an diejenigen Personen richtet, die im Zeitpunkt der Festsetzung die Verfügungsmacht ... besitzen". Er hat das, wenn ich mich recht erinnere, heute morgen mündlich dahin erläutert: es handele sich dann um einen Verwaltungsakt, wenn dem Festsetzungsbescheid „dingliche“ Wirkung zukomme, wenn er also auch gegenüber den Rechtsnachfolgern gelte und sozusagen eine öffentliche Last auf das Grundstïck lege. Nun die - bewußt überspitzte - Frage: Wenn ich sage, „Es wird d i e $\mathbf{s}$ e $\mathrm{m}$ derzeitigen Eigentümer d i e $\mathrm{s}$ e $\mathrm{s}$ Hauses verboten, anders als so (d. $h$. anders als nach Maßgabe der ihm gegenüber festgesetzten Baulinie) zu bauen; dies Verbot gilt aber mit dinglicher Wirkung, d. h. auch gegenüber den Rechtsnachfolgern" - so soll das ein Verwaltungsakt sein? Wenn ich aber 
sage: „J e d e m (auch künftigen) Eigentümer dieses Grundstücks wird verboten, anders als nach Maßgabe der Baulinie zu bauen" - so wäre dies, wenn ich Sie recht verstanden habe, eine Verordnung? Dann würde man die Unterscheidung zwischen Norm und Verwaltungsakt also lediglich von der mehr oder minder willkürlichen und beliebigen, im Effelkt doch völlig gleichen Formulierung abhängig machen (Zwischenruf: Frist!). Frist? Ob ich sage, ,mit dinglicher Wirkung, und also auch mit Wirkung gegen jeden Rechtsnachfolger", oder ob ich sage, „mit allgemeiner Wirkung gegen jeden, der einmal bauen will: das bedeutet im einen wie im anderen Falle eine unbegrenzte und unbefristete Wirkung. Somit würde es lediglich von der Formulierung abhängen, ob eine Maßnahme als Verwaltungsakt oder als Norm zu qualifizieren ist; und von dieser Formulierung allein würde es abhängen, ob ich etwas als Norm publizieren muß oder ob ich es als Verfügung einzeln zugehen lassen kann. Diese Konsequenz, die sich mir aus Herrn Obermayers Ausführungen- falls ich ihn richtig verstanden habe - zu ergeben scheint, würde mir nicht einleuchten.

Obermayer: Darf ich nochmals auf das Beispiel vom Steinbruch zurüickkommen. Es ist doch möglich, daß durch Verwaltungsakt dem Eigentümer des Steinbruchs, Herrn A, gesagt wird, dieser Steinbruch darf nicht mehr genutzt werden. Aber auf der anderen Seite gibt es Naturschutzverordnungen, die generell die Nutzung in einem bestimmten Raum untersagen. Dann ergibt sich für Herrn A als Eigentümer des Steinbruchs die gleiche Folge: er kann seinen Steinbruch nicht mehr nutzen. So ist es auch bei der Feststellung der Zulässigkeit einer Enteignung. Regelmäßig wird sie durch Verwaltungsakt gegenüber den derzeitigen, an einem (Plan-) Verfahren beteiligten Grundstückseigentümern vorgenommen. Auf der anderen Seite kennt das preußische Fluchtliniengesetz die normative Zulässigkeitsfeststellung der Enteignung. Sind die Fluchtlinien festgesetzt, dann ist auch für alle künftigen Grundstückseigentümer die Zulässigkeit der Enteignung insoweit festgestellt.

Bachof: Wenn ich darauf kurz erwidern darf: Es ist nicht zu bestreiten, daß man mit dem Verwaltungsakt oft die gleichen Wirkungen erzielen kann wie durch die Norm. Die Frage ist nur, ob man ledigli ch nach der Formulierung etwas beliebig bald als Norm und bald als Verwaltungsakt gestalten kann, obwohl es im einen wie im anderen Fall völlig denselben Adressatenkreis, völlig denselben Sachgegenstand, völlig denselben Zeitpunkt betrifft. (Zwischenruf: $\mathrm{N}$ i cht denselben Adressatenkreis!) Ob ich sage „Eigentümer Müller und alle seine 
potentiellen Rechtsnachfolger", oder ob ich sage, ,jeder, dem das Grundstuick einmal gehört", das is t doch derselbe Adressatenkreis !

Obermayer: Ich möchte nicht sagen, Herr Müller und seine Nachfolger, sondern das Grundstück des Herrn Müller, mit der Folge, daß der Nachfolger es mit dieser Last übernimmt.

Bachof: Oder auf der anderen Seite: „jeder, der dieses Grundstuick besitzt". Natürlich kann ich entweder sagen: „das Grundstü ck darf nicht bebaut werden"; oder ich kann sagen: „jeder Ei g e n $t$ ü m er des Grundstücks darf es nicht bebauen". Aber auch das ist doch kein wirklicher inhaltlicher Unterschied, sondern eben wieder nur ein Unterschied in der Formulierung.

Obermayer: Ich möchte aus der Form auf die Sache schließen. Nach der bayer. Bauordnung werden die derzeitigen Grundstückseigentümer beigeladen, ihre Grundstücke mit den Nummern werden auf dem Plan festgehalten.

Merk: Ich möchte doch nochmals wiederholen, daß mir das Wesentliche an einer Verwaltungsverfügung darin zu liegen scheint, daß ein bestimmter gegebener Sachverhalt verwaltungsrechtlich gestaltet wird. Und dies geschieht bei Fluchtlinienplänen mit Bezug auf genau bestimmte Grundstücke. Und wenn auch die betreffende Verwaltung hierbei weitere Zwecke verfolgt, nämlich einheitliche Gestaltungen der Straßen- und Baufluchtlinien, so wird doch unmittelbar in seinem Rechtskreis nur der einzelne Eigentümer mit Bezug auf sein Grundstück betroffen, und zwar jeweils in besonderer Weise. Daß es sich also dem Wesen nach um eine Verwaltungsverfügung handelt, das ergeben auch bestimmte Baugesetze, wie z. B. die bayerische Bauordnung von 1901, die württ. Bauordnung von 1910 und das badische Ortsstraßengesetz von 1908. Da wird nicht nur gesagt, $\mathrm{da} ß$ die Beteiligten vor der endgültigen Planfeststellung zugezogen werden, sondern auch, da $\beta$, wenn der Ortsbauplan endgültig festgestellt und damit wirksam geworden ist, das die Wirkung hat, daß von diesem Zeitpunkt ab diese Fluchten für die betreffenden Grundstücke, die in diesen Bebauungsplan hineinfallen, maßgebend sind. Das ist also eine unmittelbare Rechtswirkung, wie wir das beim Rechtssatz so nicht sehen; da handelt es sich um die Regelung von Tatbeständen allgemeiner Art, die sich möglicherweise in der Zukunft im Einzelfalle verwirklichen können. Diese Unterscheidung ist von grundlegender Bedeutung auch für die Frage des Rechtsschutzes, wovon noch die Rede sein wird. 
Winkler: Das Beispiel des Herrn Obermayer vom Steinbruch scheint nach den Ausführungen von Herrn Professor Forsthoff zu zeigen, da $B$ eigentlich in den rechtlichen Auswirkungen zwischen den beiden Fällen kein erheblicher Unterschied ist. Vom österreichischen Recht her gesehen, liegt gewiß auch nur ein Unterschied im Adressaten vor; das ist aber doch ein ganz wesentlicher Unterschied, denn mit ihm ist der Rechtsschutz verbunden. Vom Rechtsschutz her gesehen, erlangen diese Merkmale ganz wesentliche Bedeutung. Wenn Herr X als Grundstückseigentümer angesprochen ist, dann hat er die Möglichkeit, den administrativen Instanzenzug zu erschöpfen und eine Verwaltungsgerichtsbeschwerde einzubringen; sein Rechtsnachfolger hat kein Rechtsmittel mehr, wenn und weil der Rechtsvorgänger darauf verzichtet hat. Wenn hingegen eine Verordnung erlassen wird, also wenn der Grundstückseigentümer durch das Gattungsmerkmal "Grundstückseigentümer" angesprochen wird, dann hat er nach österreichischem Recht von vornherein kein Rechtsmittel. Das ist ein ganz wesentlicher Unterschied, der festgehalten werden muß. Zur Illustration dieser Frage ein Beispiel aus dem Flurverfassungsrecht. Im Flurverfassungsgesetz wurde für die Grundstückszusammenlegung verfügt, daß Pläne für die künftige Gestaltung der neuen Ordnung der Grundstücke aufgelegt werden. Die Auflegung der Pläne hat für sich allein keine Rechtsverbindlichkeit. Sie ist eine bloße Mitteilung. Zur Verbindlichmachung des Planes bedarf es noch für jeden Einzelnen der bescheidförmigen Vorschreibung mit dem Hinweis auf den Zusammenlegungsplan. Dadurch wird der Zusammenlegungsplan zum mittelbaren Bescheidinhalt und erlangt erst auf diese Weise Rechtsverbindlichreit. Man hat also die generelle Form der verbindlichen Verordnung vermieden, und dafür den Weg der individuellen Mitteilung gewählt, obwohl im Endeffekt die Auswirkungen dieselben sind, obwohl also auch jeder Grundeigentümer, der Rechtsnachfolger eines erstbetroffenen Grundeigentümers wird, daran gebunden ist. Bei alledem steht die Frage der unmittelbaren Bekämpfbarkeit im Vordergrund. Das ist auch ein Argument dafür, daß man doch die rechtlichen Aspekte des Fragenkomplexes „Plan" nicht in den Hintergrund drängen soll. Ich bin keineswegs dagegen, den Plan etwa funktionell zu definieren und außerrechtlich zu untersuchen, zu klassifizieren und zu qualifizieren. Aber von der rechtlichen Seite her ist der Plan kein eigener Typus, sondern er erlangt nur Wirksamkeit in den typischen Formen unserer Rechtsordnung.

Pfeifer: Das Thema lautet: „Der Plan als verwaltungsrechtliches Institut", aber die Behandlung hat den Plan vielleicht 
noch etwas weiter gefaßt. Ich würde sagen, der Plan, ganz allgemein definiert, wie es etwa Herr Obermayer zunächst getan hat, ist ein Institut, das vielleicht der Verwaltungslehre angehört. In dem Augenblick, wo er mit irgendwelchen Rechtswirkungen verbunden ist, sei es bloß interner Natur - das ist anläßlich von Anordnungen, die für die ausführende Verwaltung rechtsverbindlich sind - oder sogar nach außen mit rechtsbegründer Natur, tritt er ins Verwaltungs $\mathrm{recht}$. Mit der Wirkung auf das Verwaltungsorgan oder auf den einzelnen Bürger ist er eben ein Institut des Verwaltungsrechts. Je nachdem, was wir im Auge haben, müssen wir dieses Institut eben auch verschieden behandeln. Ich meine, wenn wir von der Rechtsnatur des Planes hier bei Punkt 1 sprechen, so können natürlich nur rechtsverbindliche Pläne verstanden sein; dabei ist aber hier noch der, ich möchte sagen, vorbereitende Plan zu erwähnen, der wie etwa der wasserwirtschaftliche Rahmenplan des österreichischen Wasserrechts eine wasserwirtschaftliche Ordnung herstellen soll und dessen Verwirklichung als im öffentlichen Interesse gelegen anerkannt ist, ohne daß die Verwaltungsorgane nun verpflichtet wären, in allen einschlägigen Verfahren nur nach diesem Plan, starr daran gebunden, vorzugehen; vielmehr sagen die Erläuterungen ausdrücklich, daß es nur ein Rahmen ist, von dem im Einzelfall die Sachverhaltswuirdigung auch zur Abweichung führen kann. Erst ein weiteres Stadium, das im Gesetz als wasserwirtschaftliche Rahmenverfügung bezeichnet wird, die durch Verordnung erlassen wird, bewirkt, daß das, was im Rahmen dieses Vorbereitungsplanes entwickelt wird, umgewandelt wird in etwas, was für den einzelnen unmittelbare Wirkungen rechtsbegründender oder rechtsbeschränkender Art hat. Man kann daher keine allgemeingültige Aussage über den Plan überhaupt machen, sondern es kommt darauf an, um welchen Zweck des Planes es sich handelt, wenn wir sein Wesen jeweils richtig erfassen wollen und je nachdem wird vielleicht auch zu unterscheiden sein, ob in dem einen oder anderen Falle ein Rechtsmittel gegeben ist oder nicht.

Friesenhahn: Ich möchte davor warnen, das Thema im Sinne der Herren Ule und Forsthoff allzusehr auszuweiten. Ich finde die Entscheidung des Vorstandes eigentlich sehr glücklich, daß das Thema auf den Plan als Institut des Verwaltungsrechts eingeengt worden ist. Mir hat das Referat von Herrn Imboden gezeigt, $\mathrm{da} \beta$ er als solcher abgrenzbar ist und uns vor eine Fülle von ganz neuen Problemen stellt. Das für mich erregende Referat von Herrn Imboden, der sozusagen von oben in das Thema eingestiegen ist und nicht mit den $\mathrm{m}$. E. zweitrangigen formalen Unterscheidungen begonnen hat, hat mir klar gemacht, 
daß der Plan, so wie er ihn als Institut des Verwaltungsrechts faßt, uns vor ebenso interessante wie schwierige Fragen stellt. Darauf sollten wir uns konzentrieren und nicht ins Uferlose übergehen. M. E. sind Fünfjahrespläne, Grüner Plan, Regierungsprogramme u. dgl. etwas ganz anderes wie Pläne, die unmittelbare oder wenigstens mittelbare Wirkung für den Betroffenen haben. Herr Imboden hat auch damit eine ganz klare Grenze gezogen, daß er sagte, Planung sei stets Verfügung über eine zur Ganzheit verschmolzene Summe von Gütern, eine Parallele zu Herrn Ipsens etwas erweiterndem Begriff der rechtlichen Schicksalsgemeinschaft. Ich möchte aber nun Herrn Peters widersprechen, der den Plan verharmlosen möchte, indem er von der reinen Technizität der Planung spricht und damit etwas beiseite schiebt, was Herr Imboden und auch Herr Ipsen richtig herausgestellt haben, daß nämlich schon zu Beginn der Einplanung, Verplanung, sofort die rechtliche Auswirkung auf den Kreis der Betroffenen einsetzt. Das Wichtige, was Herr Imboden herausgestellt hat, dürfte doch sein, zu prüfen, ob der Planer nicht schon bei der Aufstellung seines Plans an gewisse faßbare Rechtsgrundsätze gebunden ist, damit nicht sozusagen die gesamte Gütermasse den Dispositionen eines nach Ermessen handelnden Planers unterstellt bleibt. Darin sehe ich die Gefahr Threr These, Herr Peters, die mir etwas von dem Interesse des Kommunalpolitikers diktiert zu sein scheint. Der möchte immer gern über die Gesamtmasse möglichst frei verfügen! Mir scheint, da $B$ demgegenüber Herr Imboden mit Recht stärkeres Gewicht darauf gelegt hat, wie man den Planer eingrenzen kann, weil der Plan eben sehr weitgehende rechtliche Wirkungen auslöst.

Forsthoff: Ich möchte Herrn Friesenhahn durchaus zustimmen, der mich offenbar mißverstanden hat, wenn er glaubt, daß ich alle möglichen Pläne wie den Vierjahresplan und den Jugendplan in die Problematik hineinziehen möchte. Ich möchte im Gegenteil dafür plädieren, daß der Plan ein verwaltungsrechtliches Institut in einem konkreten Sinne ist oder wenigstens dahin entwickelt werden muß. Das Stichwort dafür ist schon im Referat von Herrn Imboden gefallen. Das spezifische Element des Planes ist die Koordination von Interessen und Rechtslagen. Gegenstand der Koordination sind die Rechte und Interessen Dritter und des Planträgers selbst. Diese Dritten brauchen nicht Private zu sein, wie die Planfeststellung der Bundesbahn zeigt, die sich auch auf Rechtsverhältnisse an öffentlichen Straßen, Wasserläufen usw. erstreckt. Erlauben Sie mir einen Vorgriff auf Punkt 4. Mir wird immer klarer, daß der normale Rechtsschutz, weil der Plan im Ablauf einer unter Umständen erheblichen Zeitdauer steht, in der Regel zu spät 
kommt. Deshalb werden wir unser Interesse mit besonderem Nachdruck dem Planfeststellungsverfahren zuwenden müssen. Mir scheint, daß das Planfeststellungsverfahren eine viel größere Bedeutung gewinnen muß und auch wird, als es zur Zeit noch hat. Auf diesem Gebiet besteht zur Zeit noch eine Rechtszersplitterung, die wir uns auf die Dauer nicht mehr leisten können. Wir haben Enteignungsgesetze mit und ohne Planfeststellungsverfahren (z. B. Bayern) und auch die einzelnen Verfahren weisen Unterschiede auf, die noch nicht genügend beachtet sind und vielleicht auch diese Materie unnötig komplizieren. Jedenfalls führen wir den Rechtsschutz noch am besten zum Siege, wenn wir ihn in der frühesten Phase des Planungsgeschehens, also bei der Planfeststellung, wirksam werden lassen.

Bachof: Auch mir hat von den Ausführungen dieses Vormittags den stärksten Eindruck gemacht, daß das entscheidende Element des Planes eben diese Koordinierung, diese Herbeiführung einer rechtlichen Schicksalsgemeinschaft ist; das Inbeziehungsetzen einer größeren Zahl von Grundstücken, von Eigentümern, von anderen Beteiligten, privaten Beteiligten sowohl wie öffentlichen Institutionen. Das bedingt notwendig, daß der Plan an eine größere Zahl von Beteiligten gerichtet wird, jedenfalls nicht nur an ganz wenige Adressaten; und dies, scheint mir, hat er mit der N o r m gemeinsam. Eine Baulinienfeststellung etwa in einem bisher völlig unverplanten Gebiet, von der nur e in einzelnes Grundstück betroffen würde, das wäre ja doch kein Plan, sondern im Gegenteil das Musterbeispiel eines "planlosen" Vorgehens. Erst durch das Inbeziehungsetzen zu anderen Grundstücken wird das zum „P l a n“. Wenn ich freilich bei einem vorhandenen Plan die Linie e ines Grundstücks ändere, vielleicht gerade mit Rücksicht auf die anderen Linien, dann ist das ein Teilplan oder eine Änderung eines Plans; aber is o lier $t$ betrachtet, wäre eine solche Baulinienfestsetzung niemals ein Plan. Ich meine also: Daß der Plan sich an vi e le wendet, das hat er mit der Norm gemein. Aber er u n t e r s ch eide t sich zugleich von der Norm. Denn die Norm ist, wie Herr Imboden richtig dargelegt hat, vom Grundsatz formaler Gleichheit und Gleichbehandlung geprägt; während der Plan jeden einzelnen, der in die rechtliche Schicksalsgemeinschaft eingeschlossen ist, individuell, speziell und verschieden behandelt und behandeln $\mathrm{m} u \mathrm{~B}$, wenn der Plan seinen Zweck und sein Ziel erreichen soll. Eben hierdurch unterscheidet sich der Plan von einer Norm und nähert sich, sagen wir einmal, einer Summe von Einzelverfügungen (Verwaltungsakten). Aber ich möchte sagen, er ist doch zugleich mehr als das und nicht nur eine Summe von Verwaltungsakten; denn summierte Einzel- 
verfügungen $k$ ö $n \mathbf{n}$ e zwar in einer gewissen logischen und sachlichen Beziehung zueinander stehen, sie brau chen es aber nicht zu tun. Bei der "Summe" der Verfügungen, die im Plan zusammengefaßt sind, stehen alle diese Verfügungen jedoch in einer notwendigen Beziehung zueinander. Dadurch unterscheidet der Plan sich grundlegend von einer bloßen Summe von Einzelverfügungen. Mir scheint, dieses charakterisierende Element macht den Plan doch wohl zu einem aliud. Er ist einerseits weder Einzelverfügung noch eine bloße Summe von Einzelverfügungen, andererseits aber auch keine Norm. Infolgedessen neige ich nach wie vor dazu zu sagen: Man kann den Plan nicht in seine Elemente aufspalten; jedenfalls kann man das nicht bei a lle n Plänen. Man kann ihn nicht aufspalten in normative und in Verwaltungsaktelemente; sondern man wird sich dazu bekennen müssen, daß der Plan - ich beschränke mich dabei auf diejenigen Pläne, die Herr Friesenhahn genannt hat - in der Tat etwas anderes ist, was gewissermaßen $\mathrm{z}$ wi $\mathrm{s} \mathbf{c h}$ e $\mathrm{n}$ Norm und Verwaltungsakt steht: ein tertium.

Peters: Darf ich, Herr Forsthoff, eine Frage an Sie richten? Wenn Sie die Tendenz haben, das Feststellungsverfahren möglichst früh in dem ganzen Planverfahren in Gang zu bringen, wo wollen Sie dann bei den mehrfach gestuften Plänen das Feststellungsverfahren ansetzen? Wir haben zunächst im großen den Landesraumplan, dann den Leitplan, dann kommt der Generalbebauungsplan, dann der Bebauungsplan, darauf folgt der Fluchtlinienplan. Je weiter Sie oben anfangen, um so mehr halten Sie unter Umständen durch eine einzige Person ein Jahr oder länger ein Verfahren auf, dessen Dringlichkeit als Ganzes niemand sonst bestreitet.

Forsthoff: Ich bin mir völlig darüber im klaren, daß wir Juristen es nicht verhindern können, daß den Letzten die Hunde beißen. Aber diese Chance möglichst vermindern, das können wir doch dadurch, daß wir einen ganz anderen Akzent auf das Planfeststellungsverfahren legen.

Ule: Ich habe durchaus nicht die Absicht gehabt, mit meiner Bemerkung eine Diskussion über andere Pläne herbeizuführen, wie Herr Friesenhahn angenommen hat, sondern ich habe nur herausheben wollen, daß der Plan eben kein spezifisches Instrument einer rechtsstaatlichen Verwaltung ist, sondern daß er etwas anderes ist. Es gibt ihn ja überall. Jeder Staat, ganz gleichgültig, ob er nun rechtsstaatlich oder anders geordnet ist, wird den Plan haben. Und mir scheint, die Problematik liegt 
gerade darin, daß der Plan sich in die rechtsstaatliche Ordnung nur schwer einfügen läßt. Das ist auch das Anliegen der Referenten gewesen, und ich glaube, es kommt schärfer heraus, wenn man auch diese anderen Dinge mit in die Erörterung einbezieht, als wenn man von vornherein nur bestimmte überlieferte, rechtsstaatliche, doch auch schon durchgeformte Planungen zum Gegenstand der Erörterung macht.

Ipsen: Nur eine Bemerkung zu Ihren Ausführungen, Herr Peters, im Zusammenhang mit denen von Herrn Forsthoff. Man meint, den Rechtsschutz möglichst früh bei Beginn der Verplanung einsetzen zu müssen. Es ist aber noch gar nicht sicher, ob das ein Rechtsschutz gerade im Sinne eines Gerichtsschutzes werden kann und darf. Es geht um die Frage, ob dies nicht ein ganz anderer Schutz sein muß - etwa im Sinne jener Vorstellungen, die Herr Imboden gehabt hat bei Erwähnung des preußischen Fluchtliniengesetzes, nämlich i. S. eines Aufsichtsverfahrens mit verwaltungsinternen, rechtsstaatlichen Sicherungen unter Beteiligung der potentiell Betroffenen. Das ist zwar ein Vorgriff auf Frage 4, er gehört aber hierher, weil ich Herrn Peters so verstand, als ob er die Schwierigkeiten in der Frage sähe, wo man den Rechtsschutz ansetzen solle, da die ersten rechtlich folgenschweren Entscheidungen schon im frühesten Stadium der Planung fielen. Das Rechtsmittel braucht nicht gleich die Anfechtungsklage zu sein.

Kaiser: Wenn man den Plan, wie es mehrfach geschehen ist, als eine Rechts- und Schicksalsgemeinschaft der durch den Plan betroffenen Menschen charakterisiert, dann, so scheint es mir, gibt man ihm eine Dimension, die die Folgerung rechtfertigt, daß er aus den gegebenen Kategorien und Alternativen des Verwaltungsrechts herausfällt. Daraus würde ich allerdings nicht eine so weitgehende Folgerung ziehen, wie Herr Ule sie gezogen hat, daß man den Plan als geradezu etwas Vorrechtliches ansehen müsse. Ich habe zunächst geglaubt, daß Sie, Herr Ule, auf eine Unterscheidung wie die von Recht und Politik hinzielten. Die Unterscheidung von Recht und $\mathrm{Te} \mathrm{ch}$ $n i k$ ist mir in diesem Zusammenhang schwer eingängig, weil ich der Meinung bin, daß der Staat nicht anders handeln kann als in den Formen des Rechts und daB auch die Feststellung des Plans, daß auch die dezisionistische Stufe des Plans, von der Herr Imboden gesprochen hat, gar nicht anders als in den Formen des Rechts vollzogen werden kann. Ich glaube, daß deshalb der Plan, wenn schon nicht mit den gegebenen rechtsstaatlichen Kategorien, so doch im Rahmen und System des Rechtsstaats geordnet, rechtlich erkannt und lokalisiert werden muß, wobei 
es mir wichtig erscheint, daß für den Rechtsstaat der Gleichheitssatz einen besonderen Rang einnimmt, einen höheren Rang als bestimmte gegebene verwaltungsrechtliche Institutionen.

Unter diesem Gesichtspunkt öffnet die Kennzeichnung des Plans als einer Rechts- und Schicksalsgemeinschaft den Blick auf aktuelle Zusammenhänge. Einmal liegt in dieser Kennzeichnung tatsächlich ein tertium comparationis zu Plänen wie dem "Grünen Plan", der ja auch eine Rechtsgemeinschaft darstellt. Zum anderen zeigt sich gerade an diesem Beispiel das Phänomen vorgängiger, ständisch und interessenmäßig begründeter Rechtsund Schicksalsgemeinschaften, hier der Landwirtschaft, die sich jener Qualität auch sehr bewußt ist. Für diesen Stand bewirkt der "Grüne Plan" bestimmte Rechte und Privilegien. Es gilt, die Verschiedenartigkeit solcher Rechtsgemeinschaften zu sehen, die durch Pläne eine rechtliche, begünstigende oder belastende Besonderung erfahren oder erst durch Pläne konstituiert werden, jedoch das gemeinsam haben, daß sie fast sämtlich funktions- und interessebestimmt sind.

Herr Ipsen hat die Brücke zum Eigentumsschutz geschlagen; mir scheint, daß die "Situationsgebundenheit" des Eigentums, die der Judikatur als Kriterium dient, um das Vorliegen einer entschädigungspflichtigen Enteignung zu verneinen, in unmittelbarer Nachbarschaft zum Begriff der Schicksalsgemeinschaft steht. Beide begegnen Bedenken unter dem Gesichtspunkt des Gleichheitssatzes. Das Bundesverwaltungsgericht hat in der Frage der süddeutschen Bodenreformgesetze aus dem generellen Charakter des Eingriffs sogar Folgerungen für die Festsetzung einer relativ geringen Entschädigung gezogen. An diesen Beispielen zeigt sich, daß die ihnen gemeinsame nivellierende Wirkung des Plans rechtsstaatlich noch nicht bewältigt ist.

Peters: Darf ich jetzt eine Zäsur machen? Ich glaube, daß der erste Punkt erledigt ist und daß wir jetzt zu Punkt 2, zu den "Normen für die Planaufstellung" kommen.

Winkler: Ich glaube, daß die Frage der Gleichheit zwischen diesen beiden Punkten steht, weil sie durch Herrn Imboden dazu verwendet wurde, den Typus „Plan" zu beweisen. Vom Gleichheitssatz her hat man ja auch ein wesentliches Argument für die Typisierung gewonnen. Mir scheint, daß sich der Gleichheitssatz nicht nur sonst, sondern auch hier als ziemlich trügerisch erweist. Es ist zwar zuzugeben, daß durch die Pläne Ungleichheiten hervorgerufen werden, und zwar in einem höheren Maße als sonst durch irgendwelche Rechtsakte. Aber diese Ungleichheiten sind doch nur Folgeerscheinungen von Ungleichheiten, 
die vor den Plänen bereits existieren, nämlich weil jemand Grundeigentum hat und der andere nicht, weil jemand dort Grundeigentum hat und nicht $d a$, ob und $d a ß$ er in den Geltungsbereich des Planes fällt. Die Frage ist nicht, ob tatsächlich in dem einen oder anderen Fall gleich oder ungleich gehandelt wurde, sondern die Frage ist vielmehr, ob die Maßnahme an sich, unabhängig von gleichen und ungleichen Fällen, sachlich zu rechtfertigen ist.

Merk: Es könnte Bedenken erregen, wenn man hier den Gleichheitssatz für die Rechtssatznatur anführt. M. E. fällt das nicht zusammen, sondern wir haben das Grundrecht der Gleichheit eben erst allmählich errungen. Aber ein Rechtssatz bedeutet doch nur, daß hier Verhältnisse zwischen Rechtspersonen abgegrenzt werden mit Bezug auf ihre Willensmacht. Das wir jetzt das unter den Grundsatz der Gleichheit stellen, ist etwas Besonderes.

Peters: Die Merkwürdigkeit des Gleichheitssatzes ist hier folgende: Wir haben ein großes Gebiet, das durch die Verwaltung in Industrieland, Bauland, Grünflächen usw. aufgeteilt wird. Der eine darf danach nur noch zweistöckig bauen, der andere darf ein Hochhaus errichten, wieder andere, deren Land Grünfläche werden soll, dürfen überhaupt nicht bauen. Plötzlich entstehen für zwei Nachbarn ohne deren Zutun ganz verschiedene Möglichkeiten und Beschränkungen. Ich glaube, daß darin das Problem liegt.

Bachof: Erst recht entsteht dies Problem bei Ver ä nde r u n g e n eines Planes!

Peters: Wenn der Plan verändert wird, dann gibt es u. U. Entschädigungen. Wenn der Plan aber erstmalig aufgestellt wird, dann können noch keine Entschädigungen geleistet werden.

Ipsen: Das ist mit einem Satz zu sagen. Ich möchte ja darauf hinaus, daß die Verplanung in jene Sphäre hineingehört, die ich nach unserer üblichen Teilung Legislativbereich nennen müßte - nicht, um das Normative des Plans zu unterstreichen, sondern um ihn aus dem Exekutiven herauszulösen. Für mich ist die Frage, welche Maßstäbe und welche Normen für die Verplanung unter dem Gesichtspunkt des Gleichheitssatzes in Betracht kommen. Ich brauche nur zu prüfen, ob sich die Verplanung bei der Aufteilung eines großen Gebiets in diese und jene Zonen von Willkürgesichtspunkten freigehalten hat in jenen üblichen Begrenzungen, die sich bei der Gleichheitssatzanwendung in Bezug auf den Gesetzgeber allmählich eingependelt haben. 
Merk: Man kann natürlich sagen, daß der Gleichheitssatz als Grundrecht hier keine Anwendung findet; denn der Plan kann Grundstücke in verschiedener Weise erfassen. Das ist nicht etwas, was man auf die Formel eines Rechtssatzes unter Berücksichtigung des Gleichheitsgrundsatzes bringen kann. Im übrigen sind selbstverständlich auch hier die allgemeinen Ermessensschranken $\mathrm{zu}$ beachten.

Ule: Darf ich eine Frage an Herrn Merk stellen? Wenn ein Bundesgesetz erlassen würde - ein etwas paradoxer Fall -, in dem bestimmt würde, daß $10 \mathrm{~km}$ von jedem Stadtzentrum aus nur noch einstöckig gebaut werden darf, würden Sie das nicht als einen Rechtssatz ansehen?

Merk: In einer bestimmten Straße?

Ule: Uberhaupt. Man könnte um das Zentrum jeder Stadt einen Kreis schlagen und alles Gebiet, das außerhalb dieses Kreises ist, dürfte nur einstöckig bebaut werden. Das wäre also eine Zoneneinteilung.

Merk: Es kann dies m. E. in die Form eines allgemeinen Rechtssatzes gebracht werden, genau so, wie wenn in Baugesetzen steht, es dürfe nur die Hälfte oder ${ }^{2 / 3}$ einer Grundstücksfläche bebaut werden, die Häuser dürften nur eine bestimmte Höhe haben usw. Das ist ein Rechtssatz, der für alle Fälle überall, wo gebaut wird, gilt. So könnte ja auch eine Stadt in Wohnbezirke bestimmter Art, z. B. mit offener oder auch geschlossener Bauweise, eingeteilt werden. Es kann durch örtliche Bauordnung z. B. auch bestimmt werden, daß ein Stadtteil als Industrieviertel bebaut werden darf, ein anderer nur als Wohnviertel.

Ule: Aber das ist doch, glaube ich, Diskussionsgegenstand. Auch wenn ich die Regelung auf e in e Stadt beschränke und in ihr eine solche Zoneneinteilung durch eine Bauordnung festsetze, dann muß diese Regelung doch ein Rechtssatz sein.

Merk: Das kann ich mir, wie gesagt, als Rechtssatz vorstellen, weil nicht bestimmte Grundstücke mit unmittelbarer Rechtswirkung erfaßt werden sollen, sondern für jedermann innerhalb des betreffenden räumlichen Bezirks eine bestimmte Art der Bebauung vorgeschrieben oder verboten wird. Die Rechtswirkung des badischen Ortsstraßen- und des preußischen Fluchtliniengesetzes erfassen jedoch mit ihren Wirkungen unmittelbar bestimmte Grundstücke in einer ganz bestimmten Weise; wenn der Fluchtlinienplan rechtskräftig ist, dann kann der betreffende Grundstückseigentümer nichts mehr dagegen 
tun, soweit nicht Ausnahmeerteilungen vorgesehen sind. Das ist doch ganz etwas anderes als beim Rechtssatz, der künftige Fälle in allgemein bestimmten Tatbeständen regeln will.

Hans Schneider: Wenn man auch sagen kann, daß nicht der Gleichheitssatz maßgeblich eine Planung begrenzt, sondern daß im wesentlichen, wie Herr Imboden ausgeführt hat, die zweckrationale Folgerichtigkeit das Charakteristikum des Planes darstellt, so wird doch eine Rechtsregel bei der Plangestaltung zu beachten sein, die ich aus dem Gleichheitsgrundsatz ableite, nämlich das Gebot der Verhältnismäßigkeit, also der Grundsatz von der angemessenen Relation zwischen dem verfolgten Ziel und den eingesetzten Mitteln. Ich würde von jedem Plan fordern, daß er das Prinzip der Verhältnismäßigkeit (eine Ausformung des allgemeinen Willkürverbots) beachtet.

Peters: Wir kommen jetzt zum dritten Punkt, zum Problem der Entschädigungsansprüche, die Herr Imboden in seinem Referat ausführlich behandelt hat.

Merk: Was die Entschädigung anlangt, so haben wir ja im allgemeinen bestimmte Regelungen in den Baugesetzen. Es fragt sich aber, wenn solche nicht bestehen, tritt hier eine Aufopferung ein, die der einzelne leistet und für die er zu entschädigen ist, indem er in ungleicher Weise damit belastet wird?

Peters: Wir haben doch vorhin gesagt, der Plan dü $r f$ e die Einzelnen ungleich behandeln.

Merk: Ja, gewiß, ich habe dies auch selbst gesagt. Ich meine aber jetzt die Frage, ob alle diejenigen, die vom Ortsbauplan erfaßt werden, nicht im Unterschied der einzelnen untereinander, sondern ob jeder, der hier betroffen wird durch diesen Ortsbauplan, einen Anspruch auf Entschädigung hat. Es ist die Frage: Wird hier ein besonderes Opfer erbracht? Hier ist die Rechtsprechung oberer Bundesgerichte sehr weit gegangen, indem sie z. B. Bausperren schon als Enteignung betrachtet, wenn sie über ein bestimmtes Maß und eine bestimmte Zeit hinausgehen. Es ist also die Frage zu prüfen, abgesehen von diesen Bausperren, ob durch den Ortsbauplan mit den Straßen- und Baufluchten den Betroffenen ein besonderes Opfer auferlegt wird. Das ist im allgemeinen zu verneinen. Vielmehr handelt es sich hier - z. B. nach dem badischen Ortsstraßengesetz, aber auch nach dem preußischen Fluchtliniengesetz - im allgemeinen um Eigentumsbeschränkungen i. S. des Artikel 14 Abs. 1 Satz 2 GG, die auf Grund des Gesetzes ergehen. Die Gemeinde hat aber die Möglichkeit zu enteignen, soweit die in Anspruch genom- 
menen Grundstücke in den Bereich einer öffentlichen Straße fallen, und dann bekommt der Betreffende die Enteignungsentschädigung. Und dann, wenn der Eigentümer z. B. nach badischem Recht das Grundstück freilegt, das in den Bereich einer öffentlichen Straße fällt, dann hat er sofort den Anspruch auf Ubernahme des Grundstücks gegen Entschädigung nach Enteignungsgrundsätzen. Entschädigungsansprïche kommen danach nur in ganz besonderen Fällen vor. Im übrigen werden hier vielfach Bauplatzumlegungen in Frage kommen, die grundsätzlich nicht als Enteignung aufzufassen sind.

Forsthoff: Ich möchte nur sagen, Herr Peters, mir ist sehr zweifelhaft, ob wir das Thema so allgemein diskutieren können. Es differenziert sich doch in zahlreiche Spezialtatbestände aus. Wir haben das damals bei der Vorbereitung des Entwurfs des Bundesbaugesetzes sehr genau diskutiert. Da ist die erste Frage die: Konzedieren wir, daß kein Grundstück an sich sozusagen die Baulandqualität schon in sich trägt? Ist das eine verliehene Qualität oder ist das eine unmittelbar innewohnende? Dann kommt die Frage des Bauzwangs, die Herabzonung und alle diese Dinge. Man kann die Entschädigungsfrage hier nicht allgemein diskutieren, sondern wenn das von Anfang an konkret werden soll, dann muß man jedes einzelne Planungsinstitut wieder innerhalb des Plans ins Auge fassen und $\mathrm{zu} \mathrm{ihm}$ die Entschädigungsfrage gesondert stellen. Ich weiß nicht, ob wir hier so differenzieren sollten, zumal nach den Referaten, die ja auch in diesem Sinne nicht differenziert haben.

Peters: Ich bin auch nicht der Meinung, daß wir das ganze Entschädigungsproblem aufwerfen sollten. Aber wie steht es mit der Entschädigungspflicht bei Bausperren?

Friesenhahn: Es ist von Herrn Imboden gesagt worden, Diskriminierungen von Grundeigentümern, die nicht auch im Rahmen einer rechtssatzmäßigen Ordnung haltbar wären, seien als besonderes Opfer zu qualifizieren und durch Geldersatz auszugleichen (IX, 1). Das ist doch die These, die wir allgemein diskutieren könnten. Ist diese Grenze richtig gezogen? Können wir d a f ü $r$ einige Grundsätze aufstellen?

Pfeifer: Die Frage der Entschädigung hängt eng zusammen mit dem Gleichheitssatz. Ich möchte folgendes sagen: Nach der österreichischen Verfassung haben wir leider in dem Artikel, der von der Enteignung handelt (Art. 5 StGG), keine Bestimmung, daß immer Entschädigung geleistet werden muß, im Gegensatz zu Ihren Verfassungen, Weimarer Verfassung, Grundgesetz usw. Die Rechtswissenschaft hat aber in letzter 
Zeit zur Fundierung dieses Entschädigungsanspruchs gesagt, daß, wenn eine Enteignung vorgenommen und nicht entschädigt wird, der Gleichheitsgrundsatz verletzt wird, weil man dem einen hier ein Opfer im Interesse der Allgemeinheit zumutet, das den anderen nicht trifft. Von diesem Gesichtspunkt her folgert die Rechtswissenschaft, daß, auch wenn ein ausdrücklicher Satz in der Verfassung nicht enthalten ist, doch, um die Verletzung des Gleichheitssatzes hintanzuhalten, Entschädigung geleistet werden muß. Ich meine, dieser Gedanke läßt sich natürlich hierher auch ohne weiteres verpflanzen und anwenden; denn an und für sich ist der Sinn des Eigentums der, daß man auf seinem Grundstück nach Belieben bauen kann. Kommt jetzt eine Ordnung, durch die für bestimmte Flächen überhaupt ein Bauverbot ausgesprochen wird, für andere eine Beschränkung des Bauens, dann ist es natürlich, daß hier dem Betroffenen ein Opfer auferlegt wird. Wir in Österreich haben diesen Aufopferungsanspruch nicht so allgemein geregelt wie etwa § 75 des Allgemeinen Landrechtes für Preußen. Aber bei uns wird dafür die Enteignung sehr weit ausgelegt. Enteignungsfälle sind nicht nur gegeben, wenn man jemandem sein Eigentum entzieht, sondern nach der Rechtsprechung des Verfassungsgerichtes auch, wenn Privatrechte schlechthin durch einen hoheitlichen Akt entzogen oder geschmälert werden (Erk. Slg. 71). Auch das ist schon Enteignung. Man kann das jetzt Aufopferung oder Enteignung in diesem weiteren Sinne nennen, es kommt auf dasselbe hinaus. Wenn man eben vom Gleichheitssatz ausgeht, käme man meiner Ansicht nach zwingend dazu, daß Entschädigungen gezahlt werden müssen für alle, denen b e s o $\mathrm{n} d \mathrm{e}$ r e Opfer im Interesse der Allgemeinheit auferlegt sind. Allerdings kann auch nach österreichischem Recht ( $\$ 364$ ABGB) die Ausübung des Eigentumsrechtes zum allgemeinen Wohl durch G e s e tz, also eine generelle Norm, eingeschränkt werden.

Bachof: Nur ein Wort dazu: Eigentum ist gerade $\mathrm{nicht}$ das Recht, beliebig auf dem Grundstück zu bauen oder b e li e b i g mit dem Grundstück zu machen, was man will; sondern das Eigentum hat gewisse soziale Lasten und soziale Bindungen. Die Frage ist nur: W o verläuft die Grenze zwischen Enteignung und Sozialbindung? Sie meinen, diese Grenze werde überhaupt erst durch den Plan geschaffen? Nein, sie wird durch den Plan weitgehend nur ,konkretisiert“. Aber die Frage ist, wo verläuft jene Grenze. Man kann also nich t sagen: „Der einzelne kann mit dem Eigentum beliebig tun, was er will; deshalb ist jede Beschränkung des beliebigen Tuns eine Enteignung". 
Hans Schneider: Eine ergänzende Bemerkung noch: Es ist bisher nur die Frage der Entschädigung unter dem Gesichtspunkt der Enteignung oder Aufopferung angeschnitten worden. Es könnte aber noch die Frage gestellt werden unter dem Gesichtspunkt des Schadensersatzes wegen einer Amtspflichtverletzung, begangen durch eine Verletzung des Planes seitens der Behörde. Wichtig ist dabei, inwieweit der Plan die Behörde bindet und der Behörde im Verhältnis zu Dritten eine Amtspflicht auferlegt. Deswegen ist die Unterscheidung, ob die Pläne Außenwirkung haben oder lediglich behördenintern bindend sind, bedeutsam. Wenn ein Plan nur im Verwaltungsinteresse oder nur im allgemeinen öffentlichen Interesse erlassen worden ist, wie bei zahlreichen Bauvorschriften, so ist die Verletzung einer solchen Vorschrift keine Verletzung einer Amtspflicht, die der Behörde Dritten gegenüber obgelegen hat. Wenn es sich aber handelt um Pläne, die auch im Interesse der Grundstückseigentümer erlassen worden sind, denn können Schadensersatzansprüche entstehen.

Peters: Wir kommen jetzt von den Entschädigungsfragen zum 4. Punkt, zum Probiem der Rechtsbehelfe.

Ule: Ich will vorerst zu der Frage des verwaltungsgerichtlichen Rechtsschutzes, also Anfechtungsklage oder Normenkontrollverfahren, nicht Stellung nehmen, sondern zunächst nur hervorheben, daß beide Referenten die Vorverlegung des Rechtsschutzes in das Planfeststellungsverfahren vorgeschlagen haben. Das scheint mir eine Bestätigung des Gedankens zu sein, der schon vor einem Jahr in Wien erörtert worden ist, daß man in bestimmten Verwaltungsverfahren nicht bis zu dem Erlaß des Verwaltungsaktes warten darf, um dann erst dem Betroffenen die Gelegenheit zu geben, die Gerichte anzurufen, sondern daß man bereits vorher dafür sorgen muß, daß seine rechtlichen Interessen in diesem Verfahren berücksichtigt werden. Ich habe nur ein gewisses Bedenken gegen die Formel, die Herr Imboden im Leitsatz X gebraucht hat, wo er davon spricht, daß nur ein der Natur des Planes angepaßter, besonders gestalteter, Merkmale des Aufsichtsverfahrens tragender Rechtsbehelf einen wirksamen Rechtsschutz garantieren könne. Ich habe heute von Bedenken gelesen, die im Rechtsausschuß des Bundestages dagegen vorgebracht worden sind, beim Bundesbaugesetz die Aufsichtsbehörde einzuschalten, weil damit in das Selbstverwaltungsrecht der Gemeinden eingegriffen werde. Es gibt also noch Spezialprobleme unserer Verwaltungsorganisation, die dafür sprechen könnten, das Rechtsmittel in die erste Stufe des Verfahrens zu legen. Das Aufsichtsverfahren braucht ja auch nicht unbedingt eine Stufe hinaufgehoben zu werden. Jedenfalls würde 
man wahrscheinlich vielen Schwierigkeiten, die heute in der Praxis bestehen, aus dem Wege gehen, wenn man die interessierten Kreise bereits vorher in dieses Verfahren einschalten kann.

Peters: Halten Sie es für richtig, etwa so wie beim preuBischen Fluchtlinienverfahren, daß ein Einspruchsverfahren schon bei der Aufstellung des Planes besteht?

Ule: Ja, zumindest die Möglichkeit der Beteiligung in irgendeiner Form, etwa eines Anhörungsrechts, muß für die Betroffenen bestehen und von der Verwaltung gewahrt werden. $O b$ man das als Einspruchsverfahren im strengen Sinne ausgestalten soll, ist eine andere Frage.

Forsthoff: Ich würde gerne noch einmal auf das zurückkommen, was eben Herr Ipsen - ich glaube es war Herr Ipsen gesagt hat und was mir sehr wichtig erscheint. Es muß bei der Einschaltung des Rechtsschutzes des Betroffenen in einer frühen Phase nicht notwendig an eine Verwaltungsklage gedacht werden. Die Referate und die bisherige Diskussion haben m. E. gezeigt, daß wir in Ansehung der gesamten Pläne mit dem justizstaatlichen Perfektionismus des verwaltungsgerichtlichen Verfahrens vielleicht nicht so weit kommen, wie wenn wir den Rechtsschutz innerhalb der Verwaltung selbst ernster nehmen. Ich habe immer wieder das ungute Gefühl, daß der heutige Justizstaat bei der Verwaltung eine gewisse Gleichgültigkeit in der Beurteilung der Rechtsfragen begünstigen könnte, dahingehend, da $ß$ mit der Verwaltungsklage ja doch gerechnet werden müsse und es dem Verwaltungsgericht überlassen sei, zu entscheiden, was schließlich rechtens ist. Daß zur Wahrung des Rechts der Verwaltungsbeamte zunächst einmal und zwar genau so berufen ist wie der Verwaltungsrichter, sollte oberster Leitgedanke aller Verwaltung sein und bleiben. Wir würden deshalb gut daran tun, Formen des Rechtsschutzes zu suchen, die man, wie auch die Herren Referenten betont haben, sehr früh einsetzen kann; freilich um den Preis, nicht die vollen verfahrensrechtlichen Gewährleistungen zu haben, welche die Verwaltungsklage bietet. Ich komme noch einmal darauf zurück: es scheint mir für den Rechtsschutz von entscheidender Bedeutung zu sein, daß das Planungsgeschehen ein über längere Zeiträume erstrecktes Kontinuum ist, dessen Anfänge in die unverbindlichen Vorstufen zurückreichen. Wer hier die ersten Fakten setzt und damit das praevenire spielt, mauert bereits eine Position ein, die man später auch mit dem perfektesten Rechtsschutz nur noch schwer aus den Angeln heben 
kann. Darum wären hier andere Methoden des Rechtsschutzes am Platze als diejenigen, die wir ganz zu Recht bei normalen Verwaltungsakten gelten lassen.

Bachof: Herr Forsthoff hat völlig zu Recht erneut auf das sehr Problematische der beliebten Unterscheidung zwischen "rechtsverbindlichen" und „,nicht rechtsverbindlichen" Plänen hingewiesen. Es ist in der Tat so: Wenn der nicht rechtsverbindliche ("vorbereitende") Plan erst mal im Schoße der Verwaltung geboren ist, dann beißt praktisch nachher keine Maus mehr etwas davon ab. Aber der verständliche Wunsch, deshalb den Rechtsschutz - oder, wenn ich es einmal so nennen darf, die Beteiligung oder Anhörung der Betroffenen - möglichst weit vorzuverlegen, stößt doch auf gewisse praktische Schwierigkeiten. Man schafft damit leicht eine gewisse Unruhe in der Bevölkerung. Wir haben es bei der Großplanung unserer Universität erlebt, daß schon gewisse Gerüchte und Erwartungen - als Folge einer Erörterung von Planungsabsichten - die Folge hatten, daß die Grundstückspreise auf breiter Linie spekulativ in die Höhe schossen. Wir sind deswegen dazu übergegangen, das Gremium der Personen, die an derartigen Besprechungen noch beteiligt werden, so klein wie möglich zu halten. Man kann eine ganze Planung unmöglich machen, wenn Pläne zu früh bekannt werden. Das ist die Kehrseite, und da liegt eine Grenze für die allzufrühe Beteiligung und Anhörung der Betroffenen.

Merk: Ich beschränke mich wieder auf die Ortsbauplanung als Beispiel für eine Planung mit unmittelbarer Rechtswirkung. Es ist hier von wesentlicher Bedeutung, ob wir den Plan als Rechtssatz auffassen oder aber als Verwaltungsverfügung. Wäre er ein Rechtssatz, so könnte die Rechtssatzüberprüfung in Frage kommen, wie das im süddeutschen Verwaltungsgerichtsgesetz im bekannten $\S 25$ bestimmt ist. Wenn der Plan aber eine Verwaltungsverfügung ist, dann haben wir dieselben Rechtsbehelfe, wie bei jeder Verwaltungsverfügung, also zunächst den Rechtsschutz im Verwaltungsweg, bei dem insbesondere Ermessensfragen überprüft werden können, und dann die Anfechtungsklage, mit der etwaige Rechtsmängel geltend gemacht werden können.

Winkler: Nach den österreichischen Erfahrungen hat man den Eindruck, daß der „Plan" eine gewisse Eigengesetzlichkeit hat, die auf den Rechtsschutz nicht ohne Auswirkung ist. Es gibt zwar bei vielen Planerstellungsverfahren ein förmliches Parteiverfahren. Bei verschiedenen Planverfahren wird durch die Oberinstanz und durch den Verwaltungsgerichtshof das 
Rechtsschutzbedürfnis aber doch sehr in den Hintergrund gedrängt. Ich möchte mehr zur Warnung, als um unsere Rechtseinrichtungen schlecht zu machen, einen konkreten Beispielsfall schildern. Die Gemeindevertretungen haben die Möglichkeit, Fluchtlinien festzusetzen und Verbauungspläne aufzustellen. In den Gemeindeordnungen und auch in den Bauvorschriften ist vorgesehen, daß der einzelne Betroffene die Möglichkeit hat, an die Landesregierung als Oberinstanz Berufung einzulegen. Die Landesregierungen pflegen über diese, expressis verbis als „Berufung" bezeichnete Beschwerde, durch förmlichen Bescheid abzusprechen. Dieser enthält eine Anweisung, daß die Gemeindevertretung den Plan abändern muß. In solchen Fällen handelt der Verwaltungsgerichtshof eigentlich entgegen seiner Aufgabe. Er sagt nämlich, der Bescheid, mit dem über das Rechtsmittel des Einzelnen erkannt wird, hat zwar die Erscheinungsform eines Bescheides, ist aber kein Bescheid, sondern nur eine Äußerung über die Geltendmachung des Aufsichtsrechts und auf die Ausübung des Aufsichtsrechts hat der Einzelne keinen Rechtsanspruch; deshalb ist darüber nicht mit Bescheid zu erkennen.

Das ist das eine Argument, und nun das andere: Es tritt dieser Akt der Oberbehörde zwar in der Bescheidform in Erscheinung, weil jedoch über eine Verordnung, also über Fluchtlinien- oder Verbauungspläne abgesprochen wird, wird dieser als Bescheid in Erscheinung tretende Akt als der generellen Erscheinungsform teilhaftig und daher als nicht anfechtbar angesehen. Was den Verwaltungsgerichtshof dabei bewogen haben mag, ist vielleicht die Eigengesetzlichkeit der Pläne und die Tatsache, daß bei Plänen, die einmal erstellt sind, die Gefahr besteht, daß die Verwaltungsaufgabe durch den Rechtsschutz zunichte gemacht wird.

Ipsen: Genau dieselbe Problematik beschäftigt uns nach dem Personenbeförderungsgesetz für die Planung des öffentlichen Verkehrsbedürfnisses in einem bestimmten Raum, wo Verkehrsinteressenten, Verkehrsträger, Konzessionäre ein Widerspruchsrecht haben und es darum geht, ob die Bescheidung dieses Widerspruchs ihrerseits anfechtbar ist oder nicht. Das ist bei uns kontrovers. Das Bundesverwaltungsgericht hat das Gegenteil von dem angenommen wie wir in Hamburg im Oberverwaltungsgericht, nämlich Anfechtbarkeit. Das Problem ist: Wie weit darf der einzelne sich gerichtlich gegen diese Verplanung des öffentlichen Verkehrs wenden?

Winkler: Für die angerufene Ober- oder Aufsichtsinstanz ist es schwierig, den Verbauungsplan abzuändern, weil sie kein An- 
ordnungsrecht hat, sondern weil sie gewissermaßen nur in Ausübung des Aufsichtsrechts vielleicht eine Anweisung geben kann, den Plan abzuändern.

Ule: Ich möchte trotz der Bedenken, die Herr Bachof und Herr Winkler geäußert haben, doch dafür plädieren, daß man die Beteiligung des einzelnen in das Verwaltungsverfahren vorverlegt, und zwar deshalb, weil man mit den Mitteln der verwaltungsgerichtlichen Klage oder der Normenkontrolle an die für die Betroffenen entscheidenden Fragen, die doch im wesentlichen sachtechnische Fragen und keine Rechtsfragen sind, gar nicht herankommt. Das zeigt sich auch bei anderen Plänen. Ich darf das an einem Beispiel aus dem Kommunalrecht kurz erläutern. Der Haushaltsplan eines Landkreises ist doch auch Ausdruck eines Planes der Aufgaben, die dieser Kreis wahrnehmen will. Die Kreise finanzieren sich nun aus eigenen Steuern und zum Teil aus der Kreisumlage, die von den kreisangehörigen Gemeinden getragen wird. Diese Kreisumlage darf bloß dann erhoben werden, wenn der notwendige Bedarf auf andere Weise nicht gedeckt werden kann. Ja, was ist nun der notwendige Bedarf? Das, was der Kreistag eben für notwendig hält, wenn er den Plan aufstellt. Die einzelne Gemeinde im Kreise kann sich zwar gegen den Kreisumlagebescheid wehren, aber doch praktisch ohne Erfolg. Denn z. B. die Frage, ob man den Bau eines Schwimmbades für fünf Gemeinden im Kreise für notwendig oder nicht notwendig hält, ist kaum justitiabel. Man hat die Gemeinden darauf hingewiesen, da $\beta$ sie durch ihre Abgeordneten im Kreistag darauf hinwirken können, da $ß$ die Fragen in ihrem Sinne entschieden werden. Aber es ist Zufall, ob sie einen solchen Abgeordneten haben oder nicht. Sollte man in derartigen Fällen nicht prinzipiell daran denken, bei der Aufstellung derartiger Pläne die Betroffenen in das Verfahren, zumindest im Wege der Anhörung, einzuführen? Das sind doch Dinge, die, glaube ich, sehr ernsthafter Erwägung bedürfen.

Bachof: Damit wir uns nicht mißverstehen, Herr Ule: Ich wollte keineswegs grundsätzlich gegen eine Vorverlegung des Feststellungsverfahrens sprechen. Ich wollte nur sagen: man muß das Für und Wider abwägen. Es gibt auch Erwägungen, die d a g e g e n sprechen, die Betroffenen allzu früh zu beteiligen; man muß damit vorsichtig sein.

Ule: Nur noch ein Wort. Das großartigste Beispiel einer Stadtplanung in Deutschland ohne Enteignungsverfahren ist bekanntlich Hannover, wo es gelungen ist, ohne Enteignungsverfahren die Stadt nach dem Kriege „durchzuplanen“. Daß so etwas bei geschickter Verwaltungsführung geht, zeigt ja doch gerade dieser Fall. 
Peters: Herr Forsthoff, mir wäre die Vorverlegung der Rechtsbehelfe an sich sympathisch, aber dann nur zusammen mit der Tendenz, der Ausweitung der Art. 19 Abs. 4 entgegenzutreten. Dadurch aber, daß heute schon fast alle Reflexrechte nach Art. 19 Abs. 4 zum Gegenstand von Rechtsmittelverfahren werden, haben wir kaum noch die Möglichkeit, den Rechtsweg auszuschalten, weil wir sonst subsidiär immer beim ordentlichen Rechtsweg enden. Daher haben wohl auch die Verwaltungsgerichte schon die Tendenz, ihrerseits ihre Zuständigkeit zu erweitern. Man müßte streng dabei bleiben, nur echte subjektive öffentliche Rechte als Voraussetzung für den Rechtsweg nach Art. 19 Abs. 4 GG anzuerkennen. - Dann darf ich noch auf etwas anderes kurz hinweisen. Wollen Sie doch bitte auch die andere Seite zu vieler Rechtsbehelfe sehen. Der Bürger hat ja nicht nur Rechte, sondern auch erhebliche Interessen. Eines dieser Interessen ist, daß die Verfahren im Bauwesen nicht zu lange hinausgeschoben werden. Die Verzögerungen der Verfahren sind aber nicht Schuld der Bürokratie. Die Beamten können sich auf allzu viele Vorschriften und schwebende Verfahren berufen. Eine Ermöglichung von Rechtsmittelverfahren in einem zu frühen Stadium legt unter Umständen in hunderten von Fällen das Bauen und den Bauwillen für längere Zeit lahm.

Hans Schneider: Ich möchte diesen Bemerkungen zustimmen. Sie bestätigen im Grunde, was Herr Forsthoff sagt: daß es zweckmäßig ist, die Kontrolle möglichst zeitlich vorzuverlegen. Eine verwaltungsrechtliche Anfechtungsklage ist auch wegen der Wirkung, die man mit ihr erzielen kann, nämlich der Rechtskraftwirkung des Urteils zwischen den Parteien, ungeeignet. Man muß doch immer eine Wirkung erzeugen wollen, die dann für und gegen alle am Plan Beteiligten gleichermaßen etwas feststellt. Das erreicht man mit der verwaltungsrechtlichen Klage nicht, höchstens beim Normenkontrollverfahren.

Bachof: Ich möchte Herrn Peters widersprechen. Die Frage des Rechtsschutzes (19 IV GG) liegt $\mathrm{m}$. E. auf einer anderen Ebene. Das Feststellungsverfahren hat im wesentlichen das Ziel, die widerstreitenden Interessen überhaupt erst einmal offenbar zu machen und möglichst bereits jetzt auszugleichen. Natürlich sollen in diesem Verfahren auch schon etwa vorgekommende Rechtsverletzungen behoben werden. Aber das ist nicht der eigentliche Zweck dieses Verfahrens. Dagegen hat das nachfolgende Rechtsschutzverfahren (das wir ja gar nicht ausschließen können) ausschließlich und allein die Aufgabe, Rechtsschutz zu gewähren. Es ist freilich wichtig, die Gerichte dazu zu erziehen, daß sie diese ihre Aufgabe nicht überschreiten. 
Aber ich glaube nicht, daß die Existenz des Rechtsschutzverfahrens in irgendeiner Weise das Vorverfahren beeinträchtigt. Ich vermag die Situation der Verwaltung an Hand meiner praktischen Erfahrungen auch nicht so schwarz zu sehen wie Herr Peters. Wenn die Verwaltung sich dadurch hemmen läßt, so ist das allein ein Mangel an Zivilcourage unserer heutigen Verwaltungsbeamten. Wir erleben freilich immer wieder, daß die $\mathrm{Ge}-$ richte die Verwaltung geradezu ermuntern und sie fragen: „Warum habt ihr nicht dies oder jenes getan? Warum ist nicht z. B. längst eine Vollziehungsanordnung erlassen?" Dann hören wir oft von der Verwaltung als Antwort: „Warum sollten wir das tun? Es ist ja viel bequemer, erst die Verwaltungsgerichte entscheiden zu lassen". Natürlich kann jede Institution mißbraucht werden. Aber solcher Mißbrauch der Gerichte beruht nicht primär auf der Uberdehnung des Rechtsschutzes, sondern auf der Gedankenlosigkeit oder der mangelnden Initiative der Verwaltung. Daß eine gewisse Versuchung darin liegt, die weitgespannten Rechtswegsmöglichkeiten zu mißbrauchen, um die eigene Verantwortung auf die Gerichte abzuwälzen, will ich gar nicht bestreiten. Aber ich meine, in erster Linie sei es Sache der Verwaltung, dem entgegenzutreten.

Ipsen: Ich möchte vorschlagen, diese Thematik unseres Punktes 4 auch nicht einmal mehr dem Namen nach als eine Rechtsschutzproblematik zu bezeichnen, sondern sich bewußt zu machen, $\mathrm{da} B$ diese Willensbildungsvorgänge, die schließlich zur Entscheidung führen, in diesem Stadium, im Anfangsstadium der Verplanung, sich etwa in jener Ebene vollziehen, in der in den Parlamenten Gesetzgebungsverfahren stattfinden mit allen Konsequenzen, die das hat. Aus diesen Gründen fürchte ich auch nicht so sehr um das, was Herr Bachof mit guten Gründen als Konsequenz einer allzu weiten Beteiligung an Planerwägungen bezeichnet - Stichwort: die Grundstückspreise steigen, sobald der Rektor meint, hierhin würde ein schönes Seminargebäude passen. Solche Sorgen entstehen ja auch, wenn Parlamente sich über gesetzgeberische Dinge unterhalten. Ich habe mein Heizöl für den Winter eingekauft.

In Gesetzgebungsverfahren der Parlamente, die sich in Publizität vollziehen, finden Vorgänge statt mit vergleichbaren Reaktionen. Warum soll das nicht auch erreichbar sein in der Willensbildung über den Plan, ob diese sich nun im kommunalen oder im höheren Bereich vollzieht? Die Betrachtung der ganzen Frage als gerichtliches Rechtsschutzproblem scheint mir gefährlich zu sein, weil dann sofort das Menetekel das Art. 19 Abs. IV auftaucht. 
Forsthoff: Ich möchte nur eine ganz kurze Bemerkung dazu machen und doch Herrn Peters in gewisser Weise beipflichten. Ich finde es sehr interessant, daß uns hier der Rechtsschutzperfektionismus des Art.19 Abs. IV mindestens teilweise im Wege steht. Ich finde es sehr beachtenswert, daß das in dieser ganz besonders gelagerten Materie klar zu Tage tritt. Es muß nicht nur das $A$ und $O$ sein, daß wir Art.19 Abs. IV haben.

Ule: Wenn man bereits den interessierten Einzelnen, und das heißt doch den einspruchsbereiten Einzelnen, an dem Verfahren beteiligt, würde dadurch nicht ein Teil der Klagen, die sonst entstehen würden, abgefangen werden? Dadurch würde der Art. 19 Abs. 4 zwar nicht rechtlich, aber doch praktisch weitgehend lahmgelegt werden.

Peters: Heute wirken hier bereits Interessentenverbände, die die Dinge vorbereitend mit in die Hand nehmen und viele späteren Klagen in der Praxis verhindern.

Hans Schneider: Man könnte ja durch eine gesetzliche Vorschrift (etwa in der Verwaltungsgerichtsordnung) vorsehen, daß nicht mehr klagen kann, wer die Möglichkeit hatte, seine Einwendungen vorher im Einspruchsverfahren zur Geltung zu bringen.

Winkler: Man soll gewiß den Rechtsschutz soweit als möglich vorverlegen; man soll dem Einzelnen die Möglichkeit geben, möglichst rechtzeitig seine Interessen geltend zu machen. Aber man muß sich auch wohl darüber im klaren sein, daß das noch nicht ausreicht. Der Einzelne braucht doch auch einen repressiven Rechtsschutz. Wenn nicht wenigstens die Möglichkeit der Anrufung eines Verwaltungsgerichts besteht, dann werden die Verwaltungsbehörden sehr bald diesen ,gesetzesfreien Raum" entdeckt haben und ihn benutzen, um so zu entscheiden und so vorzugehen, wie es ihnen genehm ist.

Merk: Ich möchte vergleichsweise auf das Verfahren nach $\S \S 16$ ff. Gewerbeordnung und auf die Planfeststellung für die Enteignung hinweisen, ferner auf die Ortsbaugesetze, wie z. B. das badische Ortsstraßengesetz. In all diesen Fällen haben die Beteiligten die Möglichkeit, frühzeitig Einwendungen zu erheben. Diese frühzeitige Heranziehung der Beteiligten kann dazu führen, daß Rechtsmittel später weitgehend sich erübrigen.

Bachof: Wenn ich jetzt einmal eine andere Unterfrage der Frage 4 anschneiden darf! Es scheint mir das diejenige Frage zu sein, an der sich ja der ganze Streit, ob der Plan ein Verwaltungsakt oder eine Norm oder vielleicht etwas noch anderes sei, 
entzündet hat. Das ist die Frage, wie weit nun eigentlich Art. 19 Abs. 4 gegenüber solchen Plänen durchgreift. Darum ging doch in der Praxis der ganze Streit! Ist der Plan ein Verwaltungsakt, dann kann ich ihn unmittelbar angreifen; ist er eine Norm, dann kann ich ihn $\mathrm{n} i \mathrm{ch}$ t unmittelbar angreifen, sondern bin auf Inzidentkontrolle, abstrakte Normenprüfung oder dgl. angewiesen.

Ich meine, daß sich auch hier wieder zeigt, wie sehr die ganze Alternativfragestellung „Norm o d e $r$ Verwaltungsakt ?" im Ausgangspunkt verfehlt ist. Das führt freilich wieder zur Frage 1 zurück. Wenn Judikatur und Wissenschaft in den ersten Jahren der Geltung des Art. 19 Abs. 4 ganz überwiegend gesagt haben, „öffentliche Gewalt" im Sinne dieser Vorschrift seien nur Einzelakte, so deswegen, weil auch sie stets in dem Bann der Alternative "Verwaltungsakt oder Norm" standen. Nachdem man heute doch wohl allgemein stärker zu der Erkenntnis tendiert, daß es Akte gibt, die man weder der einen noch der anderen Kategorie zuordnen kann, vielmehr als Zwischenformen oder gar als etwas Drittes anerkennen muß, wird man auch die Frage für Art. 19 Abs. 4 GG anders stellen müssen. Ich glaube, Herr von der Heydte war seinerzeit der erste, der gegenüber einer damals noch einheitlichen Meinung auf der Heidelberger Staatsrechtslehrertagung den Art. 19 Abs. 4 auch auf Normen erstrecken wollte. Später haben mein Assistent Jesch und jetzt auch Herr Dürig in seinem Kommentar sehr nachdrücklich diese Ansicht aufgegriffen; auch sie wollen alle Normen dem Art.19 Abs. 4 unterfallen lassen; bei solcher Ausweitung des Begriffs "öffentliche Gewalt" fielen wohl auch alle Plä n e notwendig unter Art. 19 Abs. 4. Ich teile diese Ansicht nicht. Wenn ich ganz kurz meine eigene Meinung skizzieren darf: Man wird auch bei Art. 19 Abs. 4 differenzieren müssen und nicht an jener Alternative „Norm oder Verwaltungsakt" festhalten dürfen. Man wird teleologisch interpretieren und also fragen müssen: Was wollte man mit dem Art. 19 Abs. 4 eigentlich erreichen? Die Antwort lautet: Man wollte einen v ollständigen Rechtsschutz gegenüber Maßnahmen der öffentlichen Gewalt überall dort vorsehen, wo die öffentliche Gewalt $u n m$ it t e l b a $r$ in Rechte Dritter eingreift. Das tut sie vielfach - und sogar normalerweise - mit einer Norm noch nicht, weil die Norm in der Regel erst die Vor a us se t zu ng des Eingriffs schafft. Mit dem Verwaltungsakt greift die öffentliche Gewalt dagegen regelmäßig unmittelbar ein und $\mathrm{des}$ w e g e n hat man gesagt: Verwaltungsakte fallen unter Art. 19 Abs. 4, Normen $\mathrm{nich}$ t. Wir haben aber heute gesehen: $P l a ̈ n$ e greifen of $t$, aber nicht i $m m$ er und nicht in allen Punkten, unmittelbar in Rechte ein. Und ich behaupte überdies: 
auch manche $\mathrm{N}$ ormen greifen unmittelbar in Rechte ein. Denn es sind keineswegs a lle Normen eines Vollzugs durch Einzelakte fähig und bedürftig, und es sind erst recht nicht alle Plä n e eines Vollzugs fähig und bedürftig. Herrn Forsthoffs Schüler Brohm hat wohl den Plan deswegen als „Vollzugsnorm" charakterisiert, weil der Plan sich sozusagen selbst vollziehe; er hat daraus die Folgerung des Unterfallens der Pläne unter Art. 19 Abs. 4 gezogen. So weit würde ich $n$ i c h t gehen. Ich würde sagen, auch der Plan vollzieht sich nicht in a 11 e $\mathrm{n}$ Punkten selbst; das ist vielmehr sehr verschieden.

Ich möchte deshalb heute - unter Abweichung von eigenen früheren Äußerungen - sagen: Art. 19 Abs. 4 kommt immer dann zum Zuge, wenn eine Maßnahme öffentlicher Gewalt - sei es ein Einzelakt, eine Norm oder ein Plan - unmittelbar und ohne Zwischenschaltung eines besonderen Vollzugsaktes in Rechte Dritter eingreift, sich also ,selbst vollzieht".

Peters: Darf ich eine Frage dazu stellen? Wenn also der Eingriff unmittelbar durch das Gesetz erfolgt, wie wollen Sie dann das Verbot behandeln? Bei einem Verbot, etwa beim Bauverbot, ist ja damit schon unmittelbar in das Recht eingegriffen. In der praktischen Wirkung geschieht es aber gewöhnlich erst, wenn man einen Antrag auf eine Bauerlaubnis stellt und dieser jetzt auf Grund des Gesetzes abgelehnt wird.

Bachof: Mit Unterschied, Herr Peters. Dieses Problem hat seinerzeit der Stuttgarter Verwaltungsgerichtshof herausgearbeitet. Es gibt Folgen, die erst auf Grund eines speziellen Vollzugsakts eintreten: Im allgemeinen bedarf es zum Bauen einer Baugenehmigung. Man kann dann die Verweigerung der Baugenehmigung (Einzelakt) angreifen; ob das in diesen Fällen stets genügt, möchte ich dahingestellt sein lassen. Aber es gibt andere Fälle, wo die Norm unmittelbar - sei es die Baunorm, sei es der Plan - in Rechte eingreift. Es ist - jedenfalls nach württembergischen Baurecht - so, daß nicht alle Bauten einer Baugenehmigung bedürfen. Gewisse Kleinbauten sind generell von der Baugenehmigung freigestellt, dürfen aber z. B. nicht errichtet werden in einem Gebiet, das die Ortsbausatzung unter Bauverbot stellt. In einem solchen Fall ist unmittelbar und allein die Ortsbausatzung die Verbotsnorm. Es ist gar kein weiterer Vollzugsakt mehr nötig, ja nicht einmal mehr möglich. Was soll der Betroffene denn nun eigentlich machen, wenn er trotzdem bauen möchte und das normative Verbot für rechtlich unbegründet hält? Soll er entgegen dem Verbot anfangen zu bauen und die Polizeiverfügung abwarten, oder was sonst? Ich bin freilich der Ansicht, daß in diesem Falle durch die unmittel- 
bar sich selbst vollziehende Norm bereits ein Rechtsverhältnis geschaffen ist, und daß man hier deshalb auch mit der Feststellungsklage helfen könnte. Aber das ist ein weites Gebiet, und ich möchte die Diskussion nicht auf verfahrensrechtliche Fragen führen.

Merk: Ich habe leider nicht alles verstanden, was Herr Bachof gesagt hat. Nach Einsichtnahme in die Niederschrift diurfte in dem von Herrn Bachof erwähnten, nicht ganz klar umschriebenen Falle die in der württ. BauO von 1910 gewährte Baufreiheit für geringfügige Bauten in zulässiger Weise nach Art. 2 d. G. rechtssatzmäßig durch Ortsbausatzung eingeschränkt worden sein. Aber ich muß sagen, daß ich die größten Bedenken habe, gegen einen wirklichen Rechtssatz als solchen einen gerichtlichen Rechtsschutz nach Art. 19 Abs. 4 GG zu gewähren. Natürlich kann auch in der Form eines Gesetzes eine Verwaltungsverfügung getroffen werden wie nach Art.14 GG. Ich glaube, man muß sich doch klar entscheiden, ob ein Plan einen Rechtssatz darstellt oder eine Verwaltungsverfügung, wegen der schon vorhin angegebenen Verschiedenartigkeit des in Betracht kommenden Rechtsschutzes.

Ule: Eine Frage zu dem, was Herr Bachof gesagt hat: Ist dieses Bebauungsverbot eigentlich ein Planproblem?

Bachof: Das Problem kann genauso gut durch einen Plan wie durch eine Norm entstehen. Ich wollte nur darlegen, daß man m. E. nicht so weit gehen kann, mit Herrn Dürig zu sagen, alle Normen fielen unter Art. 19 Abs. 4; daß andererseits aber auch die frühere (u. a. auch von mir vertretene) Auffassung fragwürdig geworden ist, nach der nur Verwaltungsakte dem Art. 19 Abs. 4 unterfallen sollten. Ebensowenig möchte ich mit Brohm sagen, alle $P l a ̈ n$ e fielen unter Art. 19 Abs. 4, weil sie Vollzugsnormen seien. Ich meine vielmehr: Es kommt darauf an und man muß danach unterscheiden, ob - sei es ein Plan, sei es eine Norm - diese Maßnahme unmittelbar schon den Vollzugsakt enthält oder noch nicht. Dies scheint mir das Kriterium zu sein.

Peters: Meine Herren! Darf ich jetzt den beiden Herren Referenten das Schlußwort erteilen; zunächst Herrn Kollegen Obermayer.

Obermayer (Schlußwort): Darf ich mir erlauben, aus der Diskussion noch einige Punkte herauszugreifen.

Es wurde davon gesprochen, daß zum Verwaltungsakt die Regelung eines konkreten Sachverhaltes gehöre. Dazu möchte ich nochmals ein Beispiel aus dem Naturschutzrecht bringen, 
weil ich glaube, daß hier die Probleme besonders deutlich werden. Wenn ein großes Gebiet unter Naturschutz gestellt wird, so ist das unbestritten eine Norm, die jedermann Beeinträchtigungen untersagt. Wenn nun die Unterschutzstellung auf einen einzelnen Baum reduziert wird, dann glaube ich, daß ein quantitativer Unterschied, aber kein qualitativer Unterschied gegeben ist. Die Unterschutzstellung eines einzelnen Baumes ist eben auch eine Anordnung, die sich gegen eine unbestimmte Vielheit von Personen richtet. Ich meine, daß die Abstellung auf eine "konkrete Sache" etwas gefährlich ist; denn konkret ist ja schließlich auch ein größeres Gebiet, das unter Schutz gestellt wird.

Dann tauchte die Frage auf, ob der Haushaltsplan nicht doch eine ausreichende gesetzliche Ermächtigung sei. Ich habe ohne weiteres zugegeben, daß der Haushaltsplan eine Grundlage für Verwaltungshandeln ist, die die Verwaltung bindet. Aber ich sehe in ihm, soweit hier Einzelpläne in Betracht zu ziehen sind, eben nicht das Gesetzmäßigkeitsprinzip gewahrt. Denn dazu gehört wohl nicht nur, daß das Parlament bestimmte Maßnahmen beschließt, sondern auch, daß der betreffende Beschluß für die Allgemeinheit evident ist. Gesetzmäßigkeit der Verwaltung heißt also nicht nur Sanktion durch das Parlament, sondern Sanktion in einer Art und Weise, die jedem Staatsbürger einsichtig ist. Deshalb habe ich Bedenken, in den Einzelplänen eine ausreichende Rechtsgrundlage zu sehen, weil sie nicht in einer der Allgemeinheit zugänglichen Art und Weise publiziert werden.

Die Frage, ob begünstigende Verwaltungsakte auch dem Grundsatz der Gesetzmäßigkeit der Verwaltung unterliegen, ist in der Tat äußerst problematisch. Ich bin geneigt, in dem begünstigenden Verwaltungsakt regelmäßig die Kehrseite einer Belastung zu sehen. Unter rechtsstaatlichen Gesichtspunkten halte ich es für sehr bedenklich, wenn man schlechthin erklärt, da $ß$ begünstigende Verwaltungsakte keine Rechtsgrundlage benötigen. (A wird begünstigt, dem $B$ wird diese Begünstigung verweigert!)

Herr Winkler hat den Gegensatz zwischen Rechtssatz und linear-geometrischer Zeichnung prinzipiell in Abrede gestellt, wenn ich ihn richtig verstanden habe. Ich glaube auch und versuchte das heute früh zum Ausdruck zu bringen, daß man Plan und Rechtssatz oder linear-geometrische Zeichnung und Rechtssatz nicht ontologisch einander entgegensetzen kann. Das erscheint mir sehr deutlich in der Baugestaltungsverordnung zum Ausdruck zu kommen, wo in $\S 2$ der Erlaß von Aufbauplänen geregelt ist, wo es aber gleichzeitig beißt, die Baubeschränkungen könnten auch in Ortssatzungen (also nur durch das ge- 
schriebene Wort) festgelegt werden. Es ist sehr interessant, wenn man nun die Aporie der Verwaltung sieht. Manchmal erläßt sie Baubeschränkungen durch Satzungen, in denen nur das geschriebene Wort vorhanden ist, manchmal durch lineargeometrische Pläne, und neuerdings - z. B. in Oberbayern zuweilen sowohl in der Form einer Satzung als auch mittels eines Planes.

Dann wurde von mehreren Diskussionsrednern die Frage aufgeworfen, ob der Plan überhaupt ein Rechtsinstitut sei, ob man ihn nicht vielleicht als ein außerrechtliches Institut bezeichnon müsse. Es fiel auch der Hinweis, daß der Plan sehr weit in die Verwaltungskunst hinüberreiche. Ich darf diese Gedanken besonders unterstreichen. Die Einsetzung und die Koordination der teamworks z. B. oder die zielstrebige Verhandlungsleitung in einem Planverfahren sind alles Vorgänge, die keine rein juristische Wesenheit besitzen. Im übrigen glaube ich doch, daß wir den Plan als verwaltungsrechtliches Institut in jedem Falle anerkennen sollten, auch wenn man sich auf den Standpunkt stellt, daß der Plan hinsichtlich seiner Rechtsnatur nicht als aliud gegenüber Verwaltungsakt und Norm gewertet werden kann. Er ist auf jeden Fall ein Rahmenbegriff, der verwaltungsrechtlich relevantes Handeln deutlich macht.

$\mathrm{Zu}$ der sehr komplizierten Frage, wann ein Bebauungsplan Verwaltungsakt ist und wann Rechtsnorm, darf ich vielleicht noch folgendes bemerken: Es würde wohl niemand bezweifeln, den Plan als einen Verwaltungsakt zu qualifizieren, wenn er als eine öffentliche Belastung gegenüber dem derzeitigen Grundstückseigentümer ergeht und wie eine (öffentlich-rechtliche) Hypothek in das Grundbuch eingetragen wird. Dann geht die Rechtswirkung auch für die Nachfolger von dem Akt aus, der den derzeitigen Grundstückseigentümer betrifft. Der entgegengesetzte Fall ist, daß eine Norm aufgestellt wird und daß die Beeinträchtigung (die „Belastung") von der publizierten Norm unmittelbar auf alle späteren Grundstückseigentümer wirkt.

tber das Verhältnis des Plans zum Gleichheitssatz noch eine Bemerkung! Es ist dies ein Punkt, in dem ich wohl am stärksten von der Konzeption von Herrn Professor Imboden abweiche. Ich glaube, die Kollision mit dem Gleichheitssatz ist in dieser Art und Weise nicht nur den Plänen eigen, sondern genauso auch bestimmten Rechtsnormen. Jetzt muß ich zum letztenmal auf das Steinbruch-Beispiel zu sprechen kommen: Es ergeht eine Rechtsverordnung, wonach Veränderungen der Erdoberfläche verboten sind; gestattet ist jedoch die landwirtschaftliche Nutzung im bisherigen Ausmaße. Mit Ausnahme von A haben alle Grundstückseigentümer in dem von der Verordnung 
betroffenen Gebiet Weide- und Ackerland. Diese Flächen sind nicht unter dem Gesichtspunkt der Verletzung des Gleichheitssatzes betroffen. Da ändert sich nichts. A hat aber einen Steinbruch. Er wird als einziger von dem Nutzungsverbot sehr ungleich betroffen gegenüber allen anderen (genauso wie vielleicht ein Grundstückseigentümer im Rahmen eines Planverfahrens). Der Steinbruch ist das ganze Vermögen des A, von dem er mit seiner Familie lebt. Das ist doch ein ganz scharfer Eingriff in die Vermögenssphäre. Wenn irgendwo der Gleichheitssatz verletzt ist, dann ist das hier der Fall.

Zum Problem des Rechtsschutzes darf ich noch ganz kurz folgendes sagen: Ich glaube nicht, daß es gut ist, vorbereitende Pläne einem rechtlichen Ubberprüfungsverfahren zu unterwerfen. Es ist doch zu berücksichtigen, daß diese Pläne geändert werden können und auch sehr oft noch geändert werden. Müßte man nicht dann auch u. U. für den Entwurf eines Gesetzes einen Rechtsschutz erwägen? Im übrigen glaube ich, daß sich doch beide Referenten und auch fast alle Diskussionsredner über folgende Notwendigkeit im klaren sind :

Beteiligung der zunächst Betroffenen am Planfeststellungsverfahren, dann ein Rechtsschutz im Anfechtungsverfahren, also jedenfalls die Wertung des endgültigen Planfeststellungsaktes unter dem Gesichtspunkt des Rechtsschutzes als Verwaltungsakt.

Unterstreichen möchte ich noch die Ausführungen von Herrn Professor Bachof zur Auslegung des Art. 19 Abs. 4. Ich glaube in der Tat, daß es doch eine ganz dringende Notwendigkeit ist, sich von jener Vorstellung zu lösen (die auch in früheren Zeiten schon unrichtig war), daß Normen in jedem Falle "vollzogen" werden müssen und daß erst die Vollzugsakte einen Rechtsschutz verlangen.

Diese Diskussion dürfte in einer überraschenden Deutlichkeit bewiesen haben, wie sehr das Verwaltungsrecht unserer Zeit in Bewegung ist, welche neuen Kräfte, die erst noch bewältigt werden wollen, wirksam sind. Für die wohlwollende und freundliche Aufmerksamkeit, die Sie meinen fragmentarischen Uberlegungen entgegengebracht haben, darf ich mich zum Schluß ganz besonders bedanken.

Imboden: Meine Herren Kollegen, ich danke Thnen für die vielfachen Anregungen, die ich aus Ihrer Aussprache schöpfen durfte. Um den Zeitplan des Herrn Vorsitzenden nicht zu stören, möchte ich mich auf ganz wenige Bemerkungen beschränken. Ich bin mir dessen bewußt, daß ich als roten Faden meiner Darlegungen einen vielleicht $\mathrm{zu}$ eng ausgewählten Modellfall be- 
stimmt habe: die reine Raumplanung mit ihren beiden Aspekten, der linearen Baubeschränkung und der Bauzoneneinteilung. Es scheint mir aber, die Diskussion habe bestätigt, daß sich an diesem Beispiel alle rechtlichen Grundaspekte der Planung illustrieren lassen. Die Aussprache hat ein wesentliches Element jeder Planung scharf hervorgehoben, nämlich die Integrationsabsicht jedes Plans, das Zusammendenken, das Zusammenfügen. Beim Zeitplan werden zeitlich sich folgende Handlungen zu einer Einheit zusammengefaßt, beim Raumplan gilt das Entsprechende für die Einheit im Raum. Es ist nicht anders beim Versorgungsplan: Bedarf und Vorräte werden als Einheit gedacht. Aber dieses Zusammendenken tritt in Kollision mit den typischen Bezugspunkten unserer Verhaltensordnung, nämlich einmal mit der Individualität der Rechtsträger und sodann mit der Individualität der Sachen. Auch die Sachen haben in unserer Rechtsordnung eine Individualität. Man kann diese Kollision zwischen dem plangebundenen Denken und den klassischen Bezugspunkten unserer Rechtsordnung dadurch sehr einfach beheben, daß man gedanklich gewissermaßen eine entschädigungslose Globalenteignung Wirklichkeit werden läßt, dann ist der Plan ohne weiteres in unser überkommenes rechtsstaatliches Gefüge einzuordnen. Aber auch bei allerweitestgehender Betonung der Sozialbindungen des Eigentums ist eine derartige gedankliche Totalexpropriation ein nicht vollziehbares Konzept. Und damit stehen wir vor der Tatsache, daß das Plandenken in Spannung steht zu den überkommenen Gesichtspunkten unserer Rechtsordnung. Diese Spannung zu lösen, ist eine der großen Zukunftsaufgaben. Das Ziel ist bei weitem noch nicht erreicht, obwohl gewiß die Diskussion sehr wertvolle Ansatzpunkte für eine Lösung gebracht hat.

Peters: spricht den beiden Referenten und allen Diskussionsrednern den Dank aus. 